\title{
Urban Robotics: Achieving Autonomy in Design and Regulation of Robots and Cities
}

Jesse Woo

Jan Whittington

Ronald Arkin

Follow this and additional works at: https://opencommons.uconn.edu/law_review

\section{Recommended Citation}

Woo, Jesse; Whittington, Jan; and Arkin, Ronald, "Urban Robotics: Achieving Autonomy in Design and Regulation of Robots and Cities" (2020). Connecticut Law Review. 436.

https://opencommons.uconn.edu/law_review/436 


\title{
CONNECTICUT LAW REVIEW
}

\begin{tabular}{cc}
\hline \hline VOLUME 52 & APRIL 2020 \\
\hline \hline Article & NUMBER 1 \\
Urban Robotics: Achieving Autonomy in Design and \\
Regulation of Robots and Cities
\end{tabular}

\author{
JESSE WOO, JAN WHITTINGTON \& RONALD ARKIN
}

Cities across the United States are facing a wave of urban robotic products that combine artificial intelligence with the basic elements of transportation technology. The firms that deploy these technologies intend to both disrupt and serve many markets with their products, including but not limited to the transportation of people and cargo, surveillance, security, entertainment, and the collection and use of vast troves of data from the sensing capabilities of their products. In the evolution of technology, however, automated vehicles, delivery robots, security robots, and follow-me drones or robots are not separate products; they represent one overall movement to combine basic technologies of mobility with modern sensors, machine learning, and data science, into robotics intended for use in urban settings. To the firms, cities are concentrated markets for services, testbeds for imperfect artificial intelligence, collections of persons to engage in beta-testing of their robotics, and public spaces to be shaped in their interest to ease access to public rights-of-way and embed intelligent communication systems in urban space. To the cities, urban robotics foster technological optimism that is often unrealistic for either the technology or the economics of the firm, and their design and deployment poses new hazards for people in public space and private life.

As robots continue to enter the public rights-of-way in cities across the country, lawmakers need to find ways to regulate these technologies in the public interest. The old Facebook mantra of "move fast and break things" becomes even more concerning when the technology in question has a physical presence and can actually break things or harm people. In addition, the introduction of connected, mobile, sensing robots into public space on a mass scale accelerates already shifting norms around privacy and surveillance in public places. Policymakers at the local, state, and federal levels are taking a variety of approaches to regulate urban robots with these issues in mind. While some may call the diversity of approaches an impediment to innovation, we argue that at this stage of technological development, the laboratory of democracy offers the best possible path forward to regulate this emerging technology in the public interest. Therefore, 
we argue that broad federal preemption of robotics technologies, like autonomous vehicles, is premature. Cities are in fact the best suited sites of experimentation for autonomous vehicles, drones, and other urban robots, and city lawmakers should be allowed autonomy in their effort to regulate the design and deployment of urban robotics in public space. States and the federal government should provide technical and regulatory expertise and a backstop against a race to the bottom, but their orientation should be to work with cities, not against them. 


\section{ARticle Contents}

INTRODUCTION. 323

I. URBAN ROBOTICS AND THE QUEST FOR INTELLIGENT DESIGN

A. Robots Are Coming to a City Near You ……......................... 328

B. URBAN Robots AND THE EVOLUTION OF TECHNOLOGY ................ 337

C. The INTELLigent Design of Urban Robotics ........................... 341

II. CITIES AS TESTBEDS FOR AUTONOMOUS VEHICLES AND

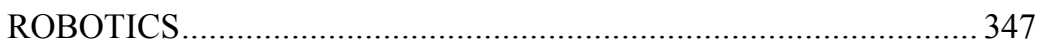

A. The Interest of Cities in Firms And Their Autonomous

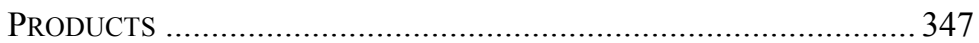

B. The Hazards in Store for Cities as Testbeds of Autonomous

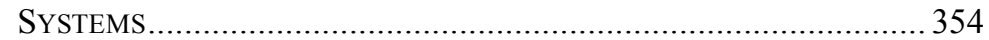

C. How Cities Can Prepare to Be Sites of Experimentation .... 359

III. THE EVOLVING LEGAL FRAMEWORKS FOR PRIVACY AND

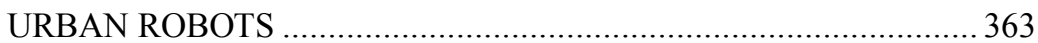

A. AdaPting Existing Laws to New Technologies ...................... 365

B. Comprehensive Privacy Regulation and the Design AND

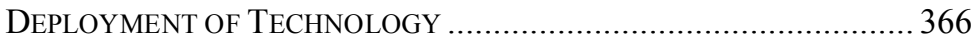

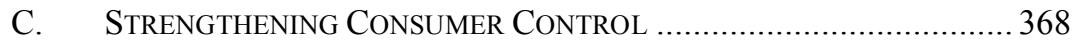

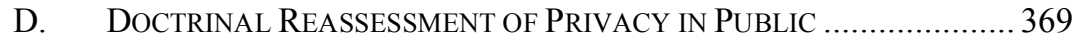

E. Proposed Comprehensive Federal Privacy Legislation ....... 372

F. Cities as Testbeds of Data Privacy …..................................... 374

IV. PREEMPTION, CITIES, AND THE REGULATION OF AUTONOMOUS SYSTEMS 376

A. An Overview of Federal Preemption and Home Rule

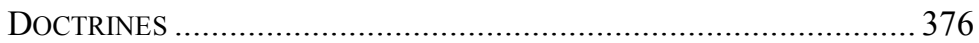

B. Federal AND State Robotics LaWs........................................ 381

C. PREEMPTION CAN INTERFERE With ROBOtic AND ENVIRONMENTAL

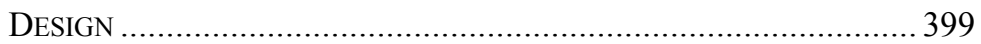

D. FEDERALISM FOR URBAN AUTONOMY ......................................... 402

V. COUNTERARGUMENTS IN FAVOR OF BROAD PREEMPTION OF

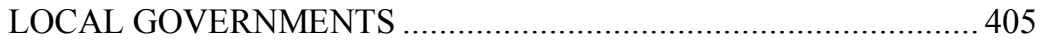

A. Firms Require Regulatory Clarity/Consistent Rules........ 405

B. State/National Agencies Are in Better Bargaining Position VIS A VIS FIRMS ...................................................................... 406

C. Cities Do Not Act In the Best Interest of THE Region (NIMBY) 406

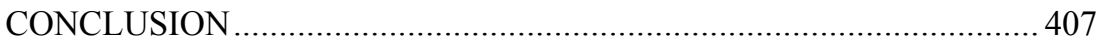





\title{
Urban Robotics: Achieving Autonomy in Design and Regulation of Robots and Cities
}

\author{
JESSE WOO, JAN WHITTINGTON \& RONALD ARKIN * \\ INTRODUCTION
}

Are cities ready for self-driving, artificially intelligent vehicles and robotics? The urban marketplace is increasingly filled with products emblematic of "smart" cities, from widely discussed autonomous vehicles (AVs) to smaller variations on the theme, such as robotics for delivery, security, and entertainment. ${ }^{1}$ Altogether, such urban robotics represent a new wave of technology in which digital sensors, networked devices, and their associated data stores are given the algorithmic, physical, and legal means to move in public space. ${ }^{2}$ As time goes on, the public is increasingly likely to encounter self-driving vehicles, robots, and drones on city streets, sidewalks, and in urban airspace. How should cities respond to these new and impending technologies?

Firms in this sector have technological, market, and financial interest in testing and deploying their products in public space, but the implications for cities span a broad array of intended and unintended consequences. Cities are natural sites of experimentation for firms interested in bringing these products to market, and the perception of economic opportunity associated

\footnotetext{
* Jesse Woo is a Fulbright Fellow and Visiting Scholar on the Faculty of Law at Kyoto University. Jan Whittington is an Associate Professor in the Department of Urban Design and Planning and the Director of the Urban Infrastructure Lab at the University of Washington. Ronald Arkin is a Regent's Professor and Director of the Mobile Robot Laboratory in the College of Computing at the Georgia Institute of Technology.

${ }^{1}$ Jeffrey Mervis, Are We Going Too Fast on Driverless Cars?, SCIEnCE (Dec. 14, 2017, 9:00 AM), http://www.sciencemag.org/news/2017/12/are-we-going-too-fast-driverless-cars ("Transportation experts have developed six levels that describe autonomous vehicles. In general, a higher number means a more independent vehicle, with less for the human driver to do, thanks to more sophisticated sensors, cameras, and algorithms. ... A level-four car . . will operate autonomously only under certain conditions, say in good weather during the day, or on a road with controlled access. The technology for that capability already exists."); Paul Miller, Taking a Ride on Segway's Loomo Robot, VERGE (Jan. 11, 2018), https://www.theverge.com/2018/1/11/16874220/segway-loomo-robot-hands-on-ces-2018; Olivia Solon, Robots Are Invading Malls (and Sidewalks) Near You, MIT TECH. Rev. (June 8, 2016), https://www.technologyreview.com/s/601635/robots-are-invading-malls-and-sidewalks-near-you/ (“[A] small but growing number of human-scale mobile robots ... are finding employment outside the confines of industrial settings like factories. They're invading consumer spaces including retail stores, hotels, and sidewalks in a quest to deliver services ....").

${ }^{2}$ On the theory of the combinatorial evolution of technology, including artificial intelligence, see W. Brian ARThur, The NATURE OF TeChNology: What It IS AND How IT EVOlves 42-43 (2009).
} 
with tech firms is leading city representatives to reclaim public spaces, transforming them into testbeds for product development. ${ }^{3}$ It is worth noting, however, that experimentation involves trial and error, and there are limitations to the ability of artificial intelligence to navigate the wide range of conditions and events that comprise the urban environment. ${ }^{4}$ Ultimately, the design of the environment may be as important to the success of urban robotics as the design of the hardware and software in those products. ${ }^{5}$ These are matters that city officials care about; the design, function, and finance of urban built environments are generally the purview of local government. Significant new questions in law, such as legal liability for the performance of artificially intelligent devices, are being addressed as autonomous vehicles and devices enter public rights-of-way. ${ }^{6}$ Additionally, artificial

\footnotetext{
${ }^{3}$ A natural site of experimentation is the intended market for the device, analogous to the natural habitat for a species. On the topic of city representatives accommodating firms, see Emily Badger, Pave Over the Subway? Cities Face Tough Bets on Driverless Cars, N.Y. Times (July 20, 2018), https://www.nytimes.com/2018/07/20/upshot/driverless-cars-vs-transit-spending-cities.html. Regarding a partnership with Ford in which Miami becomes a testbed, Mayor Carlos A. Giménez of Miami-Dade, Florida said, "We want to learn from Ford what it is we need to do to get ready for these vehicles, so that when AVs become a reality, fully, we'll be one of the first communities to get them .... We want to let the world know that Miami is ready to be a testbed." Laura Bliss, Self-Driving Pizza Just Hit Miami, CiTYLAB (Feb. 27, 2018), https://www.citylab.com/transportation/2018/02/self-driving-pizza-just-hitmiami/554138/.

${ }^{4}$ Veronica Rocha, Crime-Fighting Robot Hits, Rolls Over Child at Silicon Valley Mall, L.A. TIMES (July 14, 2016), http://www.latimes.com/local/lanow/la-me-ln-crimefighting-robot-hurts-child-bayarea-20160713-snap-story.html; see also Futuris, Urban Robots: A New Generation of Robots, YouTUBE (May 10, 2012), https://www.youtube.com/watch? $\mathrm{v}=\mathrm{t} 8 \mathrm{cstaDhjjI}$ (discussing the extent to which roboticists depend on the design of the environment); Jeremy Kahn, An Idea for Making Self-Driving Cars Safer: Reprogram Humans, L.A. Times (Aug. 17, 2018), http://www.latimes.com/business/autos/la-fi-hy-driverless-car-safety-20180817-story.html (discussing the safety of self-driving cars). One of the many challenges of designing robots to operate among people in an urban environment is, "for example, autonomous navigation, that's to say [the robots would] be able to move around and find out where they are, those are things that to us seem very routine and very simple, but for the robots they are very complex." Futuris, supra.

${ }^{5}$ As the National Association of City Transportation Officials says: "Automated vehicle technology holds many promises for cities, but the potential benefits of automation are not guaranteed. City policies must proactively guide the technology to prioritize people-centric design." NACTO, BLUEPRINT FOR AUTONOMOUS URBANISM 10 (2017), https://nacto.org/publication/bau/blueprint-for-autonomousurbanism/. U.S. Transportation Secretary Anthony Foxx notes that vehicle-to-infrastructure communication is a "critical component of a connected vehicle environment-a system of hardware, software, firmware and wireless communication that enables the dynamic transfer of data between vehicles as well as between vehicles and elements of the roadway infrastructure." U.S. Dep't of Transp., FHWA Announces Vehicle-to-Infrastructure Guidance, TRANSPORTATION.GOV (Jan. 19, 2017), https://www.transportation.gov/briefing-room/fhwa0317. See also Futuris, supra note 4 (describing one method to overcome the challenge of designing a robot to navigate the urban environment, "this campus is equipped with Wi-Fi internet and twenty cameras to allow the robots to navigate around; the same setup would be needed in any city for [the robots] to be able to work autonomously").

${ }^{6}$ The death of a pedestrian by an autonomous vehicle test driven by Uber in Arizona highlights the importance of these issues. The city of Tempe, Arizona is facing a lawsuit for inadequate street design from the relatives of a pedestrian killed by an automated Uber vehicle. Ryan Randazzo \& Paulina Pineda, Tempe Faces \$10 Million Claim in Uber Self-Driving Vehicle Fatality, ARIz. REPUBLIC (Feb. 3, 2019),
} 
intelligence imbues devices with the purpose of replacing as well as augmenting the roles and responsibilities of persons, and this tension exists at the local level. ${ }^{7}$ Lastly, these products generate rich data stores about the public, bringing market potential along with the coupled moral hazard of data monetization and loss of privacy, including surveillance. ${ }^{8}$ Which parties are positioned to benefit from this experimentation, and which will absorb the costs? In the face of these potentially widespread and enduring industrial and technological changes, how might cities act in the public interest?

https://www.usatoday.com/story/tech/2019/02/03/tempe-faces-10-million-claim-uber-self-drivingvehicle-fatality/2761875002/. Experts in the field on the inevitability of the crash said "it [was] only a matter of time," as the technology "is not mature enough to be completely driverless," and "it is unlikely that a person would be able to prevent a crash by taking over a self-driving system at the last minute." Larry Greenemeier, Uber Self-Driving Car Fatality Reveals the Technology's Blind Spots, SCI. AM. (Mar. 21, 2018), https://www.scientificamerican.com/article/uber-self-driving-car-fatality-reveals-thetechnologys-blind-spots1/. See also Mike Isaac et al., Uber's Vision of Self-Driving Cars Begins to Blur, N.Y. TiMES (Aug. 19, 2018), https://www.nytimes.com/2018/08/19/technology/uber-self-drivingcars.html (describing the firm's choice between continuing or abandoning investment in its autonomous vehicle unit); Timothy B. Lee, NTSB: Uber's Sensors Worked; Its Software Utterly Failed in Fatal Crash, ARs TECHNICA (May 24, 2018), https://arstechnica.com/cars/2018/05/emergency-brakes-weredisabled-by-ubers-self-driving-software-ntsb-says/ (summarizing findings from an investigation by the National Transportation Safety Board); Ian Wren, Uber Suspends Self-Driving Tests After Pedestrian Is Killed in Arizona, NPR (Mar. 19, 2018), https://www.npr.org/sections/thetwoway/2018/03/19/594950197/uber-suspends-self-driving-tests-after-pedestrian-is-killed-in-

arizona? $\mathrm{sc}=\mathrm{tw}$ (describing the firm's decision to suspend tests of self-driving vehicles in the wake of the fatal crash).

${ }^{7}$ Urban robots and the firms that deploy them are on "a quest to deliver services alongside human staff members for a fraction of the price of employing people to do a variety of typically unexciting tasks." Solon, supra note 1; see Mervis, supra note 1 ("Technologists see AVs as the next step in what's called 'mobility as a service.' That is what taxi fleets and ride-sharing services such as Uber and Lyft now offer. What is attracting AV investors is the huge payoff from removing the biggest cost of that service, namely, the person behind the wheel.").

${ }^{8}$ See, e.g., McKinsey \& Co., Monetizing Car Data: New Service Business Opportunities $\begin{array}{llllll}\text { TO CREATE } & \text { NEW } & \text { CUSTOMER } & \text { Benefits } & \text { (2016), }\end{array}$ https://www.mckinsey.com/ /media/McKinsey/Industries/Automotive\%20and\%20Assembly/Our\%20I nsights/Monetizing\%20car\%20data/Monetizing-car-data.ashx (outlining the business opportunity created by the generation of data from autonomous vehicles); Kayla Matthews, How Anonymous Cars Will Make Big Data Even Bigger, DATAFLOQ (Jan. 7, 2018), https://datafloq.com/read/howautonomous-cars-will-make-big-data-even-bigger/1795 (“[A]utonomous vehicles, or 'smart' cars of the future, are nothing more than a cog in a much larger data-collection system."); Matt McFarland, Your Car's Data May Be More Valuable Than the Car Itself, CNN (Feb. 7, 2017), http://money.cnn.com/2017/02/07/technology/car-data-value/index.html ("A self-driving car can generate 1 gigabyte of data per second... More data means more potential money. All sorts of creative business opportunities will arise. ... 'By collecting data from vehicles, you effectively digitize the public space, unlocking potential safety, security, municipal and commercial benefits ...."'); Sivaramakirshnan Somasegar \& Daniel Li, Business Models Will Drive the Future of Autonomous Vehicles, TECHCRUNCH (Aug. 25, 2017), https://techcrunch.com/2017/08/25/business-models-will-drive-the-future-ofautonomous-vehicles/ ("The issues of who owns data, who can access data and who will process the data will be a critical question [sic] for companies and regulators over the next several years. As vehicles generate and consume more and more data, it will be critical to watch who controls the data and how they decide to monetize the data."). 
The answers to these questions lie as much in the institutional arrangements designed to govern this new wave of technologies as they do in the intrinsic capabilities of these products. Anyone evaluating the existing policy environment for artificially intelligent devices today would find technological optimism, conflicting perspectives of the public interest, and preemptive acts at the state and federal levels. ${ }^{9}$ In particular, preemption in current policymaking raises issues because the consequences and cost of product design, including safety and surveillance as well as convenience and expense, play out at the local level. ${ }^{10}$ As city officials ask their residents to coexist with robots and negotiate with firms over the transaction costs that accompany these products, they need the flexibility and funding necessary to adapt to market conditions and the authority to act as market makers. ${ }^{11}$ Preemption cuts short the legal experimentation and regulatory competition that could provide a race to the top for firms and policymakers in the public interest. In the best of circumstances, federal agencies provide guidance and domain expertise, while states provide a supportive framework for cities to operate in with a backstop against the expansive possibility of harm. In the most egregious cases, preemption threatens to revoke the rights of the

\footnotetext{
${ }^{9}$ See Ralph Nader, Driverless-Car Legislation Is Unsafe at This Speed, WALl ST. J. (Aug. 22, 2018), https://www.wsj.com/articles/driverless-car-legislation-is-unsafe-at-this-speed-1534973755 ("Mr. Thune's bill [the AV START Act (S. 1885)] would eviscerate vehicle regulations by allowing companies to sell potentially limitless numbers of driverless cars that would be exempt from established federal safety standards. This bill would also pre-empt states from exercising their own safety duties."); Noah Seigel, Will the Feds Handcuff Cities on Automated Vehicles?, PUB. SQUARE (Nov. 9, 2017), https://www.cnu.org/publicsquare/2017/11/09/will-feds-handcuff-cities-automated-vehicles ("[AV START] includes an insidious clause that ... preempts states and cities from providing any oversight, public information, or policy direction when AVs hit their streets.").

${ }^{10}$ Susan Crawford, Autonomous Vehicles Might Drive Cities to Financial Ruin, WIRED (June 20, 2018), https://www.wired.com/story/autonomous-vehicles-might-drive-cities-to-financial-ruin/ ("[M] any cities balance their budgets using money brought in by cars: gas taxes, vehicle registration fees, traffic tickets, and billions of dollars in parking revenue [charges that autonomous vehicles can avoid]. . .. [Cities are] beginning to look at fees that could be charged [to autonomous vehicles]. . . . But many states, urged on by auto manufacturers, won't let cities take these steps."); see Seigel, supra note 9 ("There are many potential benefits to AV technology, but the bill includes an insidious clause that is sure to make everything worse: it preempts states and cities from providing any oversight, public information, or policy direction when AVs hit their streets."); see also Lisa Nisenson \& Brad Davis, Ten Steps Toward Autonomous Urbanism, PUB. SQuARE (Dec. 11, 2017), https://www.cnu.org/publicsquare/2017/12/11/ten-steps-toward-autonomous-urbanism (discussing ten steps that cities can take to prepare for the proliferation of mobility technology).

${ }^{11}$ On the potential for autonomous vehicles to impact local public finance, see Benjamin Y. Clark et al., The Impacts of Autonomous Vehicles and E-Commerce on Local Government Budgeting and Finance, URBANISM NEXT (Aug. 2017), https://cpb-us-east-1-juclugurlqwqqqo4.stackpathdns.com/ blogs.uoregon.edu/dist/f/13615/files/2017/07/Impacts-of-AV-Ecommerce-on-Local-Govt-Budget-andFinance-SCI-08-2017-2n8wgfg.pdf; Crawford, supra note 10; Jan Whittington et al., Push, Pull, and Spill: A Transdisciplinary Case Study In Municipal Open Government, 30 BerKeley TeCH. L.J. 1899, 1964 (2015) (discussing the standardization of public contracts with private technology firms and explaining that " $[\mathrm{m}] \mathrm{id}$ to large-size cities such as Seattle with big information needs and access to considerable resources have the potential to be market-makers, i.e., to drive the market toward best practices").
} 
persons at the local level, who are asked to bear the risk and cost of residing with robots, and to prevent the resolution of conflicts through local levels of government. ${ }^{12}$ Preemption debates in technology law have already arisen around the regulation of air carriers, ${ }^{13}$ the taxation of e-commerce,${ }^{14}$ net neutrality ${ }^{15}$ sharing economy platforms, ${ }^{16}$ and municipal broadband, ${ }^{17}$ with important consequences. Some proposed federal and state laws and existing state statutes already preempt cities on robotics in ways that could impede local governments' autonomy with regard to the design, management, operation, and finance of public rights-of-way. Laws that preempt cities based on broad or poorly-defined definitions of performance could limit local control of the infrastructure that constitutes the operational domain of urban robots, irrespective of the public interest.

The purpose of this Article is to provide a framework through which public decision-makers can effectively engage with the firms that are bringing artificially intelligent robotics to market in public space. With an institutional economic perspective, this Article suggests a means for evidence-based policymaking by breaking down design and its evaluation into constituent sequential components, recognizing the private and social

${ }^{12}$ See Crawford, supra note 10 ("Cities serve as the front lines of every pressing social problem the country is battling: homelessness, illiteracy, inadequate health care, you name it. They don't have any resources to lose. The rise of autonomous vehicles will put struggling sections of cities at a particular disadvantage."); Seigel, supra note 9 ("It is a not a radical idea [sic] to allow cities and local governments to lead on transportation policy and technological disruption. Before the advent of the automobile, roads were generally financed by local property taxes. When cars became ubiquitous, state and local governments adopted vehicle registration fees, fuel and weight mile taxes, and parking meters to help pay for and regulate automobiles and their externalities. All of this predated the federal gas tax and the interstate highway system. It is likely that local governments will need to foster a similar kind of innovation to cope with (and pay for) AVs. These are the kinds of conversations about the public (and private) good that are in danger of being preempted by the current version of the AV START bill.").

${ }^{13}$ Seigel, supra note 9.

${ }^{14} \mathrm{Id}$.

${ }^{15}$ See Jon Brodkin, FCC Will Also Order States to Scrap Plans for Their Own Net Neutrality Laws, ARS TECHNICA (Nov. 21, 2017), https://arstechnica.com/tech-policy/2017/11/fcc-will-also-order-statesto-scrap-plans-for-their-own-net-neutrality-laws/ (describing the FCC's attempts to preempt state net neutrality laws); Nicole Flatow, Cities Launch Plan to Protect Net Neutrality, CiTYLAB (Mar. 12, 2018), https:/www.citylab.com/equity/2018/03/net-neutrality-executive-orders-fcc-mayors-bill-de-blasio/ 555344/ (describing the efforts of states and localities to counteract FCC preemption measures). As Seigel explains, preemption clauses in the 1994 FAA Authorization Act were short-sighted in preventing local governments from enacting law or policy that would affect the "price, route, or service" of any air carrier "transporting property by air or by motor vehicle," which was then reinforced in the 1998 Internet Tax Freedom Act. Seigel, supra note 9. Together, these acts have prevented local governments from taxing the firms that depend on the public provision of local road infrastructure and thus have disrupted the long-standing ability of cities and states to ask those who benefit to pay for public improvements. Id.

${ }^{16}$ Nicole DuPois et AL., City Rights in AN ERA OF PREEMPTION: A STATE-BY-STATE ANALYSiS 2018 UPDATE 12-16 (2018), https://nlc.org/sites/default/files/2017-02/NLC\%20Preemption\%20Report $\% 202017$.pdf.

${ }^{17}$ Jon Brodkin, States Win the Right to Limit Municipal Broadband, Beating FCC in Court, ARS TECHNICA (Aug. 10, 2016), https://arstechnica.com/tech-policy/2016/08/in-blow-to-muni-broadbandfcc-loses-bid-to-overturn-state-laws/. 
costs of experimentation in cities, and recommending a limited scope for state and federal intervention. ${ }^{18}$ Part I begins by defining the characteristics of the current wave of robotics entering public space, placing public-facing robotics within the theory of the nature of technology and elaborating on the process of product design with algorithmic feedback for machine learning in complex urban environments. Part II explores the opportunities and hazards that await cities as sites of experimentation and introduces a comparative approach to policymaking to forestall negative externalities while permitting technological change. Part III explores the role of cities in the evolving policy environment for data privacy in the face of advanced sensing technologies, including robotics, that undermine existing legal protections. Part IV analyzes laws governing urban robots at the local, state, and federal levels and the impact of preemption on cities' ability to serve as sites of experimentation. It recommends against broad express preemption or field preemption at the state and federal levels, particularly the broad language in proposed federal autonomous vehicle legislation. Part $\mathrm{V}$ addresses possible counterarguments. The Article ends by presenting concluding thoughts.

\section{URBAN ROBOTICS AND THE QUEST FOR INTELLIGENT DESIGN}

This Part provides an overview of the emerging field of autonomous machines in public space, including a section that situates these products in the evolution of technology and brings the process of design to the forefront of discussion about the benefits and pitfalls of this new wave of technology for cities and local residents.

\section{A. Robots Are Coming to a City Near You}

Companies that make robots are sending their products out into the cities of the world. Not to be confused with the spectacular humanoid devices of science fiction, the robots entering our city roadways, sidewalks, parking lots, and airspace include any machine that can sense, process, and act upon the physical world. ${ }^{19}$ The robots being deployed, tested, and marketed in urban public rights-of-way could be said to fall into several categories:

\footnotetext{
${ }^{18}$ Institutional economics recognizes the polity and judiciary for creating and interpreting the rules of the game for economic actors. DOUGLASS CECIL NORTH, INSTITUTIONS, INSTITUTIONAL CHANGE AND ECONOMIC PERFORMANCE 4-5 (1990).

${ }^{19}$ People working in the field are quick to separate artificial general intelligence, such as the development of a sentient being, from today's forms of artificial intelligence: "Artificial intelligence is not about building a mind; it's about the improvement of tools to solve problems." Gideon Lewis-Kraus, The Great A.I. Awakening, N.Y. TimeS MAG. (Dec. 14, 2016), https://www.nytimes.com/2016/12/14/ magazine/the-great-ai-awakening.html; see also Ryan Calo, Robotics and the Lessons of Cyberlaw, 103 CALIF. L. REV. 513, 531 (2015) ("[R]obots are best thought of as systems that sense, process, and act upon the world to at least some degree.").
} 
automated vehicles for transporting persons and cargo, delivery robots, security robots, and entertainment or companion robots. ${ }^{20}$

The automation of vehicles currently gives drivers the impression that they may turn their attention away from the road for periods of time, ${ }^{21}$ but the purpose of this technology is to transform human-driven fleets of vehicles into services provided with self-driving fleets of vehicles. ${ }^{22}$ Many tech companies and automobile manufacturers are experimenting with these capabilities. ${ }^{23}$ Though most are working on automobiles, recent market entrants and hopefuls include automated buses, automated semi-trucks for cargo delivery, and personal drones for air travel. ${ }^{24}$ At the time of this writing, thirty-one cities in the United States have active pilot programs for automated vehicles, nearly half of the cities of the United States are reportedly preparing for them, and twenty-two states have legislation encouraging their development. ${ }^{25}$ It is important to emphasize the rapid pace of deployment underway for what is still experimental technology. It was only 2016 when the city of Pittsburgh established a test center and became an early test site for Uber. ${ }^{26}$ In the same year, Google rebranded its self-

\footnotetext{
${ }^{20}$ Technologists are also working on robots that can maintain or repair infrastructure such as roads or light posts, but we are not aware of any cities in which these systems are currently in use. Jane Wakefield, Tomorrow's Cities: Dubai and China Roll Out Urban Robots, BBC (June 10, 2018), https://www.bbc.com/news/technology-41268996. Cities aside, technologies increasingly include robots with human operators who monitor and occasionally intervene in the development and operations of large-scale infrastructure systems, such as instrumented rail inspection systems, automated trucks and yard cranes for container port operations, and tunnel construction excavating systems. This is similar to the use of robotics in manufacturing. MIT Tech. Review, China's Robot Workforce, YouTUBE (Apr. 26, 2016), https://www.youtube.com/watch?v=wUAM-7jbhIw.

${ }^{21}$ Russ Mitchell, Tesla Has a Huge Incentive to Deploy Self-Driving Tech. But Is the World Ready?, L.A. TIMES (Aug. 9, 2019, 6:00 AM), https://www.latimes.com/business/story/2019-08-08/tesla-fullself-driving-fsd-technology.

${ }_{22}$ Luke Mellor, The State of Self-Driving Vehicle Fleets, PANTONIUM (June 14, 2019), https://pantonium.com/the-state-of-self-driving-vehicle-fleets/.

${ }^{23}$ Danielle Muoio, RANKED: The 18 Companies Most Likely to Get Self-Driving Cars on the Road First, BUS. INSIDER (Sept. 27, 2017), https://www.businessinsider.com/the-companies-most-likely-toget-driverless-cars-on-the-road-first-2017-4.

${ }^{24}$ Alex Davies, Self-Driving Trucks Are Now Delivering Refrigerators, WIRED (Nov. 13, 2017), https://www.wired.com/story/embark-self-driving-truck-deliveries/; David Katzmaier, In the Future We'll All Fly Personal Drones Like This, CNET (Sept. 28, 2017), https://www.cnet.com/news/in-thefuture-fly-personal-drones-like-this/; Adele Peters, Automated Buses Are Here, Now We Have to Decide How They Are Going to Reshape Our Cities, FAST COMPANY (July 17, 2017), https://www.fastcompany.com/40444021/automated-buses-are-here-now-we-have-to-decide-how-theywill-reshape-our-cities.

${ }^{25}$ Aspen Inst., Initiative on Cities and Autonomous Vehicles, Bloomberg Philanthropies, https://avsincities.bloomberg.org/ (last visited Sept. 7, 2018). Cities may be granted or denied this authority by the state. At the time of this writing, twenty-two states have enacted legislation authorizing the operation of autonomous vehicles, and the governors of eleven states have signed executive orders for this purpose. Autonomous Vehicles: Self-Driving Vehicles Enacted Legislation, NAT'L CONF. ST. LEGISLATURES (Mar. 19, 2019), http://www.ncsl.org/research/transportation/autonomous-vehicles-selfdriving-vehicles-enacted-legislation.aspx\#Enacted\%20Autonomous\%20Vehicle\%20Legislation.

${ }^{26}$ Cecilia Kang, No Driver? Bring It On. How Pittsburgh Became Uber's Testing Ground, N.Y.
} 
driving program as Waymo. ${ }^{27}$ Google's Waymo 2019 Safety Report identifies twenty-five United States cities in its map of test locations, most of which are in the San Francisco Bay Area of California or in proximity to its early test site of Chandler, Arizona. ${ }^{28}$ Other noteworthy cities with automated vehicle pilot programs include Atlanta, Denver, Boston, Detroit, Las Vegas, Reno, San Antonio, Tampa, Miami, and Washington, D.C. ${ }^{29}$ Testing in cities should be distinguished from test centers, as the former refers to partial or complete spatial access to the city while the latter refers to sites designed for testing purposes with limited public access. ${ }^{30}$ With or without test sites, the number of participating cities has grown rapidly. ${ }^{31}$ The dedication of an area for testing, however, should not imply permanence for the technologies or the firms. Following the death of a pedestrian in Arizona, Uber temporarily suspended testing and operations of automated vehicles in all locations. ${ }^{32}$ In general, as reports of accidents have accumulated, the tenor of news about automated vehicles has changed. ${ }^{33}$ After several years of hype, people may be realizing how difficult it is to replace human judgment

TIMES (Sept. 10, 2016), https://www.nytimes.com/2016/09/11/technology/no-driver-bring-it-on-howpittsburgh-became-ubers-testing-ground.html.

${ }^{27}$ Our Journey, WAYMO, https://waymo.com/journey/ (last visited Aug. 22, 2019) (providing a timeline of Google's self-driving projects, which started in 2009).

28 ON THE ROAD tO FUlly SElF-Driving: WAYMO SAFETy REPORT 27 (2019), https://waymo.com/safety/. Note that state governments are playing roles as well. Press Release, Cal. Dep't of Motor Vehicles, Driverless Testing and Public Use Rules for Autonomous Vehicles Approved (Feb. 26, 2018), https://www.dmv.ca.gov/portal/dmv/detail/pubs/newsrel/2018/2018_17; see, e.g., Autonomous Vehicles State Bill Tracking Database, NAT'L CONF. ST. LegisLatures (June 24, 2019), http://www.ncsl.org/research/transportation/autonomous-vehicles-legislative-database.aspx (providing "up to date, real-time information about autonomous vehicle bills that have been introduced in the [fifty] states and the District of Columbia").

${ }^{29}$ Aspen Inst., supra note 25.

${ }^{30}$ See U.S. Department of Transportation Designates 10 Automated Vehicle Proving Grounds to Encourage Testing of New Technologies, U.S. DEP'T TRANSP. (Jan. 19, 2017), https://www.transportation.gov/briefing-room/dot1717 (designating the "proving ground" locations with "different facilities that can be used to gauge safety, manage various roadways and conditions, and handle various types of vehicles").

${ }^{31}$ Brooks Rainwater \& Nicole DuPuis, Cities Have Taken the Lead in Regulating Driverless Vehicles, CityLAB (Oct. 23, 2018), https://www.citylab.com/perspective/2018/10/cities-leadregulation-driverless-vehicles/573325/.

${ }^{32}$ Wren, supra note 6.

${ }^{33}$ How Do We Keep Self-Driving Cars from Killing Us?, CNN BuS., https://www.cnn.com/videos/ business/2019/01/22/how-do-we-keep-self-driving-cars-from-killing-us-beme.beme (last visited Aug. 22, 2019) (originally sourced from BEME); Timothy B. Lee, The Hype Around Driverless Cars Came Crashing Down in 2018, ARS TECHNICA (Dec. 30, 2018, 8:00 AM), https://arstechnica.com/cars/2018/12/uber-tesla-and-waymo-all-struggled-with-self-driving-in-2018/ ("'I've been seeing an increasing recognition from everybody-OEMs down to various startups-that this is all a lot tougher than anybody anticipated two or three years ago,' industry analyst Sam Abuelsamid told Ars. 'The farther along they get in the process, the more they learn how much they don't understand."'); Brian Merchant, The Deadly Recklessness of the Self-Driving Car Industry, GizMODO (Dec. 13, 2018, 12:52 PM), https://gizmodo.com/the-deadly-recklessness-of-the-self-driving-carindustr-1831027948 
behind the wheel with the algorithmic decision-making of artificial intelligence. ${ }^{34}$ One possible outcome could be a shift in attention to devices that are smaller in stature: devices that are not designed to transport people.

Delivery robots are intended to complete last mile logistics - the most complex and expensive portion of the shipping system-where products move to and from distribution centers and homes or offices. ${ }^{35}$ The wide variation in the characteristics of these devices has them destined for all manner of public spaces, including sidewalks, roadways, parking spaces, and airspace. ${ }^{36}$ For example, Starship Technologies' short, electric, six-wheeled robots operate autonomously to deliver items up to forty pounds in weight within a two-mile radius, with the possibility of intervention by remote operators. ${ }^{37}$ They have partnered with firms to offer delivery services in Redwood City, California and Washington, D.C. ${ }^{38}$ Robots from Marble, Dispatch, Robby, Eliport, and Kiwi strike a similar profile and occupy a similar market niche. ${ }^{39}$ Amazon, a late market entrant, recently unveiled a

${ }^{34}$ John McDermid, Self-Driving Cars Will Never Be Moral. Let's Stop Pretending Otherwise, FAST COMPANY (Feb. 4, 2019), https://www.fastcompany.com/90300056/self-driving-cars-will-never-bemoral-lets-stop-pretending-otherwise; Joann Muller, Wall Street Is Split on Self-Driving Cars, AxIos (Jan. 30, 2019), https://www.axios.com/split-views-about-self-driving-cars-on-wall-street-48897a1cc480-4910-8018-65d91e69bbe6.html; Anton Wahlman, Tesla Is Decades Away From Full Self-Driving Cars, THESTREET (Feb. 3, 2019), https://www.thestreet.com/investing/tesla-is-decades-away-from-fullself-driving-cars-14853271 (“'[F]ull self driving' . . remains decades away. Try having a car follow directions from a cop waving his hands, to get around a stalled truck on a one-lane road, in a snowstorm. ... [Self-driving cars] may work at lower speeds in a low-complexity campus environment. But not in the real world, where they have to mix with all kinds of real traffic, unusual obstacles, and weather. Elon Musk was right about needing to be at the $99.999 \%$ level of better. But by saying that Tesla is now at $98 \%$, he admits that he is decades away from delivering what he is promising for already this year, 2019.”).

${ }^{35}$ Elle Hunt, 'It's Like a Robot Playground': The Cities Welcoming Self-Driving Delivery Droids, GUARDIAN (May 1, 2018), https://www.theguardian.com/cities/2018/may/01/what-the-hell-is-that-selfdriving-delivery-robots-hit-london; Lora Kolodny, Postmates and DoorDash Are Testing Delivery by Robot With Starship Technologies, TECHCRUNCH (Jan. 18, 2017), https://techcrunch.com/2017/01/18/ postmates-and-doordash-are-testing-delivery-by-robot-with-starship-technologies/; Erica E. Phillips, When Robots Take to City Sidewalks, WALL ST. J. (Apr. 12, 2017), https://www.wsj.com/articles/whenrobots-take-to-city-sidewalks-1491970141.

${ }^{36}$ Olivia Solon, Robots Are Invading Malls (and Sidewalks) Near You, MIT TECH. REV. (June 8, 2016), https://www.technologyreview.com/s/601635/robots-are-invading-malls-and-sidewalks-nearyou/.

${ }^{37}$ Hunt, supra note 35 ; Kolodny, supra note 35 .

${ }^{38}$ Kolodny, supra note 35; Kat Lonsdorf, Hungry? Call Your Neighborhood Delivery Robot, NPR (Mar. 23, 2017), https://www.npr.org/sections/alltechconsidered/2017/03/23/520848983/hungry-callyour-neighborhood-delivery-robot.

398 Delivery Robot Startups for Last Mile Delivery, NANALYze (Apr. 27, 2018), https://www.nanalyze.com/2018/04/8-delivery-robot-startups-last-mile-delivery/; Eliport: Delivering an Autonomous Future, STARTEnGINE, https://www.startengine.com/eliport (last visited Aug. 23, 2019); Brian Heater, Kiwi's Robots Deliver Food to Hungry Berkeley Students, TECHCRUNCH (May 26, 2018), https://techcrunch.com/video/kiwis-robots-deliver-food-to-hungry-berkeley-students/; Lora Kolodny, Marble and Yelp Eat24 Start Robot Food Delivery in San Francisco, TeChCRUnCH (Apr. 12, 2017), https://techcrunch.com/2017/04/12/marble-and-yelp-eat24-start-robot-food-delivery-in-san-francisco/; 
delivery robot that bears a striking resemblance to Starship's models, with the announcement that they are beginning field testing in Snohomish County, Washington. ${ }^{40}$ Robots like these operate under a patchwork of legal rules, sometimes requiring a permit, either because of a lack of regulation or permissive state laws. ${ }^{41}$ Starship representatives have suggested that relaxed rules allow their use in Virginia, Florida, Wisconsin, and Idaho, as well as Washington, D.C. ${ }^{42}$ There are also firms competing in this space with larger vehicles, which may be subject to many of the same regulations as autonomous vehicles for passengers. Nuro's delivery vehicles are about half the size of an automobile, suggesting larger payloads, travel on roadways, and the need to occupy a parking space while loading, unloading, or charging. ${ }^{43}$ Reports suggest that Teleretail's prototype, similar in size, can operate within a fifty-mile radius. ${ }^{44}$ Udelv, whose vehicles may include a driver, recently announced plans to begin an operation in Oklahoma City, Oklahoma and a test program with Walmart in Surprise, Arizona. ${ }^{45}$ Notably, automakers envision a role for themselves in the autonomous vehicle market. ${ }^{46}$ Ford has announced that it will test its full-sized automated

TechCrunch, Marble's Delivery Robot Rolls Through SF, YouTUBE (Apr. 12, 2017), https://www.youtube.com/watch? $=$ pNpH4G-hoIY. In addition, there are models from Savioke and Aetheon that are being marketed for use indoors and in hotels and hospitals, respectively. Paul Miller, The Relay Hotel Delivery Robot Will Soon Spot Wi-Fi Dead Zones and Mingle with Guests, VerGe (Jan. 11, 2018), https://www.theverge.com/2018/1/11/16879432/savioke-relay-hotel-delivery-robot-wi-fidead-zones-mingle-ces-2018; Welcome to the One-of-a-Kind World of Aetheon, AETHEON, https://aethon.com/ (last visited Aug. 23, 2019).

${ }^{40}$ Matt Simon \& Arielle Pardes, The Prime Challenges for Amazon's New Delivery Robot, WIRED (Jan. 23, 2019), https://www.wired.com/story/amazon-new-delivery-robot-scout/.

${ }^{41}$ See Jeremy Hsu, Out of the Way, Human! Delivery Robots Want a Share of Your Sidewalk, SCI. AM. (Feb. 19, 2019), https://www.scientificamerican.com/article/out-of-the-way-human-deliveryrobots-want-a-share-of-your-sidewalk/ ("San Francisco . . . slapped a ban in 2017 on autonomous deliveries by sidewalk robots and has only slowly opened the door for companies seeking permits. Other U.S. communities have regulated where such robots can go and how they must behave.").

${ }^{42}$ Javier Espinoza, Delivery Robots Hit the Streets, but Some Cities Opt Out, FIN. TIMES (Jan. 30, 2018), https://www.ft.com/content/0a2a5a76-e0ea-11e7-a0d4-0944c5f49e46.

${ }^{43}$ Alan Ohnsman, Ex-Google Engineers Raise \$92 Million To Roll Out Robot Delivery Vehicles This Year, FORBES (Jan. 30, 2018), https://www.forbes.com/sites/alanohnsman/2018/01/30/ex-googleengineers-raise-92-million-to-deploy-robot-delivery-vehicles-this-year/\#3c7c739875d1.

${ }^{44}$ Lora Kolodny, Teleretail Built a Delivery Robot to Make On-Demand Delivery Easy for Small Businesses, TECHCRUNCH (May 15, 2017), https:/techcrunch.com/2017/05/15/teleretail-built-adelivery-robot-to-make-on-demand-logistics-easy-for-small-businesses/.

${ }^{45}$ David Dishman, Autonomous Vehicles to Bring Groceries to Oklahoma City Residents, TRANSP. TOPICS (Sept. 14, 2018, 10:45 AM), https://www.ttnews.com/articles/autonomous-vehicles-bringgroceries-oklahoma-city-residents; Gregory Magana, Walmart Is Piloting Another Autonomous Grocery Delivery Program, BuS. INSIDER (Jan. 10, 2019), https://www.businessinsider.com/walmart-udelvautonomous-grocery-delivery-2019-1.

${ }^{46}$ Daimler has invested in both Starship Technologies and Matternet, and Ford's recent agreement suggests the interest of automakers in automated delivery services. Automating the Last Mile: Startups Chasing Robot Delivery by Land and Air, CB INSIGHTS RES. BRIEFS (Mar. 30, 2017), https://www.cbinsights.com/research/autonomous-drone-delivery-startups/; Laura Bliss, Self-Driving Pizza Just Hit Miami, CiTYLAB (Feb. 27, 2018), https://www.citylab.com/transportation/2018/02/self- 
vehicles for package delivery services, ${ }^{47}$ and Toyota has unveiled a prototype ${ }^{48}$ Ford has opted to pair its automated delivery vehicles with a more humanoid, bipedal walking robot. ${ }^{49}$ In addition, at least two firms offer delivery services via aerial drones: Flirtey and Matternet. ${ }^{50}$ Flirtey garnered attention in 2016, with its first delivery sanctioned by the Federal Aviation Administration of a product from a 7-Eleven to a home via drone. ${ }^{51}$ Amazon Prime Air delivery by drone has been undergoing tests in the UK, but not in the United States. ${ }^{52}$ Reports suggest that Boeing is also entering the market, with a drone for payloads of up to 500 pounds. ${ }^{53}$

Security robots, which could be said to operate like mobile closed circuit television with the capacity to automatically call authorities, are intended to reduce the need for human security guards. ${ }^{54}$ Although such products are privately owned and operated, some scholars have conceptualized them as a form of automated law enforcement. ${ }^{55}$ For the most part, security robots

driving-pizza-just-hit-miami/554138/.

${ }^{47}$ Bliss, supra note 46 (discussing Ford's self-driving pizza delivery vehicle).

${ }^{48}$ Margi Murphy, CES 2018: Driverless Pizza Hut Delivery Van Draws Black Mirror Comparisons, TELEGRAPH (Jan. 9, 2018), https://www.telegraph.co.uk/technology/2018/01/09/ces-2018-driverlesspizza-hut-delivery-van-draws-black-mirror/ (describing Pizza Hut's plan to team up with Toyota to design a driverless vehicle to deliver pizza to customers).

${ }^{49}$ Isobel Asher Hamilton, Ford Might Have Out-Creeped Boston Dynamics with a 2-Legged Delivery Robot, BUS. INSIDER (May 22, 2019), https://www.businessinsider.com/ford-revealsautonomous-delivery-robot-digit-2019-5?fbclid=IwAR0DVDYIxSG4yN6e8sy-PCuWb2sOJqCsKqo LhK_6SHHAmxXdWSBeQLFucII.

${ }^{50}$ Automating the Last Mile, supra note 46.

${ }^{51} I d$.

${ }^{52}$ Kyle Bailey, Why Amazon's Drone Delivery Service Is Unrealistic, OBSERVER (Nov. 20, 2017), https://observer.com/2017/11/amazon-prime-air-drone-delivery-service-might-never-happen-in-unitedstatesr/; Jeff Desjardins, Amazon and UPS Are Betting Big on Drone Delivery, Bus. INSIDER (Mar. 11, 2018), https://www.businessinsider.com/amazon-and-ups-are-betting-big-on-drone-delivery-2018-3.

${ }^{53}$ Stephen Trimble, Unmanned Cargo Lifter Deepens Boeing's Push on Autonomy, Flight GLOBAL (Jan. 10, 2018), https://www.flightglobal.com/news/articles/unmanned-cargo-lifter-deepensboeings-push-on-auton-444788/.

${ }^{54}$ See K5 Autonomous Data Machine, KNIGHTSCOPE, https://www.knightscope.com/knightscopek5/ (last visited Aug. 19, 2019) (discussing that K5 is "equipped to keep areas such as parking lots, corporate campuses and hospitals safe autonomously"); Shan Li, Robots Are Becoming Security Guards. 'Once It Gets Arms ... It'll Replace All of Us', L.A. TIMES (Sept. 2, 2016), http://www.latimes.com/ business/la-fi-robots-retail-20160823-snap-story.html ("Already, Knightscope robots are edging into the private security industry, patrolling parking lots, a shopping center and corporate campuses in California."); Matt Simon, The Tricky Ethics of Knightscope's Crime-Fighting Robots, WIRED (Dec.

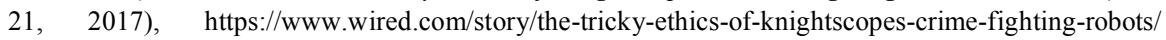
("Knightscope wants to keep humans in the loop with its robots, but it's not hard to imagine a day when someone else gets the bright idea to give other security machines a lot more autonomy.").

${ }^{55}$ Woodrow Hartzog et al., Inefficiently Automated Law Enforcement, 2015 MicH. ST. L. REV. 1763, 1763 (2015) (exploring theories surrounding automated law enforcement). See also Elizabeth E. Joh, Private Security Robots, Artificial Intelligence, and Deadly Force, 51 U.C. DAVIS L. REV. 569, 569 (2017) ("A recent use of a remote-controlled robot equipped with lethal force has raised the question of how police might use robots to supplement or replace existing police work.”). 
have been deployed without ex ante permission from cities. ${ }^{56}$ The company most prevalent in searches for security robots is Knightscope, although there are others. ${ }^{57}$ Robots from Knightscope can be programmed to patrol a predefined area and are currently being used or contemplated for use in parking lots, residential neighborhoods, and quasi-public areas such as corporate campuses, shopping malls, museums, and airports. ${ }^{58}$ The K5 units for outdoor use weigh over 400 pounds, are over five feet tall, and come with an electrical pad for charging. ${ }^{59}$ They are outfitted for 360 degree video recording, storage, and streaming, including thermal imaging, reading license plates, tracking parked cars, playing pre-recorded messages, and a two-way intercom between a remote operator and people who encounter the device. ${ }^{60}$ Also known as "automated data machines," the devices stream data to the company's "security operations center," and the firm advertises the ability to stream the same to recipients' online web portals. ${ }^{61}$ A report in October 2017 noted that the firm had already deployed forty-seven of these devices for clients in ten states, including venues in Boston, Atlanta, Dallas, Sacramento, Washington, D.C., and Tampa ${ }^{62}$ Like Knightscope, Segway markets the Loomo robot for security use, and the city of York, Pennsylvania has experimented with it to augment the city police force's surveillance and first response capabilities. ${ }^{63}$ In a curious twist, Boston Dynamics suggests that security is an appropriate use for their doglike robot, SpotMini. ${ }^{64}$ Drones are also in use in numerous police departments, though the extent to which

\footnotetext{
${ }^{56}$ Michael Hamilton, Cities Should Not Design for Autonomous Vehicles, MKT. URBANISM (Nov. 13, 2017), http://marketurbanism.com/2017/11/13/cities-should-not-design-for-autonomous-vehicles/ ("[A] permissionless innovation is the only necessary condition for the adoption of autonomous vehicles.").

${ }^{57}$ Robbie Gonzalez, I Spent the Night with Yelp's Robot Security Guard, Cobalt, WIRED (Aug. 4, 2017), https://www.wired.com/story/i-spent-the-night-with-yelps-robot-security-guard-cobalt/.

${ }^{58}$ Tim Johnson, Coming Soon: Security Robots That Patrol Streets - Or Guard Your Home, MCCLATChY (Oct. 30, 2017, 5:00 AM), http://www.mcclatchydc.com/news/nation-world/national/ article181343981.html; Li, supra note 54.

${ }^{59}$ Johnson, supra note 58.

${ }^{60} \mathrm{Li}$, supra note 54.

${ }^{61}$ Knightscope, Inc., Knightscope Security Robots Available NOW!, YouTuBE (June 17, 2016), https://www.youtube.com/watch?v=UtuLB2duq2E.

${ }^{62}$ Tim Johnson, Can Robots Replace Human Security Guards?, Gov’T TECH. (Oct. 31, 2017), http://www.govtech.com/public-safety/can-robots-replace-human-security-guards.html; Johnson, supra note 58.

${ }^{63}$ Ty Lohr, Robots on Patrol: Could These Two-Wheeled Robots Help York City Police Department?, YORK DAILY REC. (Nov. 8, 2018), https://www.ydr.com/story/news/2018/11/08/couldrobots-wave-future-law-enforcement-york-city-police/1933263002/.

${ }^{64}$ Peter Holley, This Company Is Building a Massive Pack of Robot Dogs for Purchase Starting in 2019, WASH. POST (July 24, 2018), https://www.washingtonpost.com/technology/2018/07/24/thiscompany-is-building-massive-pack-robot-dogs-purchase-starting/?utm_campaign=d3930868f3UW_Today_Thursday_July_26_2018\&utm_medium=email\&utm_source=UW\%20News\%20Subscrib ers\&utm_term $=.52 \mathrm{cf} 5207 \mathrm{~b} 7 \mathrm{~b} 8$.
} 
police use automated devices as opposed to remote control is not clear. ${ }^{65}$ The world's largest drone manufacturer and the largest police body-camera manufacturer recently partnered to sell drones to police departments, and critics fear that this partnership will put drones with powerful artificial intelligence capabilities, such as facial recognition, in the hands of police with little oversight. ${ }^{66}$

Entertainment or companion robots represent another wave of autonomous devices entering urban space. $^{67}$ For entertainment, synchronized drones, for example, are in use by Disney and were featured in the opening and closing ceremonies of the 2018 Winter Olympics. ${ }^{68}$ The film industry is using drones to replace expensive rigging with aerial cinematography. ${ }^{69}$ And, perhaps more importantly for public space, anyone can now purchase an aerial drone that follows and video records any specified person, animal, or moving object, wherever it goes, for an elaborate form of "selfie." "70 Though they appear to be no different from remote controlled commercial drones, these devices may be set to automatically track a signal or follow an individual and may also be equipped with the software necessary to detect and avoid other objects. ${ }^{71}$

${ }^{65}$ How Law Enforcement Can Harness the Benefits of an Unmanned Aircraft Systems (UAS) Program, U.S. DEP'T JUST. NIJ (Dec. 16, 2016), https://www.nij.gov/topics/lawenforcement/operations/aviation/Pages/harnass-benefits-of-unmanned-aircraft-systems.aspx

("According to the Bureau of Justice Statistics, only about 350 law enforcement agencies in the U.S. had aviation programs in active use.").

${ }^{66}$ See Dave Gershgorn, This Is the Week That the Drone Surveillance State Became Real, QUARTZ (June 8, 2018), https://qz.com/1299947/this-is-the-week-that-the-drone-surveillance-state-became-real/ (explaining the partnership between DJI and Axon and the surveillance AI's ability for facial recognition). The recent case of IBM's undisclosed use of data from the New York Police Department's closed-circuit television systems reads like a precursor for the proprietization of surveillance data from security robots, including drones. James Vincent, IBM Secretly Used New York's CCTV Cameras to Train Its Surveillance Software, VERGE (Sept. 8, 2018), https://www.theverge.com/2018/9/6/17826446/ ibm-video-surveillance-nypd-cctv-cameras-search-skin-tone.

${ }^{67}$ William Grimes, Drones Kill, Yes, But They Also Rescue, Research and Entertain, N.Y. TIMES (May 11, 2017), https://www.nytimes.com/2017/05/11/arts/design/drones-kill-yes-but-they-also-rescueresearch-and-entertain.html.

${ }^{68}$ Ron Dicker, The Olympics Opening Ceremony Drone Show Is Just So Damn Impressive, HUFFINGTON POST (Feb. 9, 2018), https://www.huffingtonpost.com/entry/opening-ceremony-droneshow-is-just-so-damn-impressive_us_5a7db877e4b08dfc930363ae; Darren Wihko, The Making of Walt Disney World's First Drones Show, YouTuBE (Dec. 1, 2016), https://www.youtube.com/watch? v=EDhHNN6nfRQ (last visited Aug. 29, 2019).

${ }^{69}$ Richard Verrier, Drones Are Providing Film and TV Viewers a New Perspective on the Action, L.A. Times (Oct. 8, 2015), http://www.latimes.com/entertainment/envelope/cotown/la-et-ct-droneshollywood-20151008-story.html.

${ }^{70}$ Fintan Corrigan, 12 Best Follow Me Drones and Follow You Technology Reviewed, DRONEZON (July 5, 2019), https:/www.dronezon.com/drone-reviews/best-follow-me-gps-mode-drone-technologyreviewed/; Antonio Villas-Boas \& Rachel Sandler, This \$2,500 'Self-flying Camera' Can Follow You Around and Snap Photos Without Anyone Controlling It - Here's How It Works, BUS. INSIDER (Feb. 15, 2018), https://www.businessinsider.com.au/skydio-r1-drone-self-flying-camera-explained-photos2018-2.

${ }^{71}$ See Corrigan, supra note 70 ("It is good to remember that the vast majority of Follow Me mode 
The same "follow me" features are also emerging in devices on roadways and sidewalks. Segway's Loomo robot may be marketed for security, but it was also intended for entertainment, as it was designed to be able to follow its user, take pictures, and display simple social computing characteristics (smiley faces). ${ }^{72}$ It is a hoverboard that users can ride or load with up to 200 kilograms of packages, and it is capable of traveling up to eleven miles per hour, with a range of twenty-two miles on a single charge and sensors and software that includes voice command and facial recognition. ${ }^{73}$ Seemingly interested in reaching all possible markets, Segway has also marketed Loomo for autonomous goods delivery, emphasizing the features of design for carrying packages. ${ }^{74}$ Similarly, the company responsible for Vespa Scooters is working on Gita, a small cargo "droid" designed to free the user's hands as they traverse dense urban environments. ${ }^{75}$ Several companies, such as Cowa and Travelmate, now offer robotic suitcases with "follow me" capabilities, though astute authors question the value of a suitcase that contains a battery large enough to pose a hazard to airlines. ${ }^{76}$ While not strictly meant as entertainment (although one writer described Gita as "more like having a pet than an artificial intelligence"), these machines are designed to delight users while contributing to leisure experiences. ${ }^{77}$

Altogether, the urban robotics profiled in this Section represent a dizzying array of firms with a rapidly expanding portfolio of products for use in the public and quasi-public spaces of cities. The diversity of uses envisioned for these technologies, however, belie the fundamental characteristics that they share in common: mobility, artificial intelligence, communications, and a fine-grained ability to sense the world around them. This confluence is the result of technological evolution, which suggests that the drivers behind these products have been with us for a long time.

drones do not have object avoidance.").

72 Paul Miller, Taking a Ride on Segway's Loomo Robot, VERGE (Jan. 11, 2018), https://www.theverge.com/2018/1/11/16874220/segway-loomo-robot-hands-on-ces-2018.

${ }^{73}$ Andrew Tarantola, Segway's Loomo Is the Robotic Hoverboard Nobody Asked For, ENGADGEI (Mar. 6, 2018), https://www.engadget.com/2018/03/06/segways-loomo-robotic-hoverboard-hands-on/.

${ }^{74}$ Marrian Zhou, Segway to Introduce Autonomous Delivery Robots at CES 2019, CNET (Jan. 3, 2019), https://www.cnet.com/news/segway-to-introduce-autonomous-delivery-robots-at-ces-2019/.

${ }^{75}$ Ian Bogost, The Cute Robot That Follows You Around the City, ATLANTIC (Feb. 28, 2018), https://www.theatlantic.com/technology/archive/2018/02/piaggio-gita-jeffrey-schnapp/554222/.

${ }^{76}$ Paul Brady, This $\$ 800$ Robot Suitcase Will Follow You Around the Airport, CONDE NASTE TRAVELER (May 30, 2018), https://www.cntraveler.com/story/ovis-robot-suitcase-will-follow-youaround-the-airport; Dean Takahashi, Travelmate Robotics' Robot Suitcase Will Follow You to CES 2018, VENTURE BEAT (Jan. 3, 2018), https://venturebeat.com/2018/01/03/travelmate-robotics-robot-suitcasewill-follow-you-to-ces-2018/.

${ }^{77}$ Entertainment robots like Gita or the robotic suitcase could conceivably constitute a separate "personal service robot" category, but until such use cases actually develop, we will use the current classification scheme. Bogost, supra note 75. 


\section{B. Urban Robots and the Evolution of Technology}

To understand the magnitude and endurance of urban robotics, it may be helpful to place these products within the evolutionary theory of technology. ${ }^{78}$

According to theory, technologies are designed to apply scientific knowledge for a purpose, they are in and of themselves assemblies of technologies, and their evolution occurs through the recombination of newly incorporated phenomena with existing components. ${ }^{79}$ Technology is commonly developed to augment the forces of nature and, as it relies on basic science about how the world works, modern technology is understood to advance along with discoveries in basic science. ${ }^{80}$ As products, however, technologies are recursive, in that they are made of assemblies of components, which are themselves technologies, each harnessing scientific knowledge about physical effects and other natural phenomena. ${ }^{81}$ Given that all technologies rely on the understanding and application of natural or physical effects, the combinatorial evolution of technology accelerates when a new family of phenomena are discovered and incorporated into components for further recombination. ${ }^{82}$

Urban robotics combine the newfound capacity for autonomous controls, brought about by machine learning and artificial intelligence, with a multitude of existing sensor, robotic, compute, communication, energy,

78 See ARTHUR, supra note 2, at 23 (presenting a theory of evolution for technology, a theory constructed from a "coherent group of general propositions" that can be used to "explain technology's behavior').

79 See id. (building an argument about the essence and evolution of technology from "three fundamental principles," first that "all technologies are combinations . . . constructed or put togethercombined - from components or assemblies or subsystems at hand," second, that "each component of technology is itself in miniature a technology," and third, that "all technologies harness and exploit some effect of phenomenon, usually several").

${ }^{80}$ See id. at 46 ("A technology is always based on some phenomenon or truism in nature that can be exploited and used to a purpose."); $i d$. at 60 ("Science is necessary for the unearthing of modern phenomena, the more deeply hidden clusters of effects, and for forming technologies from these."); $i d$. at 59 (distinguishing natural phenomena from technology, "[n]ot every phenomenon of course is harnessable for use, but when a family of phenomena is uncovered, a train of technologies follows").

${ }^{81}$ See id. at 39 (noting that "any technology . . consists of component building blocks that are also technologies, and these consist of subparts that are also technologies, in a repeating (or recurring) pattern" combined for a human purpose); $i d$. at 43 ("Combination must work not just by bringing a purpose with a concept or principle that matches it. It must provide a main set of assemblies or modules to execute this central idea. It must support this with further assemblies, and these again with further assemblies to support these. And all these parts and assemblies must be orchestrated to perform together harmoniously.").

${ }^{82}$ See id. at 59, 172 (commenting on William Ogburn's suggestion that the growth of technologies resembles a "compound interest curve," growing "exponentially"). Arthur says, "[A]s the number of technologies increases, the possibilities for combination also increase. . . . [I]f new technologies lead to further new technologies, then once the numbers of elements in the collective pass through some threshold, the possibilities of combination begin to explode." Id. at 174. 
and transportation technologies. ${ }^{83}$ Given that machines can now be programmed to use algorithms that process richly expansive data collected from the environment and, flipping the process, modify or develop new algorithms based on feedback from the environment, people can and should expect products to come to market that attempt to navigate the physical environment autonomously. ${ }^{84}$ In the language of the evolutionary theory of technology, nascent human scientific understanding of how the brain works is accelerating evolution by providing the opportunity to combine a whole new family of artificially intelligent controls with existing technologies.

With this perspective, today's autonomous urban robotics and vehicles can be understood to represent the beginning of a long arc of technological exploration, development, and proliferation, which may stretch at least as long as one can imagine it will take to learn about intelligence. ${ }^{85}$ If markets and institutions permit, people should be able to see the development and emergence of more intelligent designs over time, each competing for survival. At the moment, entrepreneurship is giving rise to a diversity of devices; the presumed standard sizes and uses for vehicles, robotics, and drones are being blurred as devices appear to fill in gaps in continua of size, shape, and purpose. As technology progresses, new applications should open up and individual robotics platforms should be able to operate in multiple task domains. In other words, the technology will converge, as devices are created to serve multiple or perhaps open-ended purposes across the variety

${ }^{83}$ Ryan Calo, Robotics and the Lessons of Cyberlaw, 103 CALIF. L. Rev. 513, 529-30 (2015) (defining robots). See also Michael Nagenborg, Urban Robotics and Responsible Urban Innovation, ETHICS \& INFO. TECH. (Jan. 30, 2018), https://doi.org/10.1007/s10676-018-9446-8 (defining "urban robots" as a term by which to address robots as urban technologies).

${ }^{84}$ Machine learning algorithms allow computers to recognize patterns and make connections that are not pre-program, but instead "learned" based on associations in large data sets. As such, they require large amounts of data to be effective. See Will Knight, The Dark Secret at the Heart of AI, MIT TECH. REV. (Apr. 11, 2017), https://www.technologyreview.com/s/604087/the-dark-secret-at-the-heart-of-ai/ ("From the outset, there were two schools of thought regarding how understandable, or explainable, AI ought to be. Many thought it made the most sense to build machines that reasoned according to rules and logic, making their inner workings transparent to anyone who cared to examine some code. Others felt that intelligence would more easily emerge if machines took inspiration from biology, and learned by observing and experiencing. This meant turning computer programming on its head. Instead of a programmer writing the commands to solve a problem, the program generates its own algorithm based on example data and a desired output. The machine-learning techniques that would later evolve into today's most powerful AI systems followed the latter path: the machine essentially programs itself."). For a noted early example, see A. L. Samuel, Some Studies in Machine Learning Using the Game of Checkers, 3 IBM J. RES. \& DEV. 211, 211-29 (1959), http://ieeexplore.ieee.org/stamp/stamp.jsp?tp=\& arnumber $=5392560 \&$ isnumber $=5392559$.

${ }^{85}$ See, e.g., M. Mitchell Waldrop, Inside the Moonshot Effort to Finally Figure Out the Brain, MIT TECH. REV. (Oct. 12, 2017), https://www.technologyreview.com/s/609070/inside-the-moonshot-effortto-finally-figure-out-the-brain/ (explaining the future of technological exploration relating to the brain). 
of public and private spaces. ${ }^{86}$ This convergence could lead to the creation of open robotics platforms, which could drive further innovation. ${ }^{87}$

The evolution of technology is an endogenous source of economic development, evidenced as new products emerge and flourish in urban markets. ${ }^{88}$ In economics, the notion that technology contributes to growth dates back to Adam Smith, with the idea that trade in surplus products may be reinvested in technology and shift the division of labor to result in more productivity and thus more surplus for trade in a virtuous cycle of economic growth. ${ }^{89}$ Technology is appealing to city officials because of the promise of economic growth that it may bring. The function of economic development for local government is practically synonymous with attracting businesses with new or established technologies, in the hope that the firms will build or expand facilities in the government's jurisdiction. Competitions to attract tech firms demonstrate that cities and states will gamble with significant amounts of tax dollars in the hope that jobs and technological advancement will expand opportunities for local residents. ${ }^{90}$

Artificial intelligence assigns, however, a new purpose to technology because it allows technology to replace as well as augment the forces of nature. ${ }^{91}$ While technological change is a source of endogenous economic development, it brings with it the force in economic theory characterized as

${ }^{86}$ See Siddhartha Menon, Policy Initiative Dilemmas Surrounding Media Convergence: A Cross National Perspective, 24 PROMETHEUS 59, 60 (2007) (defining technological convergence in terms of the integration or combination and transformation of infrastructures and media, and digitalization).

${ }^{87}$ See Ryan Calo, Open Robotics, 70 MD. L. REv. 571, 574 (2011) (“Open robotics . . . could lead to rapid innovation and growth within the personal robotics sector ....").

88 Joseph A. SCHUMPeTER, THE THEORY OF ECONOMIC DEVElopment: AN INQUiRY INTO Profits, CAPITAL, CREdit, INTEREST, AND THE Business CyCle 63 (Redvers Opie trans., Harvard Univ. Press 8th prtg. 1968) (1934) (“By 'development,' therefore, we shall understand only such changes in economic life as are not forced upon it from without but arise by its own initiative, from within."); $i d$. at 65 ("It is ... the producer who as a rule initiates economic change, and consumers are educated by him if necessary; they are, as it were, taught to want new things, or things which differ in some respect or other from those which they have been in the habit of using."); ARTHUR, supra note 2, at 19-20 ("Schumpeter was asking whether an economy could change itself without external factors - purely from within - and if so how" and "realized that there was "a source of energy within the economic system which would of itself disrupt any [economic market] equilibrium that might be attained' . . . The economy continually created the new by combining the old, and in doing so it disrupted itself constantly from within.”).

${ }^{89}$ Adam Smith, An Inquiry Into the Nature and Causes of the Wealth of Nations 17 , 22-23 (R.H. Campbell \& A.S. Skinner eds., Oxford Univ. Press 1979) (1799).

${ }^{90}$ See, e.g., Kang, supra note 26 (describing Pittsburgh's "gamble" with attracting Uber's driverless cars); Cecilia Kang, Pittsburgh Welcomed Uber's Driverless Car Experiment. Not Anymore, N.Y. TIMES (May 21, 2017), https://www.nytimes.com/2017/05/21/technology/pittsburgh-ubers-driverless-carexperiment.html (explaining the deteriorating relationship between Pittsburgh and Uber).

${ }^{91}$ See ARTHUR, supra note 2, at 215 ("If we merely used nature's phenomena in raw form, to power water wheels or propel sailing ships, we would feel more at home with technology . . . But now, with the coming of genetic engineering, machine intelligence, bionics, climate engineering, we are beginning to use technology — use nature - to intervene directly within nature."). 
creative destruction, in which new products disrupt existing markets. ${ }^{92}$ When technology attempts to replicate the functions of the brain, as in the autonomous control of an automobile, mobile robot, or drone, this technology can be designed for the purpose of replacing people. ${ }^{93}$ Thus the creation of new technology can result in the development of new markets, but also the destruction of existing ones, disrupting current pathways for the creation of wealth in the economy. As the scale of autonomous technology expands, as it is likely to do, such disruptions have the potential to change the structure of the economy for whole industries.

Borrowing from Darwin's theory of evolution by natural selection, technologies may be said to compete for survival, but there are limits to this analogy. ${ }^{94}$ What theories of natural and technological evolution share is attention to design over time. Their differences, curiously, are based on whether one can credibly say that evolution is due to intelligent design. Evolution in nature occurs by the process of natural selection, in which design consists of the traits of individuals, passed down to or emergent in offspring, as may happen over time within the resources and constraints of the environment. ${ }^{95}$ Though people have advocated for a theory of evolution that attributes the origin and abundance of variety in nature to design by an intelligent being, this concept is not applicable to the natural world. ${ }^{96}$ Natural

92 JOSEPH A. SCHUMPETER, CAPITALISM, SOCIALISM AND DEMOCRACY 83-84 (3d ed. 1950) (“The opening up of new markets, foreign or domestic, and the organizational development from the craft shop and factory to such concerns as U.S. Steel illustrate the same process of industrial mutation-if I may use that biological term - that incessantly revolutionizes the economic structure from within, incessantly destroying the old one, incessantly creating a new one. This process of Creative Destruction is the essential fact about capitalism. It is what capitalism consists in and what every capitalist concern has got to live in.... Every piece of business strategy acquires its true significance only against the background of that process and within the situation created by it. It must be seen in its role in the perennial gale of creative destruction; it cannot be understood irrespective of it ....").

${ }^{93}$ See Waldrop, supra note 85 ("AI is only loosely modeled on the brain. So what if you wanted to do it right? You'd need to do what has been impossible until now: map what actually happens in neurons and nerve fibers.").

${ }^{94}$ See ARTHUR, supra note 2, at 103 ("The process of problem solving in engineering brings forth novel solutions - novel combinations - in an abrupt way that does not match Darwin's slow cumulation of changes. Then from these, the better ones are selected, and then propagate through engineering practice, a la Darwin. . . [T] his . . . does not mean that in technology the best—or fittest—solutions always survive. ... [By] [s]mall chance events, [technologies gain prevalence and] technologies (or solutions) that gain prevalence tend to gain further advantage and to lock in, so there is a positive feedback process at work in the 'selection' of technologies.").

${ }^{95}$ Charles Darwin, ON THE ORIGIN OF SPECIES 399 (new ed. 1864) ("[T]his whole volume is one long argument ... [advancing] the theory of descent with modification through natural selection ... .").

${ }^{96}$ DANiEl C. DennetT, Darwin's Dangerous IDEA 46, 75-76 (1995) (“'[A]lthough Darwin depended on his idea of the mechanism of natural selection to inspire and guide his research on evolution, the end result reversed the order of dependence: he showed so convincingly that species had to have evolved that he could then turn around and use this fact to support his more radical idea, natural selection. ... For over a century, skeptics have been trying to find a proof that Darwin's idea just can't work, at least not all the way. They have been hoping for, hunting for, praying for . . . a 'mind first' force or power 
selection is a process which begets design, but has no designer. ${ }^{97}$ It has resulted in intelligence, but it is not intelligent. Intelligent design is, however, a useful concept for understanding the theory of the evolution of technology. ${ }^{98}$ Technology requires designers, and intelligent design, while in the eye of the beholder, is a description that becomes apt as a product competes in an economic market and survives.

\section{The Intelligent Design of Urban Robotics}

The following paragraphs provide an overview of the factors that lead firms to seek out testbeds within cities and the basic stages of design. If cities are to be urban testbeds for robots, city officials and their residents should become familiar with the process of design because, whether they realize it or not, they are participating in it.

The design of an autonomous system is a complex process, and one that cannot be optimized in the abstract. Designing an autonomous system requires an understanding of the task for the device and the environment in which it must reside. Design is a process of making trade-offs: between mobility, sensing, intelligence, cost, and much more. A roboticist must first understand the design specifications and parameters in which the system will operate. Further, robots operate within an ecology; a complex system where changes to one part may impact the whole in unintended ways.

Cities are not the easiest of environments for roboticists to contemplate in design. The simplest environments for robots are factory floors, which are typically engineered in ways that reduce the scope of the task the robot must undertake. The most complex environment for an autonomous system to

or process, an exception to the principle that all design, and apparent design, is ultimately the result of a mindless, motiveless mechanicity."). For a current account of empirical evidence of evolution by natural selection, see Jonathan Weiner, The Beak of the Finch: A Story of EVOlution in our Time (1994).

${ }^{97}$ DENNETT, supra note 96, at 59, 65 ("Darwin's dangerous idea: the algorithmic level is the level that best accounts for the speed of the antelope, the wing of the eagle, the shape of the orchid, the diversity of species, and all the other occasions for wonder in the world of nature. . . Can [the actual biosphere] be the outcome of nothing but a cascade of algorithmic processes feeding on chance? And if so, who designed that cascade? Nobody. It is itself the product of a blind, algorithmic process. . . . Darwin suggests a division: Give me Order, he says, and time, and I will give you Design. Let me start with regularity - the mere purposeless, mindless, pointless regularity of physics - and I will show you a process that eventually will yield products that exhibit not just regularity but purposive design.").

${ }^{98}$ ARTHUR, supra note 2, at 129. Consider the role of the designer in answering "the key question [in evolution] of how novel technologies arise." Arthur notes that "[t]he mechanism is certainly not Darwinian; novel species do not arise from the accumulation of small changes. They arise from a process, a human and often lengthy one, of linking a need with a principle (some generic use of an effect) that will satisfy it." Id. "[D]evelopers borrow freely from that many available solutions and select some for their designs. This is where Darwinian variation and selection really come in, in technology. The many versions of a technology improve in small steps by the selection of better solutions to their internal design problems." Id. at 132. "In technology, combinatorial evolution is foremost, and routine. Darwinian variation and selection are by no means absent, but they follow behind, working on structures already formed." Id. at 188 . 
operate in is the natural environment, which is characterized by uncertainty and lack of structure. The urban environment falls somewhere in between, where considerable structure has been put in place already for humans to navigate. Urban roadways in the United States are already highly engineered for human use, with design standards for pavement, curb cuts, sidewalks, crosswalks, auto lanes, parking, bike lanes, street signs, and so on, which have either shaped or been shaped by existing cultural conventions of behavior in public space, such as passing on the left and signaling a turn. To follow in the path already established by existing modes of transport in public rights-of-way is a fairly obvious economical approach to urban robotic design.

The notion of robots operating in an ecology manifests in an inverse relationship between the intelligence of the robot and investments made in the environment to assist the robot in carrying out its intended tasks. As autonomous systems perceive the world quite differently than humans do, forcing robots to rely entirely on cues that are embedded in the environment for people makes the task for the designer more difficult. Cities simplify the design process when they create controlled spaces or stable task environments where autonomous systems can operate freely and safely. In some domains, such as supermarkets, barcodes, radio-frequency identification (RFID) tags, and the like have been embedded in the environment to simplify navigation and identification tasks for autonomous agents. Ultimately, though, these products are not operating in their intended markets until they are active in public space. Thus, one pressing question autonomous system designers have for city decision-makers is how much information will be embedded in the urban infrastructure and not simply the autonomous agent. ${ }^{99}$

As a practical matter, this means that efforts to embed signals for use by robots in urban infrastructure or modify the allocation or design of urban space to accommodate autonomous systems will simplify the effort required by the roboticist. ${ }^{100}$ Some policy commentators, mainly stakeholders in automated vehicles, have advocated that cities update or change their infrastructure to speed the adoption and testing of robots. The installation of advanced sensors to create smart streets or smart intersections, characterized

99 See Tech Policy Lab Univ. OF Wash., Driverless Seattle: How Cities Can Plan for AutOMATED VEHICLES 12-13 (2017), http://techpolicylab.org/wp-content/uploads/2017/02/TPL_ Driverless-Seattle_2017.pdf (explaining the importance of infrastructure itself to AV use).

${ }^{100}$ See Nagenborg, supra note 83 ("Humanoid robots with a similar size and weight to human beings may have the advantage of being able to use structures designed for humans. However, any deviation from the culturally and materially embedded body norms may result in a disabling environment for such machines in much the same way that similar differences would be disabling for humans. Thus, a question arises whether we should build cities for robots or robots for cities. The answer to this question is likely to be found in a mixed approach, where the built environment will be adopted to enable new robotic applications while safeguarding the quality of city life."). 
as vehicle-to-infrastructure communication, is one idea. ${ }^{101}$ The idea is that city infrastructure can be updated to communicate with automated vehicles to collect and send the data that helps them drive safely. ${ }^{102}$ The city of Atlanta has already begun to implement this, touting the sensors on its "smart corridor" for their ability to promote automated vehicles. ${ }^{103}$ Similarly, engineering firm Eng proposed a dedicated lane for automated vehicles in New York that would allow a fleet of automated vehicles to move quickly around the city. ${ }^{104}$ Graduate students at UC Berkeley have designed a similar system for automated vehicles dubbed a Hyperlane. ${ }^{105}$ From the point of view of the roboticist, such investments raise concomitant tradeoffs in mobility and sensing, which have impacts on cost and energy efficiency for the robot.

What the inverse relationship between the design of an autonomous system and its environment suggests, however, is that simple environments and smart infrastructure for designers will not bring about the safest or most viable outcomes for urban robots or automated vehicles. The greater the complexity of the task environment in which the robot can navigate unassisted, the greater the likelihood that the same robotic design will perform successfully in the variety of conditions that occur in urban settings. In other words, unaltered, chaotic urban environments can give rise to smarter autonomous systems. Also, any reliance on embedded technology in urban infrastructure will limit the spatial extent of the market for that robot and its associated firm.

In truth, firms may seek out cities regardless of embedded technology in infrastructure. Cities provide unique conditions, which firms and their roboticists take up as challenges in the process of design. ${ }^{106}$ New York City is considered a particularly attractive automated vehicle testing location because of its narrow streets and dense pedestrian population. ${ }^{107}$ San

${ }^{101}$ See Adam Theier \& Ryan Hagemann, Removing Roadblocks to Intelligent Vehicles and Driverless Cars, MERCATUS CTR. (Sept. 2014), https://www.mercatus.org/system/files/ThiererIntelligent-Vehicles.pdf (describing smart infrastructure).

${ }^{102}$ Michael Hamilton, Cities Should Not Design for Autonomous Vehicles, Mкт. URBANISM (Nov. 13, 2017), http://marketurbanism.com/2017/11/13/cities-should-not-design-for-autonomous-vehicles/.

${ }^{103}$ Holly Beilin, Atlanta Is Betting on a Smart Corridor to Reduce Traffic Jams, VENTURE BEAT (Oct. 11, 2017), https://venturebeat.com/2017/10/11/atlanta-is-betting-on-a-smart-corridor-to-reducetraffic-jams/.

${ }^{104}$ Benjamin Schneider, Do Driverless Cars Need Their Own Roads Around Manhattan?, CiTYLAB (July 26, 2017), https://www.citylab.com/transportation/2017/07/will-autonomous-vehicles-lead-to-aresurgence-of-auto-centric-infrastructure/534804/.

${ }^{105}$ Benjamin Preston, Berkeley Duo's Plan to Solve Traffic Jams: Hyper-Fast Lanes for SelfDriving Cars, GUARDIAN (June 3, 2017), https://www.theguardian.com/technology/2017/jun/03/selfdriving-cars-high-speed-lane-berkeley-california.

${ }^{106}$ John Markoff, A Guide To Challenges Facing Self-Driving Car Technologists, N.Y. TIMES (June 7, 2017), https://www.nytimes.com/2017/06/07/technology/autonomous-car-technologychallenges.html.

${ }^{107}$ Andrew J. Hawkins, GM Will Be the First Company to Test Self-Driving Cars in New York City, 
Francisco also attracts firms with its complex and dense urban environments. This density means more interactions between robots and humans, and these interactions generate more data with which to train the algorithms that control the robots. The population density in cities also provides a greater marketplace for services like autonomous vehicle taxis or food delivery, and the ability to earn revenue while testing is appealing to firms.

In order to effectively proceed in the design of an urban robot, corporate developers, consumers, and city managers should all be engaged to better understand and characterize the available trade space prior to design. ${ }^{108}$ Trade space may be described as "the range of possible implementation options," and early evaluation involves brainstorming to identify the full range of options. ${ }^{109}$ The expertise involved includes those with knowledge of the various subsystems and existing technological concepts relevant to the design of the new autonomous system, plus those with knowledge of the environment and the intended users of the system. Just identifying the trade space in the fast-paced industry of urban robotics poses challenges because the technology is itself a moving target. Designing for today may mean you are superseded by those designing for tomorrow, so there is inherent risk in the overall enterprise. At this early stage, the purpose of gathering information is to understand the risks that the various options bring in terms of cost, the need for new development of software or hardware, the ability of the system to reliably perform its intended tasks, and the time it may take to move to market. This information becomes valuable to designers, who then must down-select, or reduce the pool of available options and make trade-offs across the subsystems of robotic design, to result in a prototype.

To ease the integration of consumers and city managers with robotic designers, it may be helpful to borrow vocabulary from the video game industry, which is known for its reliance on participants from outside the firm as designs are given shape, tested, and prepared for commercial release. In video game development, the first meaningful milestone for bringing a product to market is "alpha." Alpha is reached when designers have

VERGE (Oct. 17, 2017), https://www.theverge.com/2017/10/17/16488330/gm-cruise-nyc-self-drivingcar-test-cuomo.

${ }^{108}$ The idea that the design of urban technologies should involve societal actors and innovators working together is captured in the general idea of "Value-Sensitive Design" by Batya Friedman. Batya Friedman, Value-Sensitive Design Interactions, INTERACTIONS, Nov.-Dec. 1996, at 16-23. This idea is incorporated by reference into Urban Robotics by Michael Nagenborg. Nagenborg, supra note 83.

${ }^{109}$ CONTEMPORARy Planetary Robotics: An APPROACH TOWARD AutONOMOUS SySTEMS $\S$ 2.5.2.4 (Yang Gao ed., 2016). Explanations of the concept of trade space are perhaps easier to find for areas of robotics supported by public funds, such as robotics for space exploration. Zachary James Bailey, A Trade Space Model for Robotic Lunar Exploration 19 (May 21, 2010) (unpublished M.S. thesis, Massachusetts Institute of Technology), https://dspace.mit.edu/handle/1721.1/59552. See also Jessica Knizhni et al., Robotic Satellite Servicing Trade Space Down-Selection, U. MD. (July 2017), https://user.eng.umd.edu/ austin/reports.d/INCOSE2017-JK-MA-CC-Paper.pdf (describing the developments of robotic space satellite technologies). 
completed one of each of the objects, features, and environments to be developed in the game with basic functionality (a.k.a. "vertical slice") and can thus demonstrate the game to others, begin testing the play of the game with a few trusted people outside the firm, and continue making modifications, adding features, and building out the remaining copies or versions of objects and environments. For urban robots, alpha could be the milestone that is reached when a prototype that is designed to carry out predetermined tasks is ready for testing in one or more closed or controlled environments of the physical world (as opposed to simulated, virtual tests, which may also be productive). ${ }^{110}$

Once a prototype is developed, the next major milestone is reached when all of the features and environmental interactions have been completed and are ready for large-scale user feedback, but contain bugs or glitches that have to be discovered and fixed. Testing at this phase, known as "closed beta," is often by invitation to a wider audience of persons interested in playing the game, but progress for these players in the game is reset or discarded prior to commercial release. ${ }^{111}$ Until recently, firms did not charge players for closed beta invitations, but market interest sometimes allows them to do so. During closed beta, milestones are set up as hurdles to meet before the game can proceed to "open beta," a form of commercial release in which anyone can play and all of the features of monetization are activated. For urban robotics, closed beta milestones could involve increasing the complexity of the task environments and user testing amongst a wide array of groups, in a wide variety of settings. For city managers, closed beta could be a useful period in development for gradual expansions of geofenced areas for testing, for neighborhoods to opt-in to requests to join the testing environment for a given product, and for heightened calls for feedback from residents. Commercial release, or launch, finishes the process and allows marketing to begin.

Roboticists have an interest in communicating with governmental decision-makers during the beta testing phase because legislation passed after a system has been designed can invalidate the initial design

${ }^{110}$ Selected individuals for alpha game testing may be asked to sign non-disclosure agreements to protect the interest of the firm, and waivers of liability may also be appropriate for tests in a physical environment.

${ }^{111}$ Importantly, reports about Waymo's recent launch of driverless taxi services, "Waymo One" in Pheonix, Arizona, note that beta-testers were contractually prohibited from sharing their experiences, and that the same early adopters were retained for the recent launch. See Andrew J. Hawkins, We Spoke to a Waymo One Customer About How Robot Taxis Get Confused by Rainstorms, Verge (Jan. 20, 2019), https:/www.theverge.com/2019/1/20/18175563/waymo-one-customer-interview-self-driving-arizona. Non-disclosure agreements during closed beta testing would have the effect of eliminating any communication between consumers and government and limiting the extent of communication by the firm to the government to either information the firm wanted to share or information the government required the firm to share. Such limitations, while tempting for the firm, can ultimately slow or restrict the potential for a product to serve the public interest. $I d$. 
assumptions. ${ }^{112}$ Participation also creates opportunities for public agencies to research the potential effects of rules to govern robots in the public interest. For example, should there be a speed limit for robots operating on the sidewalk? Should robots or autonomous vehicles ever legally be allowed to bump into people? When technology progresses faster than regulatory systems, designers build systems for the unknown, which can have the effect of raising costs and risks for both the firm and the communities in which its products operate.

Still, many robotic system designers have assumed that they know what people want and have moved through the design process without prior consultation. This historically has led to the bankruptcy (e.g., Denning Mobile Robotics, ${ }^{113}$ Lily Robotics ${ }^{114}$ ) or abandonment of product by numerous companies that have created security robots, entertainment (iRobot's "My Real Baby""15), research platforms, and the like. This is also what happens when firms adopt strategies that involve asking forgiveness rather than permission and purposefully move to market before legal issues are settled. This aggressive stance is risky because it may result in harm to consumers and local action to ban the product. ${ }^{116}$ Yet the prospect of being a first-mover in a new market, or competing for market share in the early years of development, has been known to motivate firms to take this risk. ${ }^{117}$ Perhaps it is for this reason that machine learning pioneer Andrew $\mathrm{Ng}$ has suggested that "[r]ather than building AI to solve the pogo stick problem [of unknown edge cases causing problems for AI], we should partner with the government to ask people to be lawful and considerate. . . . Safety isn't just about the quality of the AI technology."118

\footnotetext{
${ }^{112}$ One noteworthy example of this is the FAA restriction on drones that limits their operation to the area within the line of sight of the operator and the limits this places on air package delivery for firms such as Amazon.

${ }^{113}$ Hans Moravec, Re: The Company Status of Denning Mobile Robotics, Inc., CARNEGIE MELLON U. (1999), https://www.frc.ri.cmu.edu/ hpm/project.archive/robot.papers/2000/Denning.Mobile. Robotics.bankruptcy.

114 Jessica Pishko, The Drone Company that Fell to Earth, WIRED (July 26, 2017), https://www.wired.com/story/the-drone-company-that-fell-to-earth/.

115 Danny Allen, Creepy: iRobot's "My Real Baby", Gizmodo (Aug. 8, 2009), https://www.gizmodo.com.au/2009/08/creepy-irobots-my-real-baby/.

${ }^{116}$ Julia Carrie Wong, San Francisco Sours on Rampant Delivery Robots: 'Not Every Innovation is Great', GUARDIAN (Dec. 10, 2017), https://www.theguardian.com/us-news/2017/dec/10/san-franciscodelivery-robots-laws.

${ }^{117}$ Matt Simon, San Francisco Just Put the Brakes On Delivery Robots, WIRED (Dec. 6, 2017), https://www.wired.com/story/san-francisco-just-put-the-brakes-on-delivery-robots/.

${ }_{118}$ Russell Brandom, Self-Driving Cars Are Headed Toward an AI Roadblock, Verge (July 3, 2018), https://www.theverge.com/2018/7/3/17530232/self-driving-ai-winter-full-autonomy-waymotesla-uber.
} 


\section{CITIES AS TESTBEDS FOR AUTONOMOUS VEHICLES AND ROBOTICS}

This Part of the Article explores the enthusiasm that city decisionmakers and managers have for autonomous vehicles and robotics, and the hazards that await cities as sites of experimentation. This Section begins with the arguments city officials make in favor of automated systems, followed by an overview of the hazards for cities that pertain to the uses and physicality of autonomous products and the hazards involved in the collection and use of data from these systems. Lastly, an evidence-based, comparative institutional economic approach to policymaking is recommended, to forestall negative externalities while permitting technological change.

\section{A. The Interest of Cities in Firms and Their Autonomous Products}

City decision-makers that welcome autonomous vehicles and devices perceive their efforts through the lens of economic development, job creation, and the need to position for a wave of economically beneficial technological change and as part of visionary plans for the future in the transportation sector. Through the formation of partnerships, the adoption of tech-friendly policy, and changes to city information systems and physical environments, city decision-makers are extending invitations to firms and their products. As the intended markets for these products, cities and their decision-makers will be vital to any effort to shape these products and their uses in the public interest.

As cities have formed partnerships with the firms that want to mobilize autonomous products, their decision-makers have raised the hope or expectation of reciprocal efforts on the part of firms to deliver civic benefits. Public reports of Alphabet's Waymo use in Austin highlight the ability of a blind person to achieve mobility by hailing a driverless automobile. ${ }^{119}$ Pittsburgh assisted Uber in acquiring a large plot of land and the Mayor and Governor fended off state legislation that would have banned autonomous vehicles with the expectation that the firm would provide jobs, free rides, and further commitments in an application for a high-profile U.S. DOT "smart city challenge" grant. ${ }^{120}$ Boston's approach, which has included testing by nuTonomy, Optimus Ride, and Aptiv, has been framed by the

\footnotetext{
${ }^{119}$ See, e.g., Ashley Halsey III \& Michael Laris, Blind Man Sets Out Alone in Google's Driverless Car, WASH. POST (Dec. 13, 2016), https://www.washingtonpost.com/local/trafficandcommuting/blindman-sets-out-alone-in-googles-driverless-car/2016/12/13/f523ef42-c13d-11e6-8422-eac61c0ef74d _story.html?noredirect=on (detailing how a blind person successfully drove around Austin, Texas).

${ }^{120}$ See Ashley Gold, How Uber Lost Its Way in the Steel City, Politico (May 1, 2017), https://www.politico.com/story/2017/05/01/uber-pittsburgh-city-mayors-237772 (discussing how Uber lost its relationship with Pittsburgh); Kang, supra note 26 (describing the anticipated future of the pilot project for Uber); Kang, supra note 90 (describing Pittsburgh's disdain with Uber's driverless car experiment).
} 
city's action plan for transportation, with goals for equity, economic opportunity, and climate responsiveness. ${ }^{121}$ The recipient of the U.S. DOT challenge grant, Columbus, Ohio, set the target of reducing infant mortality by forty percent by 2020 , through the automation of transit in low-income neighborhoods. ${ }^{122}$

While some benefits can be expected from investments in transportation services, the scale of claims associated with autonomous systems has been beyond the imaginable. Free rides, expanded employment opportunities, services for the disabled, reduced traffic congestion, equities in transit, and climate responsiveness are goals of critical importance to cities, but they are only likely to be of passing interest to firms in the transportation sector. The idea that firms would offer free rides is inimical to the definition of the firm as a profit-making entity. The goal of automation is the elimination of jobs: obtaining a profit margin from automated transport by eliminating the driver. ${ }^{123}$ Transportation for the disabled is already proving to be a challenge for ride-sharing firms, as it will for automated vehicles. ${ }^{124}$ The promise of improved safety is made by firms with a strong incentive to make such claims, and it is a promise that has not yet been realized. ${ }^{125}$ Proposals to use

\footnotetext{
$121 \quad$ Autonomous $\quad$ Vehicles: Boston's $\quad$ Approach, https://www.boston.gov/departments/new-urban-mechanics/autonomous-vehicles-bostons-approach (last visited Oct. 25, 2019); Go Boston 2030, BosTON.Gov, https:/www.boston.gov/departments/ transportation/go-boston-2030 (last visited Aug. 28, 2018); Vision Framework, BosTON.Gov (Mar. 2017), https://www.boston.gov/sites/default/files/document-file-03-2017/go_boston_2030_-_plan_ highlights_to_download.pdf (outlining the goals and targets of Boston in 2030).

122 Laura Bliss, Who Wins When a City Gets Smart?, CiTYlaB (Nov. 1, 2017), https:/www.citylab.com/transportation/2017/11/when-a-smart-city-doesnt-have-all-theanswers $/ 542976 /$.

${ }^{123}$ See Muller, supra note 34 ("The business model for AVs assumes that by removing the driver, the cost per mile falls dramatically, from today's $\$ 2.50$ or $\$ 3$ per mile, to less than $\$ 1$, unlocking a much larger market opportunity."); Anton Wahlman, Driverless Cars Will Be the Biggest Investment Write-Off Ever, THESTREET (Dec. 21, 2018), https:/www.thestreet.com/opinion/driverless-cars-will-be-thebiggest-investment-write-off-ever-14818507.

${ }^{124}$ Charlie Sorrel, Ride-Hailing Services Like Uber Are Terrible for Disabled People, FAST COMPANY (Nov. 24, 2015), https:/www.fastcompany.com/3052721/ride-hailing-services-like-uber-areterrible-for-disabled-people; Joanne Tang, Without Accommodations, Uber and Lyft are Leaving Customers with Disabilities at the Curb, GREATER GREATER WASH. (Aug. 28, 2018), https:/ggwash.org/view/68138/without-accommodations-uber-and-lyft-are-leaving-customers-withdisabilities-at-the-curb.

125 Jack Stewart, Why Tesla's Autopilot Can't See a Stopped Firetruck, WIRED (Aug. 27, 2018), https://www.wired.com/story/tesla-autopilot-why-crash-radar/. From the Tesla car manual,

Traffic-Aware Cruise Control cannot detect all objects and may not brake/decelerate for stationary vehicles, especially in situations when you are driving over $50 \mathrm{mph}$ (80 $\mathrm{km} / \mathrm{h}$ ) and a vehicle you are following moves out of your driving path and a stationary vehicle or object is in front of you instead.
}

Similarly, the author explains, based on language in the car manual, a Volvo "won't brake to avoid hitting a stopped car that suddenly appears up ahead. It might even accelerate towards it." Aarian Marshall, The Maddening Struggle to Make Robo-Cars Safe-and Prove It, WIRED (Dec. 15, 2018), https://www.wired.com/story/zoox-self-driving-cars-safety/ ("'Most of what I'd heard in press and at 
automated vehicles to address equity issues may also be the product of wishful thinking: cities of the United States have underinvested in transit and related transportation infrastructure for decades, with noticeable impacts to equity. ${ }^{126}$ The widely touted notion that artificially intelligent vehicles and devices can eliminate traffic congestion, while freeing up the vast acreage of asphalt and concrete currently devoted to parking, is ludicrous. The simple math of public space allocation and single occupancy vehicles does not add up in favor of these claims. ${ }^{127}$ Instead, current economic incentives motivate firms to send empty vehicles to cruise in search of free parking. ${ }^{128}$ In regard to climate change, the transportation sector is responsible for about one third of U.S. greenhouse gas emissions, giving the U.S. government the burden of investing in or overseeing the electrification of the transportation system, with concurrent investments in carbon neutral energy sources. ${ }^{129}$ How could people possibly believe that automated vehicles will reduce emissions, when the fleets licensed for automated driving continue to use fossil fuels? The public good and current designs, composition, or envisioned uses of automated vehicles and robotics are not aligned, and the effects of their deployment, for better or worse, are going to be experienced locally. In the face of unrealistic claims of benefits from firms, cities must become critical forces in the effort to shape these products and their uses for public good.

Perhaps the strongest rationale for recognizing the role of cities in shaping urban robotic markets is the fact that the built environment, and its associated economic conditions, are subject to local control. The choice of whether to allow and financially support changes to urban physical infrastructure to accommodate autonomous systems is almost entirely local,

events with autonomous vehicle people was political rhetoric: "We won't hurt anybody; this will be safer than a person." But there is no engineering to back that up,' says Stefan Seltz-Axmacher, CEO and cofounder of robotic truck startup Starsky Robotics.”).

${ }^{126}$ Junfeng Jiao \& Chris Bischak, People Are Stranded in 'Transit Deserts' in Dozens of U.S. Cities, CONVERSATION (Mar. 13, 2018), http://theconversation.com/people-are-stranded-in-transit-deserts-indozens-of-us-cities-92722.

${ }^{127}$ See NACTO, supra note 5, at 11 ("This future is not guaranteed - and history shows we could easily end up with the opposite. Traffic and emissions could skyrocket, 'roboroutes'-walls of autonomous vehicles with few gaps-could divide communities, people could be relegated to inconvenient and unpleasant pedestrian bridges, and high-priced, inequitable mobility could supplant transit."). See also Allison Arieff, Automated Vehicles Can't Save Cities, N.Y. TimES (Feb. 27, 2018), https://www.nytimes.com/interactive/2018/02/27/opinion/automated-vehicles-cant-save-cities.html

(debunking the common promises that proponents of autonomous vehicles make regarding how these vehicles will improve city life).

${ }^{128}$ Adam Millard-Ball, “The Autonomous Vehicle Parking Problem”, 75 TRANSP. POL'Y 105, 99108 (2019), available at https://doi.org/10.1016/j.tranpol.2019.01.003.

129 See Sources of Greenhouse Gas Emissions, ENVTl. Protection AgENCY, https://www.epa.gov/ghgemissions/sources-greenhouse-gas-emissions (last visited Sept. 26, 2019) ("In 2017, greenhouse gas emissions from transportation accounted for about 28.9 percent of total U.S. greenhouse gas emissions, making it the largest contributor of U.S. greenhouse gas emissions."). 
in that state departments of transportation tend to have responsibility only for state and national highways. Even for drones, the Federal Aviation Administration regulates airspace, but changes to the local urban infrastructure to accommodate delivery or "follow me" drones will be almost entirely up to local governments and the physical environments that they own or regulate. This means that city managers and decision-makers are likely to experience pressure from firms to modify the allocation of public space, environmental design, pricing, and associated local public revenues and expenditures, regardless of state and federal legislation. For example, online magazine Quartz reported that in negotiations with the city of Pittsburgh, Uber wanted the city to grant non-exclusive access to bus lanes and municipal parking lots to use as staging areas. ${ }^{130}$ These demands contributed to the breakdown in the working relationship between Uber and the city. ${ }^{131}$ Relatedly, other groups have advocated that cities reduce parking space to promote automated vehicles, though the economics of the situation simply look like increased demand for curbside use, and parking is often an important source of municipal revenue. ${ }^{132}$ Accidents can also take their toll on cities: even though an Uber automated vehicle failed to brake, killing a pedestrian, and the relatives settled with Uber, the relatives have also filed a $\$ 10$ million claim against the city of Tempe, Arizona, saying that the city was in part responsible for the accident because of a faulty street design. ${ }^{133}$ City officials may capitulate, designing streets in favor of the interests of firms and dedicating rights-of-way to automated vehicles, resulting in a loss of public rights to the street in favor of automated fleets of vehicles and robots. ${ }^{134}$ Cities are, however, comprised of people who vote, and as

${ }^{130}$ See Alison Griswold, Uber Asked a Lot of Pittsburgh for Its Self-Driving Cars, and Offered Back Very Little, QUARTZ (Dec. 29, 2016), https://qz.com/874548/uber-asked-a-lot-of-pittsburgh-for-its-selfdriving-cars-and-offered-back-very-little/ (describing a list of "smart infrastructure upgrade" proposals suggested by Uber).

${ }^{131}$ See id. ("Pittsburgh didn't win the Smart City Challenge but neither did Austin; the prize went to Columbus, Ohio, in June. The city did not reach any agreements with Uber on infrastructure upgrades or routes, a spokesman for the mayor's office told Quartz.").

132 See Shared Mobility Principles for Livable Cities, https://www.sharedmobilityprinciples.org/ (last visited Sept. 26, 2019) ("Transportation and land use planning and policies should minimize the street and parking space used per person and maximize the use of each vehicle. We discourage overbuilding and oversized vehicles and infrastructure, as well as the oversupply of parking.").

${ }^{133}$ See Bernie Woodall, Uber Avoids Legal Battle With Family of Autonomous Vehicle Victim, REUTERS (Mar. 28, 2018), https://www.reuters.com/article/us-autos-selfdriving-uber-settlement/uberavoids-legal-battle-with-family-of-autonomous-vehicle-victim-idUSKBN1H5092 (explaining the circumstances surrounding the settlement between the family of a woman killed by a self-driving vehicle and Uber). See also Associated Press, Relatives of Woman Killed in Self-Driving Uber Crash File \$10M Claim, NBC NEws (Feb. 5, 2019), https://www.nbcnews.com/news/us-news/relatives-woman-killedself-driving-uber-crash-file-10m-claim-n966971 (stating that the previously undisclosed claim filed last fall against the City of Tempe sought five million dollars each for the husband and daughter of the woman killed by Uber's autonomous vehicle).

${ }^{134}$ See Ian Bogost, Will Robocars Kick Humans Off of City Streets?, ATLANTIC (June 23, 2016), 
enthusiastic as city decision-makers and managers may be for firms with autonomous products, they still need to represent the interest of local residents and taxpayers, and this places them in a position to negotiate with firms on behalf of the general public.

As stewards of the public good, city managers and decision-makers care about efficiency, effectiveness, and equity in the provision of essential goods and services, as well as the effects of the choices they make on jobs and the economy. Publications from the National Association of City Transportation Officials (with membership from fifty-two cities across the United States) and the Regional Plan Association (serving the New York metropolitan area) urge city managers to brace against the potentially disruptive effects of automated vehicles, for example, by engaging in proactive policymaking to ensure that "public benefit guides private action," to "shape how [automated vehicles] interact with transit," and to "prioritize street space for public transit, pedestrians, bikes, and freight." ${ }^{\text {"135 }}$ Several of these choices are exhibited today in the attempts of ride-sharing firms to partner with local governments and transit agencies, for example, for subsidized first and last mile passenger delivery to remote transit stations. ${ }^{136}$ Guidelines for city officials break down the components and possible effects of autonomous vehicles into modules and provide schema for the gradual, sequential alteration of the design and allocation of public space. ${ }^{137}$ Highlighting the disruptive effects of artificially intelligent transportation, the Regional Plan Association also suggests that plans get underway to determine how to transition the 220,000 or so persons in vulnerable positions in the region to new forms of employment. ${ }^{138}$

For the public good, cities are also interested in the information that firms collect through these technologies. City officials have a general need to govern the flow of information for accountability, transparency, and

https://www.theatlantic.com/technology/archive/2016/06/robocars-only/488129/ ("It's not hard to imagine a near future in which municipalities like Altamonte Springs might use the cost savings (or direct investment) of companies like Uber, Lyft, or Google to invest in much-needed maintenance and updates. Once cars become autonomous, the benefit of investments like these will increase even further, since the cost and liability of human drivers can be averted. Better roads mean lower maintenance costs.").

${ }^{135}$ See NACTO, supra note 5, at 13-14 (listing "public benefit guides private action" as one of six principles for autonomous urbanism).

136 See Mobility on Demand (MOD) Sandbox Program, Fed. TRAnsit ADMIN., https://www.transit.dot.gov/research-innovation/mobility-demand-mod-sandbox-program.html (last visited Sept. 18, 2018) (describing the Mobility on Demand Sandbox Program).

${ }^{137}$ See NACTO, supra note 5, at 16-17 (detailing critical steps that NACTO cities have already adopted and are implementing to prepare for the autonomous future).

${ }^{138}$ See New Mobility: Autonomous Vehicles and the Region, Reg'L Plan Ass'N (Oct. 2017), http://library.rpa.org/pdf/RPA-New-Mobility-Autonomous-Vehicles-and-the-Region.pdf ("There are about 220,000 motor vehicle operators in the RPA region. These occupations, which span the trucking, taxi, black car and bus sectors, are among the shrinking number of well-paying jobs that generally do not require a college degree. It will be essential that there be pathways into different careers for those workers whose jobs are replaced by AVs."). 
privacy; a need which may be heightened by local or state regulations regarding privacy and surveillance. ${ }^{139}$ At the same time, city managers see value in gaining access to this data for direct use in balancing demand and supply of services and built environments. Historically, transportation agencies have had to rely on relatively expensive and time-consuming methods to collect data on travel behavior and the use of transport facilities because of the lack of integration of information technology in vehicles and the fact that autos and trucks are predominantly owned and operated by individuals. ${ }^{140}$ The information technology of transport is already undergoing dramatic changes: rideshare, car-share, and bike-share services concentrate travel information into the hands of a comparatively small number of firms. ${ }^{141} \mathrm{With}$ the adoption of autonomous systems, the industrial organization of the entire transport sector is headed for upheaval: autonomous controls are likely to result in the concentration of the ownership of vehicles as well as information about their uses and users. ${ }^{142}$ The ability of public agencies to make smart decisions about the allocation and governance of public space will depend on their ability to access and merge this information with data on public services and investments. ${ }^{143}$ If disputes between the firms of the sharing economy and cities over access to data are indicators of what is to come, there will have to be neutral third

139 See Saad Bashar, About the Surveillance Ordinance, SEATTLE INFO. TECH., https://www.seattle.gov/tech/initiatives/privacy/surveillance-technologies/about-surveillance-ordinance (last visited Sept. 18, 2018) (describing the effect Seattle Surveillance Ordinance 125376 has on cityowned surveillance technology).

140 The World Bank Launches New Open Transport Partnership to Improve Transportation Through Open Data, WORLD BANK (Dec. 19, 2016), http://www.worldbank.org/en/news/pressrelease/2016/12/19/the-world-bank-launches-new-open-transport-partnership-to-improve-

transportation-through-open-data ("[T]raditional methods for collecting traffic data needed to address congestion are costly and rely either on labor-intensive field work or capital-intensive sensor data networks that far exceed available resources."). In U.S. cities, labor-intensive traffic counts and travel diary surveys as information sources for transportation system decisions have recently been augmented by license plate readers, cell phone tracking data, data feeds from Bluetooth, and Wi-Fi sniffers, as cities have contracted with private vendors and university researchers to serve this need. Id.

${ }^{141}$ Prominent firms in U.S. markets include Uber and Lyft in rideshare, Reachnow and Car2Go in car-share, and Lime, Jump, Spin, and Mobike in dockless bike-share markets, plus numerous firms in scooter markets, all of which collect information on travelers from a combination of their mobile apps and the GPS and related technologies installed in the cars, bikes, and scooters.

${ }^{142}$ See Self-Driving Cars Will Require New Business Models, ECONOMIST (Mar. 1, 2018), https://www.economist.com/special-report/2018/03/01/self-driving-cars-will-require-new-businessmodels ("It is likely to be many years before AVs are cheap enough for individuals to buy them, and capable enough to operate outside predefined, geofenced areas. Meanwhile, the roll-out of cheap robotaxis in urban areas might encourage many young urbanites, who are already going off car ownership anyway, to abandon it altogether. The combination of ride-hailing and autonomous-driving technology confronts carmakers with 'the most profound challenge to their business models in a century,' declares a recent report from BCG.").

${ }^{143}$ See NACTO, supra note 5, at 20 ("Billions of detailed street-level data points are collected in real time daily on everything from traffic speeds and volumes to travel patterns and transit use. This data is vital to the operations and management of streets, regardless of the entity generating them."). 
parties to operate trusted data platforms and broker these exchanges. ${ }^{144}$ Travel patterns are remarkably unique and sensitive for what they reveal about individuals and the actions of the firm, making the data valuable to firms inside and outside of the transport market and of great concern to officials tasked with protecting the privacy of city residents. ${ }^{145}$ At the same time, government agencies need to use the same data sources to hold firms accountable, and the public deserves transparency in the actions of government agencies for the same. ${ }^{146}$

Cities are critical to the rollout of autonomous systems because, in contrast to federal and state governments, the diversity of approaches taken by city decision-makers in the adoption of new technologies makes cities laboratories for policy, governance, and implementation of enforcement mechanisms. Governments are in the business of institutional change; institutions are the "formal rules, informal norms, and enforcement characteristics" developed and used by the polity and judiciary to govern in the public interest. ${ }^{147}$ In the face of rapid change in technology, it is remarkably difficult to determine ex ante the structure and content of policies most beneficial to the public. The public interest is, in and of itself, a complex phenomenon. Institutional change has historically been led by cities and related local and state governments in the bottom-up fashion of a federalist system to take advantage of experimentation with a diversity of

\footnotetext{
${ }^{144}$ See Kevin Schofield, The City - and Public - Get a Win in Court, SCC InSIGHT (June 1, 2018), https://sccinsight.com/2018/06/01/the-city-and-the-public-get-a-win-in-court/ (summarizing a recent ruling in Washington State Supreme Court in favor of public disclosure of Uber and Lyft data by the City of Seattle). See also NACTO, supra note 5, at 21 ("In order to protect user data, an independent thirdparty company can sort and anonymize data collected before it is used for analysis, ensuring individual users are not identified. Once analyzed, this data can be used to direct city policy and prioritize projects."); Transportation Data Collaborative, URBANALYTICS, https://urbanalytics.uw.edu/projects/transportationdatacollab/ (last visited Jan. 30, 2020) ("The Transportation Data Collaborative (TDC) is an initiative at the UW to create a protected and linked data repository of sensitive information from public and private transportation providers... The TDC allows partnering agencies to create data-driven policy, support research uses, and provide individuals with authenticated access to their own transportation records.").

${ }^{145}$ See Yves-Alexandre de Montjoye et al., Unique in the Crowd: The Privacy Bounds of Human Mobility, 3 SCI. REP. 1376, 1376 (2013) ("We study fifteen months of human mobility data for one and a half million individuals and find that human mobility traces are highly unique. In fact, in a dataset where the location of an individual is specified hourly, and with a spatial resolution equal to that given by the carrier's antennas, four spatio-temporal points are enough to uniquely identify $95 \%$ of the individuals."). See also NACTO, supra note 5, at 20 (“[I]ntricate information on people movement is laden with personally identifiable information that neither government nor private companies should have access to.").

${ }^{146}$ See Muller, supra note 34 ("Investors are betting the real value of AV companies will come from the estimated 4 terabytes of data each car will generate per day. And based on the way they're valuing the major AV players, Wall Street seems to think tech companies have a better shot than Detroit at capitalizing on that data.").

${ }^{147}$ Douglass C. North, Institutions, 5 J. ECON. PERSP. 97, 97-98 (1991); Douglass C. North, Prize Lecture: Economic Performance Through Time, NOBEL PRIZE (Dec. 9, 1993), https://www.nobelprize.org/prizes/economic-sciences/1993/north/lecture/.
} 
policies and evaluations of related outcomes before forming more lasting federal regulations. At the local level, pilot programs, sunset clauses with requirements for audit and program evaluation, and geofencing are mainstays of governance-when testing new concepts, technologies, and environmental designs in public space- that have the practical purpose of supporting evidence-based changes to policy over time. Irrespective of technology, the authority city decision-makers have to draw boundaries that limit the spatial extent of the market, affix rules to public and private space that limit allowed activities, determine required and allowed uses and flows of information, develop and enforce pricing schemes, issue or revoke operating permits, and tax, audit, charge fees, levy fines, and ban goods constitutes critical leverage in the negotiations between firms and city governments for the public good.

In sum, as enthusiastic as they may be, city decision-makers should be strategic in their evaluation, adoption, and regulation of autonomous vehicle and robotic technologies. ${ }^{148}$ The benefits of utilizing cities as laboratories for policymaking depends on the ability of city managers and decision-makers to shape these new markets for the public good and to enter these relationships with eyes wide open, on the lookout for unintended as well as intended consequences.

\section{B. The Hazards in Store for Cities as Testbeds of Autonomous Systems}

Cities are appropriate centers of autonomous robotic innovation, but they should proceed carefully to avoid treating the associated risks of these technologies and partnerships as afterthoughts. The problems that accompany autonomous systems in cities could be understood in the same terms as the promises associated with these technologies-for safety, convenience, equity, emissions, and the economy. Though less prominent in the literature, the hazards of these systems also derive from their use of sensing and communication technologies, in the form of surveillance and associated losses to privacy.

Safety is the risk that has risen to the forefront of governmental offices as they have witnessed the early adoption of autonomous vehicles and robotics. The bulk of activities at the federal, state, and local levels, from reports and model legislation to the development of testbeds outside as well as within public rights-of-way, highlights the importance of safety in the design and use of these products. ${ }^{149}$ Similarly, accounts of accidents in the

${ }^{148}$ New Mobility: Autonomous Vehicles and the Region, REG'L PLAN ASS'N (Oct. 9, 2017), http://www.rpa.org/publication/new-mobility-autonomous-vehicles-and-region; Driverless Seattle, U. WASH. TECH POL'Y LAB, http://techpolicylab.org/wp-content/uploads/2017/02/TPL_DriverlessSeattle_2017.pdf.

${ }^{149}$ The main issues addressed at the federal and state levels have been enabling legislation and safety. See, e.g., Autonomous Vehicles: Self-Driving Vehicles Enacted Legislation, NAT'L CONF. ST. 
news have raised public and private concern over the continuing role of the human behind the wheel or with hands on the controls and the impacts to people and property from collisions with autonomous vehicles, robots, and drones. ${ }^{150}$ The first accident involving the death of a pedestrian from an automated vehicle shocked many advocates of the technology. ${ }^{151}$ Such anecdotes appear to have temporarily pierced the popular notion that autonomous systems will eliminate death and injury. The idea that autonomous controls will eliminate injury is unrealistic because, like all complex technological systems, artificially intelligent autonomous controls are never completely understood, even by those that design the system. ${ }^{152}$ The complexity and processing power of autonomous controls are expected to increase over time as the systems are trained to operate within complex environments. ${ }^{153}$ But, because of the tendency designers have to add responsibilities to these systems as quickly as possible, there are some in the field who caution that it may be impossible to create a truly safe autonomous system. ${ }^{154}$

Public pronouncements that autonomous systems will usher in an unprecedented era of convenience contrast with early evaluations of autonomous vehicles that show, in the context of the holistic use of urban public space, that the vehicles are not as cost-effective as existing alternatives. Most of the firms engaged in trials of autonomous vehicles are using cars that would carry three or fewer occupants. ${ }^{155}$ Recent studies of the

LEGISLATURES (Mar. 19, 2019), http://www.ncsl.org/research/transportation/autonomous-vehicles-selfdriving-vehicles-enacted-legislation.aspx (listing enabling legislation at the state level); USDOT Automated Vehicles Activities, U.S. DEP'T TRANSP., https://www.transportation.gov/AV (last updated Feb. 27, 2019) (discussing prominent reports and model legislation).

${ }^{150}$ See Megan Geuss, Drone Crashes in Arizona National Forest, Starts a Wildfire, ARs TECHNICA (Mar. 9, 2018), https://arstechnica.com/tech-policy/2018/03/drone-crashes-in-arizona-national-foreststarts-a-wildfire/ (discussing drone crash in Arizona which caused a wildfire); Will Knight, The Dark Secret at the Heart of AI, MIT TECH. REV. (Apr. 11, 2017), https://www.technologyreview.com/s/604087/the-dark-secret-at-the-heart-of-ai/ (discussing concerns related to AI); Swapna Krishna, San Francisco Restricts the Use of Delivery Robots on Its Sidewalks, ENGADGET (Dec. 7, 2017), https://www.engadget.com/2017/12/07/san-francisco-restricts-deliveryrobots/ (discussing challenges to legislation in San Francisco regarding drone delivery service).

${ }^{151}$ See Wren, supra note 6 (discussing first incident of pedestrian struck and killed by self-driving car in Arizona and how the government investigators linked an "overreliance on vehicle automation" to the crash).

${ }^{152}$ Arend Hintze, I Am an AI Researcher. This Is What Keeps Me Up at Night, PopUlaR MECHANICS (Jan. 3, 2018), https://www.popularmechanics.com/technology/security/a14537028/i-aman-ai-researcher-this-is-what-keeps-me-up-at-night/.

${ }^{153}$ See Wilko Schwarting et al., Planning and Decision-Making for Autonomous Vehicles, 1 ANN. REV. CONTROL, RoBotics, \& AutONOMOUS Systems 187, 203 (2018) (“Autonomous systems still need to reach human-level reliability in decision-making, planning, and perception, and current detection and segmentation accuracies do not yet suffice in difficult conditions ....").

${ }^{154}$ E.g., Hintze, supra note 152 (discussing fears regarding AI technology from the perspective of an AI developer)

${ }^{155}$ Economy cars, sedans, and SUVs are the norm for Waymo, Uber, and most automobile 
impact of autonomous vehicles on traffic in downtown Boston, with associated simulations to model preferences for mode choice, show a fifteen percent reduction of vehicles on the road, coupled with a sixteen percent increase in vehicle miles traveled, resulting in only a four percent improvement in travel time in general and a five percent increase in travel time and associated congestion in the downtown area. ${ }^{156}$ As improvements, these impacts fall short of traditional investments in bus and rail transit services and underscore the importance of transitioning from single occupancy vehicles to pooled ridership and renewed investment in transit. ${ }^{157}$ Otherwise, the influx of autonomous services, in the form of vehicles and robots, would be predicted to increase congestion and cause more of a nuisance than a convenience.

Autonomous vehicles and robotics can only be expected to make cities more equitable if they are accessible to all at affordable rates. The firms participating in these markets are like any other firms in that they will reach a point in time when the profitability of autonomous services matters. ${ }^{158}$ As they strive for profitability, firms can be expected to care about pricing, market share, participation in two-sided markets, their ability to influence the adoption of rules and regulations that stave off competition, and safeguarding their financial self-interest. The moves of firms in these areas can also be expected to be regressive - having a disproportionate impact on those who have relatively little ability to pay for transportation services, such as those who are in vulnerable, low-wage jobs. ${ }^{159}$ These economic conditions are not going to change with autonomous systems. Reading the media today, it would be easy to assume that the free or low-priced services

companies in this sector. See Andrew J. Hawkins, Uber's Self-Driving Cars Return to Public Roads for the First Time Since Fatal Crash, VERGE (Dec. 20, 2018), https://www.theverge.com/2018/ 12/20/18148946/uber-self-driving-car-return-public-road-pittsburgh-crash (discussing Uber's selfdriving tests with Volvo SUVs).

${ }^{156}$ Bos. Consulting Grp., How Autonomous Vehicles Affect City Traffic, YouTuBE (Jan. 25, 2018), https://www.youtube.com/watch?v=zMZIEBoR49U [hereinafter BCG Study].

${ }^{157}$ See Patrick Sisson, Sick of Traffic? Get Cities to Invest in Bikes and Mass Transit, Says Report, CURBED (June 11, 2019), https://www.curbed.com/2019/6/11/18661586/bike-train-traffictransportation-congestion (citing reports indicating that congestion adds, on average, forty-one percent more time to the average commute and recommending solutions such as investment in optimized traffic lights, bike infrastructure, and mass transit).

${ }^{158}$ Tech firms benefit in early development and market expansion from venture capital and other types of investment for revenue. See Kate Conger, Uber's Self-Driving Cars Are Valued at \$7.25 Billion by Investors, N.Y. TIMES (Apr. 18, 2019), https://www.nytimes.com/2019/04/18/technology/uber-atgautonomous-cars-investment.html (discussing Uber's profitability and its business model surrounding its self-driving car technology).

159 See Hana Creger et al., Autonomous Vehicle Heaven or Hell? Creating a Transportation Revolution that Benefits All, GREENLINING INST. (Jan. 2019), http://greenlining.org/wpcontent/uploads/2019/01/R4_AutonomousVehiclesReportSingle_2019_2.pdf (discussing the "hell" created by personal autonomous vehicles, including environmental concerns, increased economic inequality, outpacing regulations, and congestion, and providing recommendations to make the autonomous vehicle revolution beneficial for all, not just higher-income individuals). 
that accompany the initial rollout of products to market would continue into the future because it is tempting to think that firms will pass on the cost savings that come from automated fleet services to customers. To assume so would be naive. The need for free and reduced-price services and the requirements of service-area coverage enforced today by transit and transportation agencies will not disappear with new technologies. The equitable pricing of and access to transportation services will continue to be of critical importance for policymakers in the era of autonomous systems.

Emissions will only be reduced by autonomous vehicles and robotic systems if the sources of energy used to power them are less carbon intensive than the current fuel mix. Environmental and political pressure to convert from fossil fuel sources to electricity are transforming the auto industry at the same time that automakers are partnering en masse with information technology firms to adopt autonomous control systems. ${ }^{160}$ The conversion to electric energy is also leading automakers to search for opportunities to lock in new sources of revenue, such as long-term concession agreements that would place firms in the position of controlling the access price of public parking spaces in exchange for capital investment in electric charging stations. ${ }^{161}$ Altogether, the combined forces of automation and electrification may upend the industrial organization of the transportation industry, transforming what has been a highly disaggregated ownership structure based on private, personally-held assets into a highly concentrated ownership of fleets and firms with ownership in search of preferential or exclusive rights to currently public rights-of-way.

Amongst policymakers, the most pressing concern about urban robotics is likely to be the question of whether they will bring about economic and associated financial improvements to the cities responsible for the infrastructure that these systems rely on. Early reports already suggest that public parking, which is one of the most important sources of revenue for cities in the transportation sector, may be under threat by autonomous

${ }^{160}$ See, e.g., Reese Counts, Toyota, VW and GM Partner on Autonomous Vehicle Education, AUTOBLOG (Jan. 9, 2019), https://www.autoblog.com/2019/01/09/pave-autonomous-vehicle-education/ (discussing recent partnerships between GM, Volkswagen, Toyota, and more with various AV firms); Alex Davies, General Motors Is Going All Electric, WIRED (Oct. 2, 2017), https://www.wired.com/story/general-motors-electric-cars-plan-gm/ (discussing recent announcements from automakers, including GM, converting market offerings to all electric); Alanna Petroff, These Countries Want to Ban Gas and Diesel Cars, CNNMONEY (Sept. 11, 2017), https://money.cnn.com/2017/09/11/autos/countries-banning-diesel-gas-cars/index.html (discussing recent announcements from France, China, and other nations to ban the sale of vehicles that rely on fossil fuels).

${ }^{161}$ See BMW, Volkswagen and ChargePoint Announce Initiative to Create Electric Vehicle Express Charging Corridors on the East and West Coasts, CHARGEPOINT, https://www.chargepoint.com/ about/news/bmw-volkswagen-and-chargepoint-announce-initiative-create-electric-vehicle-express/ (last visited Oct. 25, 2019) (discussing an initiative between the electronic charging network ChargePoint and BMW and Volkswagen to create a large span of charging stations on the East and West coasts). 
systems. Results from last year's simulation of the effect of autonomous vehicles on Boston's parking system show a reduction in demand for parking by forty-eight percent. ${ }^{162}$ At the same time, cities can expect pressure from firms to invest more in public rights-of-way, by either embedding technologies in infrastructure or redesigning and constructing built environments to favor their products, and to provide preferential or exclusive allocations of public space for their private use. ${ }^{163}$ In general, such efforts should be recognized as attempts to pass on the private cost of adopting these technologies to the public taxpayer and, with that, to society.

That said, perhaps the least appreciated of the hazards from urban robotics are the acute risks they bring to city residents of increased surveillance and loss of privacy. Urban robots have sensing and computing capabilities that enable them to collect and process information in public spaces on a potentially massive scale, challenging existing information privacy governance frameworks. ${ }^{164}$ Furthermore, they may combine mobility with capacity to identify individuals or group members, raising the prospect of their use within and across spaces to target and pursue personsan invasion of privacy that is without parallel in smart city technology. And, as in other data rich sectors, firms can be expected to take advantage of every opportunity to collect and monetize data about people, whether those people opted in to said collection and uses. Market analysts in the automated vehicle sector are already anticipating the opportunity for firms to add value by monetizing data on secondary markets, as evidenced in the differential valuations given to the information technology firms in comparison to the automotive firms. ${ }^{165}$ Whether firms should be allowed to do so or not is something that should matter to city officials because of the long-term impact this choice creates for public life.

By combining the basic functionality of Internet of Things (IoT) devices with mobility for urban robots, including autonomous vehicles, the evolution of technology is bringing about an unprecedented risk to privacy in the public environment of city streets. A robot is essentially a mobile computing platform that senses and operates in the physical world and can therefore be conceptualized as a type of IoT application. ${ }^{166}$ IoT devices can

${ }^{162}$ BCG Study, supra note 156.

${ }^{163}$ See Gold, supra note 120 (discussing Pittsburgh lawmakers' frustrations with Uber's relationship with the city, especially Uber's failure to help the city obtain a Smart Cities grant).

164 M. Ryan Calo, Robots and Privacy, in RoBot ETHICS: THe ETHICAL AND SOCIAL IMPLICATIONS OF ROBOTICS 187, 187-88 (Patrick Lin et al. eds., 2012).

${ }^{165}$ See Muller, supra note 34 ("Investors are betting the real value of AV companies will come from the estimated 4 terabytes of data each car will generate per day. And based on the way they're valuing the major AV players, Wall Street seems to think tech companies have a better shot than Detroit at capitalizing on that data.").

${ }^{166}$ See Pieter Simoens et al., The Internet of Robotic Things: A Review of Concept, Added Value and Applications, 15 InT'L J. Advanced RoBotic Systems 1, 1 (2018) (discussing a survey of how "Internet of Things" technology will impact robotic systems). 
be deployed to surveil locations and situations with near perfect recall. For example, many cities have or plan to install cameras on streetlights that can observe and record the public space under its purview. ${ }^{167}$ Unlike a human observer, it will never tire and can record for as long as it has storage capacity and a power source. These recording capabilities can be combined with facial recognition and other AI-powered processing tools that could, for instance, query police databases in real time. ${ }^{168}$ They may be employed by governments or private companies, often in cooperation with one another. Furthermore, traditional privacy controls like notice and choice become more difficult to execute with respect to IoT devices; this is because IoT devices often lack an interface through which to communicate information about privacy practices to the subjects of data collection. ${ }^{169}$ Even where devices or their operators can provide notice to data subjects, those individuals may lack meaningful choice about being recorded. ${ }^{170}$ A person can choose not to use Facebook if they do not agree with the company's data practices, but they cannot opt out of being recorded by IoT devices on city streets without effectively retreating from public life. ${ }^{171}$

\section{How Cities Can Prepare to Be Sites of Experimentation}

This Paper argues that cities should be given the authority and flexibility to experiment with autonomous vehicles and robotics and that city managers and decision-makers should prepare to participate in the testing process with the designers of artificially intelligent systems. This Section provides an overview of the task that lies ahead for cities, and it highlights perspectives and methods useful for evaluating the effects of policy choices in the public interest.

From an institutional economic perspective, cities as sites of experimentation need to recognize and harness their ability to act as market makers. Governments create the rules of the game for private firms. In times of institutional change, governments can act in the public interest by orienting policymaking toward the purposes of minimizing social harm,

\footnotetext{
167 See Sarah Holder, The Shadowy Side of LED Street Lights, CITYLAB (Mar. 8, 2018), https://www.citylab.com/equity/2018/03/their-lights-were-watching-odd/554696/ (discussing concerns about surveillance related to cities' use of "smart city service[s]" including LED lighting grids).

${ }^{168}$ Clare Garvie et al., The Perpetual Lineup: Unregulated Police Face Recognition in America, CTR. ON PRIVACY \& TECH. GEO. L. (Oct. 18, 2016), http://www.perpetuallineup.org/.

${ }^{169}$ Peter Swire \& Jesse Woo, Privacy and Cybersecurity Lessons at the Intersection of the Internet of Things and Police Body-Worn Cameras, 96 N.C. L. REV. 1475, 1511 (2018).

170 Kelsey Finch \& Omer Tene, Welcome to the Metropticon: Protecting Privacy in a Hyperconnected Town, 41 FORDHAM URB. L.J. 1581, 1606-07 (2014).

${ }^{171}$ Some have argued that large social media companies like Facebook have become the "digital public square" and should therefore be treated like public spaces or regulated like utilities. For a discussion of such proposals, see Peter Swire, Should the Leading Online Tech Companies Be Regulated as Public Utilities?, LAWfare (Aug. 2, 2017), https://www.lawfareblog.com/should-leading-onlinetech-companies-be-regulated-public-utilities.
} 
internalizing externalities, and preventing the transfer of private costs to society. ${ }^{172}$ When considering the many facets of change accompanying autonomous vehicles and technologies, focus should move to evidence-based policy and evaluations that compare the costs to firms and the public of existing and new technologies as they occur under various institutional arrangements.

City managers and decision-makers will need support for sophisticated negotiations in the domain of automated vehicles and robotics. Policies, procedures, regulations, and enforcement implicated in governing these technologies span the boundaries of the transportation and information technology sectors as we understand them today. It is perhaps for these reasons that several cities have formed interdisciplinary working groups to focus on becoming testbeds for autonomous vehicles. These include partnerships with outside organizations, some of which appear to be unique in the history of the sector. One of these is Boston's multi-year partnership with Boston Consulting Group and the World Economic Forum, which-in the first of several reports - affirms that cities should work cooperatively with state and federal agencies but argues that cities should be in "the lead in establishing a governance structure and testing policy and parameters to foster innovative solutions to their most pressing transportation challenges." 173

Support can be especially helpful if it can be interdisciplinary because it provides a clearer picture of the implications of various policy options. At times like this - when the adoption of policy can actually reshape the entire industrial organization of a sector of critical infrastructure - it pays to place policy debates in economic and social terms. When political arguments have economic motivations, it is particularly important to know the economic implications of their adoption in law and policy. Arguments for the freedom to innovate may have ideological merit, but the practical implications for policy change are usually about the reallocation of property rights across the public and private sectors for economic or financial gain. These reallocations have the effect of determining, inter alia, the factors and associated costs that will be internal to markets and therefore borne by firms and established in the pricing of goods and services on the market and the factors and associated costs that will be externalized and thus borne by public agencies, the taxpayers that fund them, and society in general.

${ }^{172}$ NORTH, supra note 18 , at 3 .

173 Boston Test of Self-Driving Cars Reveals Five Key Lessons for Cities Worldwide, Bos. CONSUlting GROUP (Oct. 17, 2017), https://globenewswire.com/news-release/2017/10/17/11484 05/0/en/Boston-Test-of-Self-Driving-Cars-Reveals-Five-Key-Lessons-for-Cities-Worldwide.html; see also Nikolaus Lang et al., Making Autonomous Vehicles a Reality: Lessons from Boston and Beyond, Bos. CONSUlTING GROUP (Oct. 17, 2017), https://www.bcg.com/publications/2017/automotive-makingautonomous-vehicles-a-reality.aspx. 
Furthermore, the methodologies used to reveal these relationships matter. Simple cost-benefit analyses, commonly recommended in the analysis of public expenditures, are not appropriate when the alternatives to be evaluated serve differing policy goals. More promising analyses are possible if-borrowing somewhat from research methodologies in institutional and transaction cost economics - the economic effects of policy options are examined holistically: by examining the trade-offs experienced by the various public and private parties involved in delivering and receiving services, while keeping in mind current and potential future industrial organizations of the sector. ${ }^{174}$ In all cases, it is important to understand the comparative effects of current and proposed policy options with respect to the distribution of both production and transaction costs across the parties involved in delivering, governing, and consuming the products and services. The methodologies for examining comparative institutional arrangements from transaction cost economics - which break down the delivery of services by task, noting which party bears costs, which receives benefits, and in what amounts - may be adapted to this purpose. ${ }^{175}$

It is also important that research consider the effects that policies may have on competition and the resulting impacts if competition in the transport sector were to be replaced by concentrated ownership of assets. Competition is still the most important force in delivering economic benefits from markets, but the extent to which society reaps these benefits and maintains competition also depends on the institutions that govern the sector. Historically, the private ownership of mobile assets and public investment in networks - operated as a non-excludable asset - have assisted this sector in avoiding several market failures that are more visibly acute in, for example, the communication sector's struggle over net neutrality or rent-seeking behavior on the part of organizations that own the transmission systems needed to wheel water from one community to another. Policies that preserve equal access to essential infrastructure (such as the underlying network of roads, parking, conduit, utility poles, curbs, and gutters) and resist the urge to privatize public space on transportation and related communication networks have the economic effects of keeping this space in play for all parties and keeping barriers low for competitors seeking entry to

${ }^{174}$ Jan Whittington, When to Partner for Public Infrastructure? Transaction Cost Evaluation of Design-Build Delivery, 78 J. AM. Plan. Ass'N 269, 282-83 (2012) (discussing a transaction cost methodology for comparing costs and trade-offs, shown as the amount of funding allocated to and from the parties involved in the various tasks involved in delivering infrastructure projects, according to alternative policies); Jan Whittington \& Chris Jay Hoofnagle, Unpacking Privacy's Price, 90 N.C. L. REV. 1327, 1352 (2012) (explaining the consequences of small numbers of competitors for consumers in information-intensive industries, such as social network services, with demand and supply side economies of scale).

${ }^{175}$ See, e.g., Whittington, supra note 174, at 270 (explaining that the principles of transaction costs economics can be applied to evaluate infrastructure projects). 
the market with mobile assets. Privatization of public space and policies that offer preferred or exclusive access have the opposite effect: they lock public entities into monopoly or oligopoly relations in the provision of services and thus carry the potential for multiple downstream hazards, such as disputes over pricing, quality of service, and a host of opportunity costs that accompany the privatization of public assets. ${ }^{176}$

Guidance from the National Association of City Transportation Officials and the Regional Plan Association of New York suggests that cities create public-facing, proactive strategies for exploring, testing, permitting, and supporting autonomous vehicles. ${ }^{177}$ The same guidance should be extended to include urban robotics and drones. City strategies should be designed to assist decision-makers in understanding the strengths and limitations of artificially intelligent products, as well as the prevailing business models that firms are relying on as they enter the market. It would be important to know, for example, the interests of firms as they seek access to the public rights-of-way, the models for pricing goods and services, any plans for market and service-area expansion, and the disposition of the data the firm collects about the public. These factors are central to the operation of firms and happen to coincide with the interests that cities have in crafting policies in the public interest. Each city should be prepared to evaluate these products and their providers on the merits and the costs to city government and city residents. Existing guidance attempts to summarize the values that city decision-makers and managers consider important, and, as noted above, these considerations are not necessarily aligned with the interests of firms. Firms may seek to externalize costs and use data about local residents on secondary markets, and cities should avoid this trap. The capacity to evaluate policy will matter, as noted in this Section, as will the capacity to evaluate the various forms of agreements and contracts that will be instrumental in preserving public values while adopting these new technologies.

In their efforts, city managers should perhaps make a point of explaining to the various parties in these new industries that environmental design is local, expensive, and extremely consequential. Guidance from the National Association of City Transportation Officials and the Regional Plan Association makes this point in subtle ways, by emphasizing efficient options for intersection design, for example, and laying out a timeline for the gradual redesign of urban arterials that surely appears to be slow in

176 Elliott D. Sclar, You Don't Always Get What You Pay For: The ECONOMics of Privatization 69, 92 (2000); Ellen Dannin, Crumbling Infrastructure, Crumbling Democracy: Infrastructure Privatization Contracts and Their Effects on State and Local Governance, 6 Nw. J. L. \& SOC. POL'Y 47, 60-69 (2011) (discussing the hidden costs of privatization).

${ }^{177}$ NATCO, supra note 5, at 8-11; REG'L PlAN Ass'N, New MobiLity: AUTONOMOUS VeHICLES AND THE REGION 3 (2017), http://library.rpa.org/pdf/RPA-New-Mobility-Autonomous-Vehicles-andthe-Region.pdf. 
comparison to the business plans of firms and their investors. ${ }^{178}$ From the point of view of city management, this slow pace of environmental design may be realistic under the most ambitious of timeframes, given how changes to the built environment actually proceed. Earthwork, concrete, utility posts, and the relocation of utilities - these are the types of modifications that people take for granted but are highly significant for their expense and opportunity cost in the budget cycle of public agencies. One new sensor or communication device on a utility pole will not cost very much, but when contemplated at the scale of the transportation system, the cost quickly becomes prohibitive for all but the wealthiest of jurisdictions. The consequences of alterations to the built environment are of course physical, but they are also financial - their financial impact depends on the contractual arrangements that made them possible, and they matter to the extent that they give rise to new flows of information, impacts to privacy, and monetization of data about local residents. Lastly, many legal requirements extend from local environmental design, from local speed limits to liabilities for safety, nuisance, security, and privacy.

\section{THE EVOLVING LEGAL FRAMEWORKS FOR PRIVACY AND URBAN ROBOTS}

As discussed above, the potential for urban robots to serve as data gathering and surveillance tools will challenge existing societal expectations of what is "private," as well as the laws that protect privacy. Urban robots will contribute to a trend, already underway, of digital technologies forcing changes to the legal frameworks governing personal data. Currently, the law gives individuals very little control over their data once it has been disclosed to a third party. ${ }^{179}$ Once an individual's information has been disclosed to a company - for instance, on a social media platform like Facebook-the company can analyze, aggregate, and sell that data with very few restrictions as long as it gave notice and obtained consent. The underlying theory is that information that has been made public (i.e., is no longer secret) is not private and therefore is not protected. The same reasoning has applied to government and law enforcement access to data. The third-party doctrine holds that the Fourth Amendment does not protect information shared with

\footnotetext{
${ }^{178}$ NATCO, supra note 5, at 18-19 (showing a timeline of how cities are preparing and can prepare for automated vehicles); $i d$. at 26-27 (laying out a new design for city streets and intersections); $i d$. at 38-41 (diagramming the gradual redesign of urban arterials).

${ }^{179}$ See, e.g., United States v. Weast, 811 F.3d 743, 747 (5th Cir. 2016) (noting that other federal courts have uniformly concluded that the Fourth Amendment's privacy expectation does not protect subscriber information provided to an internet provider, including IP addresses, because that information is voluntarily conveyed to third parties); Low v. LinkedIn Corp., 900 F. Supp. 2d 1010, 1016-17, 102224 (N.D. Cal. 2012) (dismissing class action suit claiming that defendant-a social media companyviolated the Stored Communications Act by disclosing users' personal information to advertisers, marketing companies, data brokers, and other third parties).
} 
a third party because that information is no longer private. ${ }^{180}$ This is why the Supreme Court struck down a constitutional warrant requirement for law enforcement to access the telephone numbers a person dials; when people share those numbers with the phone company, they "assume[] the risk that the information [will] be divulged to the police," 181 even though many people might consider that information sensitive. However, these legal rules were developed in an analog world without widespread digital recording. They become problematic when an individual will be subject to extensive recording by robotic sensors by virtue of the mere act of existing in an urban public space. If recording in public spaces is ubiquitous, as it will be with urban robotics, there will be no meaningful way to opt out of recording without withdrawing from public spaces altogether. The same is true of the third-party doctrine. If robots record nearly everything that happens in public, the very act of moving in public spaces will expose personal information to collection by third parties. This shift is already under way through the widespread use of technologies like vehicle license plate readers, and it is changing the way police and private security forces conduct their business. ${ }^{182}$

There is no federal regulation that addresses this problem; in fact, there is no single, comprehensive federal privacy law at all. ${ }^{183}$ State laws have also struggled to fill this gap. Still, some regulators and lawmakers have been innovating, which has led to some noteworthy legal developments. ${ }^{184}$ There are at least four approaches to coping with the erosion of privacy in public spaces by ubiquitous computing: (1) adapting existing doctrine and U.S. law; (2) regulating the design and deployment of information systems with limits on collection and use of data; (3) allowing data collection but giving consumers more control over their data; and (4) rethinking the third-party doctrine. Privacy law is in a state of flux, and its future shape is unknown. But as policymakers at all levels experiment with new regulatory approaches, cities will feel the impacts and serve as the testbeds for new rules.

${ }^{180}$ Smith v. Maryland, 442 U.S. 735, 743-44 (1979).

${ }^{181} I d$. at 745 .

182 Josh Kaplan, License Plate Readers Are Creeping into Neighborhoods Across the Country, SLATE (July 10. 2019), https://slate.com/technology/2019/07/automatic-license-plate-readers-hoapolice-openalpr.html.

${ }^{183}$ The United States takes a sectoral approach to privacy, regulating specific industries or sectors like banking or health. The Federal Privacy Act governs how federal agencies keep a "system of records," but these rules are not relevant to the privacy issues cities will face with robotics. 5 U.S.C. § 552a(a)(5) (2012).

184 Margot Kaminski, Toward Defining Privacy Expectations in an Age of Oversharing, ECONOMIST (Aug. 16, 2018), https://www.economist.com/open-future/2018/08/16/toward-definingprivacy-expectations-in-an-age-of-oversharing. 


\section{A. Adapting Existing Laws to New Technologies}

The efforts of the Federal Trade Commission ("FTC," or the "Commission") at regulating IoT are emblematic of the first approach: adapting existing laws to cover the uses of new technologies in public spaces. The FTC is the principal privacy regulator in the United States. Absent an industry-specific law, most firms' privacy practices fall under the FTC's authority to regulate "unfair and deceptive acts and practices in or affecting commerce." 185 The scope of this authority allows the FTC to target companies that break public promises about their privacy practices-for instance, through companies' publicly available privacy policies-but imposes few substantive requirements beyond what companies themselves promise. The Commission has not yet brought an enforcement action against any commercial robotics company for privacy violations, but its work with IoT device makers suggests how it might handle similar technology. ${ }^{186}$

The Commission is aware of the privacy challenges posed by IoT, and its approach is best captured by the Nomi consent decree. Nomi is a company that partners with retailers to track shoppers' locations within stores using sensors that track cell phone MAC addresses. ${ }^{187}$ This information can tell retailers who visits their stores, how long they spend inside, and even what they might want to buy. ${ }^{188}$ The FTC enforcement action alleged that Nomi promised in its privacy policy to inform individuals when they were being tracked and to offer an opt-out mechanism but ultimately did neither. ${ }^{189}$ Because it broke these promises, the FTC was able to bring a complaint against Nomi for deceptive acts.

The Nomi action highlights both the FTC's willingness to enforce privacy rules in public spaces and the limits of its authority. Had Nomi simply tracked individuals without making promises about notice and choice and thereby avoided committing any deceptive acts, the FTC would have been largely powerless to stop it. ${ }^{190}$ This is the big gap in U.S. federal privacy law: absent a sector-specific law or regulation, companies can largely do as they please so long as they do not commit a deceptive act. ${ }^{191}$ While the FTC

\footnotetext{
18515 U.S.C. $\S 45(a)(1)(2012)$.

${ }^{186}$ The FTC has enforced against makers of connected toys for having poor cybersecurity, but such toys are outside the scope of our discussion.

187 Complaint at 1, In re Nomi Techs., Inc., Docket No. C-4538 (F.T.C. Aug. 28, 2015) https://www.ftc.gov/system/files/documents/cases/150902nomitechcmpt.pdf.

${ }^{188}$ Stephanie Clifford \& Quentin Hardy, Attention, Shoppers: Store Is Tracking Your Cell, N.Y. TiMES, July 14, 2013, at A1.

${ }^{189}$ Complaint at 2-3, In re Nomi Techs., Inc., Docket No. C-4538 (F.T.C. Aug. 28, 2015) https://www.ftc.gov/system/files/documents/cases/150902nomitechcmpt.pdf.

${ }^{190}$ It is theoretically possible that the Commission could have relied on its unfairness authority in such a situation, but highly unlikely.

${ }^{191}$ The Commission has relied on its unfairness authority to enforce against poor cybersecurity practices, but even that authority is in doubt in light of a recent Eleventh Circuit ruling. See, e.g., LabMD
} 
has worked hard to adapt to new technologies, it can only do so much with its existing legal tools. Robotics companies operate under this same regime. They can and do deploy sophisticated sensors in public spaces, gathering personal data (such as video footage of people) governed only by the public promises of the company. There is no law stopping companies from reselling this data or using it for a secondary purpose.

The SELF DRIVE Act follows this adaptive approach, requiring AV companies to develop a privacy plan that addresses data collection, use, sharing, storage of information, and other common privacy practices. ${ }^{192}$ The law does not mandate any particular privacy practices or create a minimum level of protections however. For this reason, the SELF DRIVE Act's requirement for $\mathrm{AV}$ companies to have a privacy policy may not be adequate to protect privacy. Without more substantive rules to set a floor of protection in company data practices, companies will largely get to set their own rules of the road.

\section{B. Comprehensive Privacy Regulation and the Design and Deployment of Technology}

Recent changes to European data protection law exemplify the second approach of comprehensive regulation that seeks to influence the design and deployment of technologies. The General Data Protection Regulation (GDPR) is a comprehensive overhaul of European privacy law that, among other things, requires that organizations only collect information when they have a legal basis to do so, and only as much as necessary. ${ }^{193}$ The legal bases to collect data are narrowly defined categories like consent or a "legitimate interest" (where the company's interests are carefully weighed against the individual's privacy rights). ${ }^{194}$ This requirement applies even where data is collected in public spaces, such as by a CCTV camera. Organizations must conduct a data privacy impact assessment when handling large volumes of sensitive data ${ }^{195}$ and have data retention limits, meaning they can only keep the data as long as necessary. ${ }^{196}$ Where companies rely on consent, it must be granular, meaning that companies that "seek[] consent for various different purposes should provide a separate opt-in for each purpose."197

\footnotetext{
Inc. v. FTC, 894 F.3d 1221, 1236-37 (11th Cir. 2018) (holding the FTC's command to LabMD was unenforceable, where that command was based on the FTC's unfairness authority).

${ }^{192}$ SELF DRIVE Act, H.R. 3388, 115th Cong. § 12(a) (2017).

${ }^{193}$ Regulation 2016/679 of the European Parliament and of the Council of 27 April 2016, art. 6(1), 2016 O.J. (L 119) 1, 36 [hereinafter GDPR].

${ }^{194} \mathrm{Id}$.

${ }^{195} \mathrm{Id}$. art. $35(3)(\mathrm{b})$, at 53

${ }^{196} I d$. art. 5(1)(e), at 35-36.

197 Article 29 Working Party Guidelines on Consent Under Regulation 2016/679, at 12 (Apr. 10, 2018), https://ec.europa.eu/newsroom/article29/item-detail.cfm?item_id=623051.
} 
These provisions offer much more privacy protection than laws in the United States.

The GDPR seeks to constrain companies by creating guidelines on how they design and deploy technology. Stiff penalties of up to four percent of global revenue create strong incentives for firms to comply. ${ }^{198}$ Firms must now justify the data they collect and apply strict safeguards. They must respect principles of fairness and transparency in their data processing activities. The effect of the law is that firms have afforded new rights to users and revamped their privacy practices to comply with the law. Many have lauded the strong privacy protections, though some worry that the law will stifle the development of AI. ${ }^{199}$

A recent proposal in Washington State called the Washington Privacy Act (WPA) takes a similar approach, borrowing several of the concepts and rules from the GDPR. These include, for example, rights of access and data portability, requirements for contracts between controllers and processors, and opt-in consent. ${ }^{200}$ However, its penalties are capped at $\$ 2500$ per violation or $\$ 7500$ per intentional violation. ${ }^{201}$ It also preempts local governments "regarding the processing of personal data by controllers and processors." 202

The WPA also puts Washington at the forefront of the debate over facial recognition. It would require private facial recognition firms to place a human in the loop by "employ[ing] meaningful human review prior to making final decisions" that "produce legal effects concerning consumers. ${ }^{203}$ Facial recognition companies must also obtain consent from consumers, post conspicuous warnings where they employ the technology, ${ }^{204}$ and in many cases make their services available for audit for "accuracy and unfair bias" through an application programmer interface. ${ }^{205}$ These provisions would impact any urban robots that implemented facial

\footnotetext{
${ }^{198}$ GDPR, art. 83(5), at 83.

${ }^{199}$ There is controversy over whether GDPR Recitation 71 requires that automated decision making be "explainable." If so, then current deep learning techniques that are largely inscrutable by their nature would be prohibited. Compare Christopher Kuner et al., Machine Learning with Personal Data: Is Data Protection Law Smart Enough to Meet the Challenge?, 7 INT'L DATA PRIVACY L. 1, 2 (2017) (contending that Recital 71 may embolden regulators to require explanation of automated decision making in specific cases), with Sandra Wachter, Brent Mittelstadt \& Luciano Floridi, Why a Right to Explanation of Automated Decision-Making Does Not Exist in the General Data Protection Regulation, 7 INT'L DATA PRIVACY L. 76, 76-78 (2017) (contending that the GDPR does not grant a right to explanation of specific decisions made by automated systems).

${ }^{200}$ S. 5376, 66th Leg., Reg. Sess. §§ 3(2), 5(3), 6(1) (Wash. 2019).

${ }^{201} I d$. $\S 12(3)$.

${ }^{202} I d . \$ 13$.

${ }^{203}$ Id. § 14(1).

${ }^{204}$ Id. § 14(4).

${ }^{205}$ Id. § 14(5).
} 
recognition for navigational, social, or any other purposes. Any data an urban robot collected would also be subject to the WPA. ${ }^{206}$

The WPA also addresses state and local government use of facial recognition. It bans governments from using facial recognition for "ongoing surveillance of specified individuals in public spaces," except with a court order or in an emergency involving imminent danger or risk of death. ${ }^{207}$ One concern is that because this provision only applies to ongoing surveillance, it leaves the door open to using facial recognition in other situations, such as to match still pictures against drivers' license pictures, without a court order. The lack of a probable cause warrant requirement is also troubling. But the greatest concern for this Paper is the potentially onerous preemption of local governments. Cities are pioneering privacy regulation for both the private and public sectors, but the WPA could cut off that fertile area of policy innovation prematurely. It is possible, for instance, that the WPA would invalidate Seattle's police surveillance ordinance, which has been heralded as a model for cities across the country. ${ }^{208}$ Further, if a city wanted to protect the privacy of its residents by controlling how urban robots used facial recognition, the WPA's private sector facial recognition sections could interfere. The WPA would certainly be an important tool in any litigation over the matter. A separate Washington proposal, SB 5528, would impose a moratorium on state and local government use of the technology until the State Attorney General can certify that it has been independently audited and is accurate and free of bias. ${ }^{209}$ SB 5528 also requires a warrant to use facial recognition to monitor public spaces and prohibits using it on any police-worn body camera footage. ${ }^{210}$ As of writing, neither proposal has cleared the legislature.

\section{Strengthening Consumer Control}

Some state privacy laws seek to strengthen consumers' rights and control over their data instead of targeting digital technology with comprehensive reforms. However, these proposals would still impact the robotics market as long as robots are collecting information on consumers.

\footnotetext{
${ }^{206}$ See id. $\S 4$ (1)(a) (stating that the WPA applies to businesses that collect and process the data of 100,000 customers or more). A company operating a robot in an urban area in the state of Washington would presumably be subject to this law.

${ }^{207}$ Id. $\S 15(1)$.

${ }^{208}$ Ira S. Rubinstein, Privacy Localism, 93 WASH. L. ReV. 1961, 1989-91 (2018); cf. Jesse W. Woo, Smart Cities Pose Privacy Risks and Other Problems, But That Doesn 't Mean We Shouldn't Build Them, 85 UMKC L. REV. 953, 969 (2017) (describing Seattle's privacy vetting process and its creation of a "chief privacy officer" to coordinate compliance across city departments).

${ }^{209}$ S. 5528, 66th Leg., Reg. Sess. § 3 (Wash. 2019).

${ }^{210} I d . \S 4$.
} 
The recently passed California Consumer Privacy Act $^{211}$ places fewer restrictions on data collection and minimization than the GDPR and instead seeks to offer consumers more control over the data they share with companies. It creates several rights for individuals, such as the right to request deletion of data ${ }^{212}$ and the right to opt out of sharing with third parties. ${ }^{213}$ However, the law exempts "publicly available information" from its definition of personal information. ${ }^{214}$ This definition will likely limit its protections in public spaces. For example, whether a video recording of a public space captures "publicly available information" is an open question. Though the law seeks to offer consumers more control over their data with strong opt-out and consent requirements, it does not strictly limit what information companies collect or what they can do with it. It remains to be seen whether this approach addresses problems of ubiquitous recording in public. The law is also likely to change, given the unique circumstances under which it was passed. ${ }^{215}$ With an effective date of January 1, 2020, there will be much time before the impacts of the law are felt or fully understood.

California is not alone in pushing to expand consumer privacy protections at the state level. New York State has proposed its own privacy law, the Right to Know Act of $2019,{ }^{216}$ which focuses on transparency for when companies share personal data with third parties. It would require companies to identify third parties with whom they share information and the categories of information that they share. ${ }^{217}$ Vermont recently passed a law that would require data brokers to register with the State and disclose certain information such as the number of data breaches each year, ${ }^{218}$ and Washington has its own proposal that mirrors Vermont's. ${ }^{219}$

\section{Doctrinal Reassessment of Privacy in Public}

The Supreme Court has been at the forefront of reshaping privacy doctrines that have previously offered very few protections in public spaces. Recent Supreme Court cases have begun to reconsider the third-party doctrine in light of large amounts of personal data that are subject to

${ }^{211}$ California Consumer Privacy Act, 2018 Cal. Stat. 1807 (codified at CAL. CIV. CoDE $§ 1798.100$ (West 2020)).

${ }^{212}$ CAL. CIV. CODE $§ 1798.105$ (a) (West 2020).

${ }^{213}$ Id. $\S 1798.120(\mathrm{a})$.

${ }^{214}$ Id. $\$ 1798.140(\mathrm{o})(2)$.

215 See Issie Lapowsky, The Fight Over California's Privacy Bill Has Only Just Begun, WIRED (Aug. 29, 2018), https:/www.wired.com/story/california-privacy-bill-tech-lobbying/ (describing how the group Californians for Consumer Privacy sought a ballot initiative for the California Consumer Privacy Act in order to prevent substantial changes to the law by lobbyists and trade associations). The ballot initiative was withdrawn after the bill passed. Id.

${ }^{216}$ Right to Know Act of 2019, S. 224, Reg. Sess. (N.Y. 2019).

${ }^{217}$ Id. $\$ 4$.

${ }^{218}$ VT. STAT. ANN. tit. 9, § 2446(a)(1), (3)(E) (2019).

${ }^{219}$ H. 1503, 66th Leg., Reg. Sess. § 2(1)(a), (c)(iv) (Wash. 2019). 
recording by modern digital technology. The first hint of change came with United States $v$. Jones, a case about whether the police needed a warrant to surreptitiously track a suspect's vehicle by attaching a GPS device to the undercarriage. ${ }^{220}$ Justice Scalia's majority opinion held that the use of the GPS tracker without a warrant constituted a search because by attaching the device to the defendant's car, police had trespassed against his property. ${ }^{221}$ Justices Sotomayor and Alito wrote separate concurrences, with Justices Ginsburg, Breyer, and Kagan joining Alito, supporting a different rationale than Justice Scalia's property-based trespass theory. They reasoned that even though the GPS tracked information that could be observed in public and not normally considered private (the location of the defendant's vehicle on public roads), using technology to collect large amounts of this information could trigger the privacy protections of the Fourth Amendment. ${ }^{222}$ Thus, in Jones five Justices on the Court expressed support for the "Mosaic Theory" that recording and compiling large amounts of public information could violate a person's privacy even if the individual data points were not especially revealing on their own. ${ }^{223}$

The Court again recognized the sensitive nature of digital stores of information in Riley v. California, when it held unanimously that examining the digital contents of a cell phone was a Fourth Amendment search requiring a warrant. ${ }^{224}$ Chief Justice Roberts wrote that a cell phone is not simply another piece of property to be searched incident to arrest, but rather a modern tool to store large quantities of potentially sensitive data. ${ }^{225} \mathrm{He}$ reasoned that the breadth of different types of data, collected in large amounts in one place, could be especially revealing. ${ }^{226} \mathrm{He}$ concluded by writing that "[m]odern cell phones are not just another technological convenience. With all they contain and all they may reveal, they hold for many Americans 'the privacies of life."'227 Thus, in Riley the Court recognized that the cell phones contain personal information that requires protection by the Fourth Amendment and that digital technologies that collect large amounts of revealing data can present an acute threat to privacy.

Chief Justice Roberts built on the foundation laid in the previous two cases to reshape the third-party doctrine for the digital age in Carpenter $v$.

\footnotetext{
${ }^{220}$ United States v. Jones, 565 U.S. 400, 402 (2012).

${ }^{221}$ Id. at $403-10$.

${ }^{222}$ Id. at $413-25$.

${ }^{223}$ For a discussion of mosaic theory and Jones, see David Gray \& Danielle Citron, The Right to Quantitative Privacy, 98 MinN. L. REv. 62, 71, 90-91 (2013); Christopher Slobogin, Making the Most of United States v. Jones in a Surveillance Society: A Statutory Implementation of Mosaic Theory, 8 DukE J. CONST. L. \& PUB. POL'Y 1, 24-25 (2012).

${ }^{224}$ Riley v. California, 573 U.S. 373, 403 (2014).

${ }^{225} \mathrm{Id}$. at 395 .

${ }^{226} \mathrm{Id}$. at 403 .

${ }^{227}$ Id. (quoting Boyd v. United States, 116 U.S. 616, 630 (1886)).
} 
United States. ${ }^{228}$ In Carpenter, the Court decided whether the Fourth Amendment required a warrant for an individual's cell phone location records. ${ }^{22}$ Investigators in the Carpenter case used the Stored Communications Act to request the history of which cell phone towers the defendant's phone had connected with around the same time as a string of robberies in Detroit. ${ }^{230}$ The phone's connections to the cell towers revealed the defendant's location around the time of the robberies, which prosecutors used to convict him. ${ }^{231}$ Law enforcement was able to acquire the information using the Stored Communications Act (which has a lower standard) instead of a warrant because of the Court's ruling in Smith v. Maryland that individuals have no privacy rights in information they share with third parties like telephone companies. ${ }^{232}$

However, Roberts' opinion declined to extend Smith v. Maryland and United States v. Miller and held that the Fourth Amendment required a warrant to access a suspect's cell tower location history. ${ }^{233}$ Although it did not overturn Smith or Miller, by declining to extend those cases to cell tower location history, Carpenter marks a significant reversal of the third-party doctrine. Roberts' reasoning relied heavily on the impact of digital technology. Americans share digital data with third parties in quantities and kinds that would have been unfathomable to the framers, and so the new digital reality warrants a change in legal doctrine. Roberts also noted that in the time between Carpenter's conviction and when the Court heard the case, the number of cell towers had greatly increased, which made cell tower location information much more precise and revealing. ${ }^{234}$ The proliferation of cell phone towers is analogous to advances in IoT generally and robotics specifically; sensors become more capable and more numerous and gather even more personal information in public. Professor Orin Kerr sees Carpenter as a form of "equilibrium-adjustment," where the Court adjusts privacy protections to preserve privacy in light of encroachments from new technologies. ${ }^{235}$ Roberts' opinion was controversial, however, with four Justices dissenting.

Justice Gorsuch's dissent was perhaps the most intriguing, as it proposed an alternate, property-based theory to protect private information shared with third parties. In his lone dissent, he reasoned that positive law may have indicated an intent to treat cell phone location data as private by enacting

${ }^{228}$ Carpenter v. United States, 138 S. Ct. 2206 (2018).

${ }^{229}$ Id. at 2221.

${ }^{230} \mathrm{Id}$.

${ }^{231} I d$.

${ }^{232}$ Smith v. Maryland, 442 U.S. 735, 743-45 (1979).

${ }^{233}$ Carpenter, 138 S. Ct. at 2221.

${ }^{234} \mathrm{Id}$. at $2211-12$.

235 Orin S. Kerr, First Thoughts on Carpenter v. United States, REASON (June 22, 2018), https://reason.com/volokh/2018/06/22/first-thoughts-on-carpenter-v-united-sta/. 
protections against unauthorized dissemination. ${ }^{236}$ Therefore, the information concerning Carpenter's location could be considered his property for Fourth Amendment purposes. ${ }^{237}$ If that information was Carpenter's property, then investigators seized it without a warrant in violation of the Fourth Amendment. Gorsuch argued that the property-based theory of the Fourth Amendment was in line with other property-based decisions such as Jones and Florida v. Jardines. ${ }^{238} \mathrm{He}$ would have preferred to overturn Katz and do away with the reasonable expectation of privacy test in favor of this theory, but lamented that the property theory of the Fourth Amendment had not been briefed or developed by the parties. ${ }^{239}$

The Court is in the middle of a debate about the theoretical underpinnings of Fourth Amendment privacy that will have significant implications for the relationship between technology and privacy in public spaces. More cases addressing new technologies will come before the Court in time, and this debate is likely to intensify as robots are increasingly deployed in public spaces.

\section{E. Proposed Comprehensive Federal Privacy Legislation}

2018 and 2019 have seen multiple proposals for new federal privacy legislation that vary greatly in their approaches to privacy protection, likely in response to a series of privacy scandals in 2018 involving Facebook and other large tech firms. Some proposals rely on existing concepts in privacy law, especially consent and transparency through privacy notices. ${ }^{240}$ While this is an important part of the conversation, as we discuss above the nature of robots and IoT in public spaces may require protections beyond traditional notions of notice and consent. Here, we focus on proposals that go further toward addressing this reality.

Instead of relying on notice and consent, the Data Care Act would impose certain fiduciary duties on online service providers similar to those required of attorneys and corporate board members. The Act creates duties of care, loyalty, and confidentiality and expands the duty to inform in the event of a data breach. ${ }^{241}$ It also gives the FTC rulemaking authority and allows for separate enforcement by state attorneys general, although pending FTC actions would preempt states for their duration. ${ }^{242}$

${ }^{236}$ Carpenter, 138 S. Ct. at 2270 (Gorsuch, J., dissenting).

${ }^{237} \mathrm{Id}$. at 2272.

${ }^{238} I d$. (citing Florida v. Jardines, 569 U.S. 1 (2013)).

${ }^{239}$ Id. at 2272.

${ }^{240}$ This includes the Social Media Privacy Protection and Consumer Rights Act of 2018, S. 2728, 115th Cong. § 3(a)(1) (2018); the CONSENT Act, S. 2639, 115th Cong. § 2(b)(2)(B) (2018); and the Information Transparency and Personal Data Control Act, H.R. 2013, 116th Cong. § 3(a) (2019).

${ }^{241}$ Data Care Act of 2018, S. 3744, 115th Cong. § 3(b), (c) (2018).

${ }^{242}$ Id. § 4(b)(5). 
The idea of data fiduciaries could have potential as an alternative to notice and consent regimes that struggle to address robots and the IoT. However, in its current form, the Data Care Act is limited to online service providers, ${ }^{243}$ so it would not apply to robots, where physicality is a major feature. Even so, it is an important start to a broader debate.

The most ambitious proposal is likely Senator Ron Wyden's Consumer Data Protection Act. The Consumer Data Protection Act is not limited to online service providers, but rather applies to any "person, partnership, or corporation over which the Commission has jurisdiction under section 5(a)(2) of the Federal Trade Commission Act (15 U.S.C. 45(a)(2)[)]," with an exception for small businesses. ${ }^{244}$ The bill's many provisions include recognition of "noneconomic" injuries in FTC jurisprudence, ${ }^{245}$ implementation of a national Do-Not-Track system, ${ }^{246}$ and impact assessments for automated decision systems. ${ }^{247}$ It would not only give the FTC rulemaking authority but also increase its funding and establish a Bureau of Technology within the Commission. ${ }^{248}$

Two other proposals take divergent approaches but share one important feature: federal preemption of state (and by implication local) privacy rules. First, the American Data Dissemination Act of 2019 takes the protections of the Privacy Act of 1974, which currently only applies to federal agencies, and applies them to online service providers. ${ }^{249}$ The Act and resulting regulations would preempt any state laws as far as they relate to internet service providers. ${ }^{250}$ Alternatively, the Center for Democracy and Technology (CDT), a prominent think tank and advocacy group, has also proposed model baseline federal privacy legislation. The CDT bill would apply to any "person or business entity that as part of its activities processes personal information in or affecting interstate commerce," but excludes government actors and natural persons. ${ }^{251}$ It proposes individual rights that appear to be inspired by the GDPR: rights to access and correct, data portability, and deletion. ${ }^{252}$ In a novel innovation, it defines certain acts as

\footnotetext{
${ }^{243} I d . \S 3$.

244 Consumer Data Protection Act, SIL18B29, 115th Cong. $\S 2(5)$ (2018), https://www.wyden.senate.gov/imo/media/doc/Wyden\%20Privacy\%20Bill\%20Discussion $\% 20 \mathrm{Draft} \% 2$ 0Nov\%201.pdf.

${ }^{245} I d . \S 3$.

${ }^{246} I d . \S 6$.

${ }^{247} \mathrm{Id} . \S 7(\mathrm{~b})(1)(\mathrm{G})$.

${ }^{248} I d$. $\S \S 8-9$.

249 American Data Dissemination Act of 2019, S. 142, 116th Cong. (2019), https://www.congress.gov/bill/116th-congress/senate-bill/142/text.

${ }^{250} I d . \S 6$.

${ }^{251}$ CTR. FOR DEMOCRACY \& TeCh., CDT FEDERAl Baseline Privacy LEGISLATION Discussion DRAFT § 1(5) (Dec. 5, 2018), https://cdt.org/files/2018/12/2018-12-12-CDT-Privacy-Discussion-DraftFinal.pdf.

${ }^{252} I d . \S 2(1)-(3)$.
} 
per se deceptive or unfair, effectively strengthening and broadening the FTC's enforcement authority. ${ }^{253}$ However, it only gives the FTC rulemaking authority in certain narrow subjects, such as for security, health information, and unfair targeted advertising. ${ }^{254}$ As with the American Data Dissemination Act, the CDT's proposed bill would preempt privacy laws by state and local governments. ${ }^{255}$ Because the proposal applies to all companies, not just online service providers, the scope of this preemption is much broader and would include many if not all of the local privacy laws we discuss in this Paper.

As of writing, the most recent new proposal is the Consumer Online Privacy Rights Act (COPRA). COPRA would apply to any entity already covered by the FTC Act that transfers data that identifies or is reasonably linkable to an individual. ${ }^{256}$ It would create a duty of loyalty for such entities as well as individual rights, such as rights of access, deletion, data minimization, and data security. ${ }^{257}$ Notably, it would preempt state laws that conflict with its provisions, but not those that create stronger protections. ${ }^{258}$

One common thread is that many of these proposals are specific to online service providers. This is likely because one of the principle catalysts for this legislative activity is the Facebook/Cambridge Analytica scandal. ${ }^{259}$ Lawmakers are reacting to the problem in front of them, which is privacy abuse by online platforms and service providers. This is important and necessary work, but it ignores the looming privacy issues that are around the corner with robotics, IoT, and the third-party doctrine.

\section{F. Cities as Testbeds of Data Privacy}

It is difficult to predict precisely what impact these changes in privacy law will have on cities, but those impacts will certainly be felt strongly at the local level. Cities are the places where robots, and their accompanying sensors, will be tested and deployed. The physical infrastructure of cities is also likely to be embedded with sensors and computers to allow the robots to interact more smoothly with the built environment. Further, the density of people in cities means that the scale of data collection will be at its greatest in urban areas. Cities have an interest in using the data robotics companies collect and in protecting the privacy rights of their residents. Do

\footnotetext{
${ }^{253} I d . \S \S 4-5$.

${ }^{254} I d . \S \S 3,5,6$.

${ }^{255} I d . \S 10(2)$.

256 Consumer Online Privacy Rights Act, S. 2978, 116th Cong. § 2(9) (2019), https://www.congress.gov/bill/116th-congress/senate-bill/2968/text.

${ }^{257} I d . \S \S 101-10$.

${ }^{258} I d . \S 302$.

${ }^{259}$ See Zoe Kleinman, Cambridge Analytica: The Story So Far, BBC NEws (Mar. 21, 2018), https://www.bbc.com/news/technology-43465968 (summarizing the Facebook/Cambridge Analytica scandal).
} 
comprehensive privacy protections prevent firms from developing cutting edge technologies? What balance of market power and control between firms and individuals allows for innovation and privacy protection? Will a change in the third-party doctrine impact policing practices at the local level? These questions will play out at the local level. ${ }^{260}$ As privacy law continues to evolve, cities can serve as testbeds for governance not just of the robots but the data those robots collect.

Ira Rubinstein has begun an important exploration of the role of cities in privacy policymaking through "privacy localism." ${ }^{261} \mathrm{He}$ documents the rise of local privacy laws and surveillance oversight bodies in the cities of Seattle and New York. He argues the federal and state privacy laws leave significant gaps by failing to protect against surveillance in public spaces (the "public surveillance gap") and failing to protect local government records (the "Fair Information Practices gap"). ${ }^{262}$ Because privacy localism fills these gaps and fulfills the democratic values inherent in federalism, cities should be allowed to develop their own privacy localist programs within the framework of federalism. ${ }^{263}$

Cities will continue to fill the privacy gap for urban robotics because federal legislative attempts to address privacy issues with robotics are inadequate. As discussed, the SELF DRIVE Act's privacy rules are based on existing, inadequate privacy frameworks that rely on self-regulation through corporate privacy policies. ${ }^{264}$ The AV START Act establishes an AV "Data Access Advisory Committee" to consider the issue of privacy and AVs and issue a report to Congress within 180 days. ${ }^{265}$ However, federal regulators are prohibited from issuing new rules on AV privacy until the committee submits its report. ${ }^{266}$ So the SELF DRIVE Act establishes no baseline protections for this highly sensitive technology, and the public will not even know what privacy protections result from AV START for 180 days. Federal rules for drone privacy have also been lacking. The FAA has explicitly declined to issue rules on drone privacy. Meanwhile, these technologies are being deployed and tested in urban public spaces and collecting large amounts of data. It is up to cities to set their own rules of the road as the sites of this experimentation.

\footnotetext{
${ }^{260}$ For example, aldermen in the city of Chicago have introduced a local ordinance that would create opt-in consent and disclosure requirements similar to California's law. Amendment of Municipal Code Title 4 By Adding New Chapter 4-402 Entitled "Data Collection and Protection Ordinance", CHI. LEGISTAR (Apr. 18, 2018), https://chicago.legistar.com/LegislationDetail.aspx?ID=3480452\&GUID $=241$ F981B-94D6-43E8-AC73-D122DBECD413\&Options=Advanced\&Search $=$.

${ }^{261}$ Rubinstein, supra note 208, at 1982-2020.

${ }^{262}$ Id. at $1974-82$.

${ }^{263} \mathrm{Id}$. at $2017-18$.

${ }^{264}$ See supra text accompanying note 192.

${ }^{265}$ AV START Act, S. 1885, 115th Cong. § 15(d)(1) (2017), https://www.congress.gov/115/ bills/s1885/BILLS-115s1885rs.pdf.

${ }^{266} I d . \S 15(\mathrm{c})(1)$.
} 
Cities continue to innovate with respect to privacy protections. Professor Rubinstein documents many salient examples, in particular local ordinances that place restrictions on police use and procurement of new surveillance technologies like drones. ${ }^{267}$ Cities, however, have additional tools available to them. For instance, the city attorney of Los Angeles recently sued The Weather Channel app for unfair and fraudulent business practices, alleging that it failed to properly disclose the extent of its tracking and data sharing with third parties to consumers. ${ }^{268}$

We agree that cities should be empowered to develop local privacy regimes. Not only does privacy localism comport with the values of federalism, it reflects the fact that impacts of privacy regulations will be felt most keenly at the local level. Any federal action related to data use by robots in public spaces or to creating nationwide baseline privacy protections should be aware of the unique and evolving role of cities in developing privacy policy. Such federal action should respect the autonomy of cities, especially when it comes to preemption. Overly broad or aggressive preemption will only serve to stifle policy innovation. Further work is required to explore the implications of robotics on privacy localism and the role of privacy localism to shape privacy policymaking more broadly.

\section{PREEMPTION, Cities, AND the REGUlation of AutONOMOUS SYSTEMS}

This Part is an account of the law of urban robotics. It begins with an overview of federal and state preemption and city police powers, noting that federal and state governments can greatly restrict local authority, although there are some spheres where cities typically exercise their authority. Next, it surveys existing or proposed federal and state robotics laws, with particular attention to preemption issues. We then provide an account of how cities are regulating urban robots and serving as testbeds for innovation.

\section{A. An Overview of Federal Preemption and Home Rule Doctrines}

Two types of preemption are important for this account of urban robotics: federal preemption of states and localities and state preemption of localities. Federal preemption is where federal law supersedes and invalidates a state or local government law. It is based on the Supremacy Clause of the U.S. Constitution, which provides that federal law and the Constitution are "the supreme Law of the Land; and the Judges in every State shall be bound thereby, any Thing in the Constitution or Laws of any State

\footnotetext{
${ }^{267}$ See Rubinstein, supra note 208, pt. II (documenting Seattle and New York City case studies).

${ }^{268}$ Complaint for Injunctive Relief and Civil Penalties for Violations of Unfair Competition Law (California Business \& Professions Code $\S \S 17200$, et seq.) at 3, California v. TWC Prod. \& Tech., LLC (Cal. Super. Ct. 2019).
} 
to the Contrary notwithstanding." ${ }^{269}$ The dispositive question for a court in finding federal preemption is whether Congress intended to preempt the states on the matter. ${ }^{270}$ If Congress expresses its preemptive intent in the text of the law, it has created express preemption. ${ }^{271}$ If a court finds express preemption, it must then determine "the substance and scope of Congress' displacement of state law." ${ }^{272}$ The Supreme Court has said that when statutory preemption language has more than one plausible reading, courts should "accept the reading that disfavors pre-emption."273

If a court finds no language that expressly preempts state law, it may still find implied preemption in the legislation's structure and purpose. ${ }^{274}$ Implied preemption takes two forms: conflict preemption and field preemption. With conflict preemption, state or local laws either conflict with federal law or present an obstacle to the congressional purpose. ${ }^{275} \mathrm{With}$ field preemption, Congress has expressed an intent to occupy the field on that issue, leaving no room for states to supplement the law or otherwise regulate. ${ }^{276}$ For example, the Supreme Court has held Illinois licensing and training requirements for hazardous waste handling to be invalided by the Occupational Safety and Health Administration's regulations. ${ }^{277}$

While federal law may be supreme, the constitutional system of federalism provides only certain enumerated powers to the federal government, while reserving all others to the states. ${ }^{278}$ The Tenth Amendment prevents the federal government from "commandeering" state governments by imposing affirmative duties to do things that they would not otherwise do. ${ }^{279}$ For example, Congress may not force states to assume liability for radioactive waste ${ }^{280}$ or use state police resources to conduct federal background checks for firearm purchases. ${ }^{281}$ Congress may condition federal grant money on certain state actions, such as raising the drinking age

${ }^{269}$ U.S. CONST. art. VI, § 1, cl. 2; see also McCulloch v. Maryland, 17 U.S. 316, 326-27 (1819) ("The constitution, therefore, declares that the constitution itself . . . shall be the supreme law of the land.").

${ }^{270}$ Altria Grp. v. Good, 555 U.S. 70, 76-77 (2008).

${ }^{271} I d$.

${ }^{272}$ Id. at 76 .

${ }^{273}$ Bates v. Dow Agrosciences LLC, 544 U.S. 431, 449 (2005).

${ }^{274}$ Altria Grp., 555 U.S. at 76.

${ }^{275}$ Id. at 70.

${ }^{276}$ Gade v. Nat'l Solid Wastes Mgmt. Ass'n, 505 U.S. 88, 98 (1992).

${ }^{277}$ Id. at $98-99$

${ }^{278}$ U.S. CONST. amend. X.

${ }^{279}$ See, e.g., Printz v. United States, 521 U.S. 898, 925 (1997) (“[T]he Federal Government may not compel the States to implement, by legislation or executive action, federal regulatory programs."); New York v. United States, 505 U.S. 144, 176 (1992) (holding that the Act was effectively commandeering the state governments because "[a] choice between two unconstitutionally coercive regulatory techniques is no choice at all").

${ }^{280}$ New York v. United States, 505 U.S. at 188.

${ }^{281}$ Printz, 521 U.S. at 933. 
to twenty-one. ${ }^{282}$ However, the conditions of the grant may not be so onerous that they coerce the states into action. ${ }^{283}$

State preemption of local governments does not operate under the same constitutional framework as federal preemption. While the U.S. Constitution reserves broad power for states through the Tenth Amendment, ${ }^{284}$ cities are not even mentioned in the document. Broadly speaking, there are two views of local power in relation to states: Dillon's Rule and home rule. Under the traditional view described in Dillon's Rule, cities are simply administratively convenient organizations that derive their power from states, so they only have the limited powers granted by the state. ${ }^{285}$ They are not themselves sovereign. Discontent with Dillon's Rule eventually led states to grant more powers to cities, first on matters of "local" concern, and later, broader "police powers."286 Police powers encompass the public's health, safety, welfare, and morals. ${ }^{287}$ However, they are still "subject to denial of power in a particular substantive field by specific act of the state legislature." 288 That is, local governments typically do not have unfettered police powers even under home rule. States enact home rule either in their constitutions or legislatively. ${ }^{289}$ Home rule powers come in two forms: (1) empowerment/initiative - the ability to enact substantive policy; and (2) immunity - "the ability to resist encroachment from another governmental entity or from a private party." 290

Though state preemption of cities exists under a different constitutional framework than federal preemption, it often operates in similar ways. As with the federal level, state preemption can be either express or implied. ${ }^{291}$ Implied preemption in turn can be either field or conflict, although most

${ }^{282}$ South Dakota v. Dole, 483 U.S. 203 (1987).

${ }^{283}$ Nat'l Fed'n of Indep. Buss. v. Sebelius, 567 U.S. 519, 578 (2012).

${ }^{284}$ U.S. CONST. amend. X.

${ }^{285}$ As the Supreme Court stated:

Municipal corporations are political subdivisions of the State, created as convenient agencies for exercising such of the governmental powers of the State as may be entrusted to them. ... The number, nature and duration of the powers conferred upon these corporations and the territory over which they shall be exercised rests in the absolute discretion of the State.

Hunter v. City of Pittsburgh, 207 U.S. 161, 178 (1907).

${ }^{286}$ Paul Diller, Intrastate Preemption, 87 B.U. L. REV. 1113, 1122-25 (2007).

${ }^{287}$ Richard Briffault et al., The Troubling Turn in State Preemption: The Assault on Progressive Cities and How Cities Can Respond, AM. CONST. SoC'Y FOR L. \& POL'Y, Sept. 2017, at 4, https:/www.acslaw.org/wp-content/uploads/2017/09/ACS_Issue_Brief_-_Preemption_0.pdf.

${ }^{288}$ Diller, supra note 286 , at 1125.

${ }^{289}$ Briffault et al., supra note 287, at 5.

${ }^{290}$ Nestor M. Davidson, Cooperative Localism: Federal-Local Collaboration in an Era of State Sovereignty, 93 VA. L. REV. 959, 975 (2007).

${ }^{291}$ Lauren E. Phillips, Impeding Innovation: State Preemption of Progressive Local Regulations, 117 COLUM. L. REV. 2225, 2233-35 (2017). 
states do not use these exact terms. ${ }^{292}$ However, the nuances of home rule versus Dillon's Rule and the exact wording of state grants of authority to cities can impact the outcome of state preemption cases. ${ }^{293}$ For example, Oregon's state constitution has been read to create a presumption for preemption in criminal law matters but against preemption in civil matters. $^{294}$

A group of legal experts convened by the American Constitution Society (citing the National League of Cities) identifies five categories of municipal power. Structural authority is the power to choose or modify the form of city government. ${ }^{295}$ Personnel authority is the power to set employment policies, compensation, and collective bargaining. ${ }^{296}$ Fiscal authority is the power to "raise revenue, borrow money, and spend." 297 Proprietary authority is the power to set policy through the procurement and contracting process, what we call market making. ${ }^{298}$ Regulatory or "functional" authority encompasses the "police power" to set substantive policy and regulate health, safety, welfare, and morals. ${ }^{299}$ Cities often rely on regulatory power when setting rules for firms, so it is often at issue in state preemption fights. ${ }^{300}$

Home rule schemes vary a great deal from state to state. In states where the home rule grant is purely legislative, the state can preempt any city action, and cities have no immunity. ${ }^{301}$ On the other extreme is the Colorado state constitution, which expressly protects local authority. ${ }^{302}$

Cities and state legislatures have engaged in high profile preemption conflicts on a variety of issues. These issues run the gamut from anti-discrimination rules for transgender individuals, to sanctuary city and minimum wage laws, to municipal broadband and ride-sharing apps. ${ }^{303}$ Cities feel that they have an interest in the impact of technological change on the health or safety of their residents or the provision of city services. Where firms operate new technological platforms in cities, namely ride and

\footnotetext{
${ }^{292} I d$. at 2234.

${ }^{293} \mathrm{Id}$. at $2234-35$.

${ }^{294} I d$. at 2234 n. 49

${ }^{295}$ Briffault et al., supra note 287, at 5.

${ }^{296} I d$. at 5.

${ }^{297} I d$. at $5-6$.

${ }^{298} I d$. at 6 .

${ }^{299} I d$. at 5 .

${ }^{300} \mathrm{Id}$.

${ }^{301} I d$. at 6 .

${ }^{302}$ Id. at $6 \mathrm{n} .18$ (citing COLO. CONST. art. XX, $\S 6$, which declares that local charters and ordinances involving "local and municipal matters ... shall supersede ... any law of the state in conflict therewith").

${ }^{303}$ Nicole DuPuis et Al., NAT'L LeAgue of Cities, City Rights in AN ERA OF PreEMPTION: A StATE-BY-STATE ANALYSIS 2018 UPDATE 1, 3 (2018), http://www.nlc.org/sites/default/files/201703/NLC-SML\%20Preemption\%20Report\%202017-pages.pdf.
} 
room sharing, several states have preempted city regulation. ${ }^{304}$ Cities have also sought to impose regulation or alter street design to keep traffic algorithms like Waze from redirecting freeway traffic onto urban and suburban side streets. ${ }^{305}$ These recurring debates highlight the fact that cities occupy a legally difficult space when it comes to the source and scope of their power to regulate.

Even with the variety that exists among states, cities tend to have a great deal of authority in certain areas related to environmental design. They typically have broad powers in zoning to determine the nature and character of city neighborhoods. ${ }^{306}$ Cities usually control the maintenance of public streets within their territory, although the lines of which government body is responsible for which street can blur. ${ }^{307}$ Cities also regulate the design of public and private spaces by placing restrictions on building height or space between the building and the street (called the "setback"). ${ }^{308}$ Cities exercise broad taxing authority to raise funds for improvements to public space, manage those improvements, and maintain the condition of the space, either in house or in contract with the private sector. Many utility services, such as parking, electricity, water, communications, wastewater, storm water, and solid waste, occupy the same rights-of-way and may be publicly owned.

The preemption debate is already beginning to play out with urban robots. Proposed federal autonomous vehicle legislation has quite broad preemption language. One libertarian think tank has raised the alarm that ride-sharing firms will lobby cities to ban individual ownership of autonomous vehicles and urged states to preempt cities on that issue. ${ }^{309}$ Several state laws currently preempt city regulation of autonomous

${ }^{304}$ Id. at 12,15 .

${ }^{305}$ Lisa W. Foderaro, As Apps Like Waze Reroute Commuter Traffic, Towns Fight Back, Bos. GLOBE (Dec. 24, 2017), https://www3.bostonglobe.com/business/2017/12/24/apps-like-waze-reroutecommuter-traffic-towns-fight-back/WqzeqfiikCc9yPtBFkgvbO/story.html?arc404=true.

${ }^{306}$ Richard Briffault, Our Localism: Part I-The Structure of Local Government Law, 90 COLUM. L. REV. 1, 39-59 (1990) (discussing history of local governments enjoying broad powers over land use and the more recent attempts by courts to impose regional conformity).

${ }^{307}$ See, e.g., Amanda Gray, Who Is Responsible for Sidewalks: The City, the State, or You?, GoSHEN NEws (Aug. 3, 2012), http://www.goshennews.com/news/who-is-responsible-for-sidewalks-the-citythe-state-or/article_3a89622d-f811-56ea-853e-734fa7b317a8.html; Maintenance Questions, CITY OF SACRAMENTO, https:/www.cityofsacramento.org/Public-Works/Questions/Maintenance (last visited Aug. 29, 2018) (stating that although the sidewalk is "in the City's right-of-way," property owners are required to maintain the sidewalks in front of their property); Street Maintenance, RICHMOND PUB. WORKS, http://www.richmondgov.com/PublicWorks/StreetMaintenance.aspx (last visited Aug. 30, 2019) (noting that Richmond is responsible for sidewalk cleanup, but some residents may be responsible for alley maintenance).

${ }^{308}$ E.g., DAVIS, CAL., MuN. CODE $§ 40.26 .010$ (c) (last amended 2015); Building Setbacks: What Is a Setback?, CITY BELLEVUE, https://development.bellevuewa.gov/zoning-and-land-use/zoningrequirements/building-setbacks/ (last visited Aug. 29, 2018).

309 Marc Scribner, Uber Wants to Make It Illegal to Operate Self-Driving Car in Cities, COMPETITIVE ENTERPRISE INST. (Feb. 1, 2018), https://cei.org/blog/uber-wants-make-it-illegal-operateyour-own-self-driving-car-cities. 
vehicles. ${ }^{310}$ On the other hand, the states with delivery robot laws on the books explicitly allow cities to regulate such machines. ${ }^{311}$

\section{B. Federal and State Robotics Laws}

The following section reviews local, state, and federal laws and policies pertaining to autonomously controlled vehicles, delivery robots, security and entertainment robots, and drones. ${ }^{312}$

For each category of robot, we examine the interaction between different levels of government and the likely sources of conflict or preemption. We also discuss the impact that preemption might have on the urban built environment or the design of the robots themselves.

\section{Autonomous Vehicles}

AV regulation in many cities is in danger of preemption by both state and federal laws. Cities have been at the forefront of AV testing and employed sundry regulatory approaches based on local needs and political realities. However, some state laws already preempt city regulation of AVs, and proposed federal legislation would go even further, cutting off this period of technological and regulatory experimentation prematurely.

The diversity of local AV regulations reflects the varied needs of cities to control their public rights-of-way as well as the current experimental state of this technology. Many cities have pilot programs to implement automated vehicles into their own transportation systems, such as with autonomous buses. ${ }^{313}$ For instance, the city of Atlanta has created a "smart corridor" that

310 Autonomous Vehicles: Self-Driving Vehicles Enacted Legislation, NAT'L CONF. ST. LEGISLATURES (Mar. 19, 2019), http://www.ncsl.org/research/transportation/autonomous-vehicles-selfdriving-vehicles-enacted-legislation.aspx (listing Tennessee, Texas, Illinois, and North Carolina as states that have enacted legislation preempting local regulation on autonomous vehicles).

${ }^{311}$ H.B. 1325, 66th Leg., Reg. Sess. § 2 (Wash. 2019) (recently enacted bill on delivery robots in Washington that respects local control provided the robots operate in a jurisdiction and operate within local governments' rules and regulations).

312 Autonomous flying cars present a separate set of challenges and do not fit neatly into these categories. The FAA has issued exemptions to some of its regulations on general aviation aircraft to some companies, but the process is reported to be quite complicated and time consuming. This process could, for example, complicate Uber's promise to deliver flying car service by 2020. See Jacob Bogage, Flying Cars Just Took a Big Step Closer to Being Legal, WASH. PosT (June 20, 2016), https://www.washingtonpost.com/news/the-switch/wp/2016/06/20/flying-cars-just-took-a-big-stepcloser-to-being-legal/?utm_term=.a42f4cdc9a84; Jim Moore, Uber Promises Flying Cars by 2020, AOPA (Apr. 27, 2017), https://www.aopa.org/news-and-media/all-news/2017/april/27/uber-promisesflying-cars-by-2020; Andrew Ross Sorkin, Larry Page's Flying Taxis, Now Exiting Stealth Mode, N.Y. TIMES (Mar. 12, 2018), https://www.nytimes.com/2018/03/12/business/dealbook/flying-taxis-larrypage.html; Joe Stumpe, FAA Excites Nascent Flying-Car Industry, AerospaCe AM. (Jan. 3, 2017), https://aerospaceamerica.aiaa.org/faa-excite-nascent-flying-car-industry/.

313 S.F. Mun. Transp. Agency, Advanced Transit and Congestion Management TECHNOLOGIES DEPLOYMENT INITIATIVE (ATCMTD), https:/www.sfmta.com/sites/default/files/ projects/2017/ATCMTD\%20Grant\%20Application.pdf (last visited Feb. 7, 2020) [hereinafter 
pairs a driverless bus with smart infrastructure like traffic lights that will communicate with the AV. Cities experimenting with autonomous buses have made infrastructure upgrades that incorporate computers that can communicate with AVs. ${ }^{314}$ In many cases, these pilot programs appear to be implemented through public-private partnerships between cities and firms. ${ }^{315}$ With the exception of Boston, we have not been able to find publicly available copies of these agreements. ${ }^{316}$ Boston requires compliance with federal AV safety guidelines and strictly controls the driving conditions under which companies can test their AVs. ${ }^{317}$ This includes weather conditions, time of day, and presence of safety drivers who can take control of the vehicle in an emergency. Cities such as Ann Arbor and San Jose have also created dedicated physical spaces for automated vehicle testing. ${ }^{318}$ They have already begun planning the necessary infrastructure upgrades to accommodate and prepare for widespread automated vehicle deployment. ${ }^{319}$ Chandler, Arizona has become the first city to modify its zoning laws to accommodate AV passenger pick-up and drop-off. ${ }^{320}$ Private companies have proposed dedicated lanes of traffic for AVs both on highways and city streets, although to our knowledge no city has taken steps to implement such lanes yet. ${ }^{321}$ And consultants and firms are promoting the necessity of infrastructure upgrades to promote AVs. ${ }^{322}$

ATCMTD REPORT]; Skip Descant, Atlanta's Second Smart Transportation Corridor Takes Shape, GOV'T TECH. (June 22, 2018), https://www.govtech.com/fs/infrastructure/Atlantas-Second-SmartTransit-Corridor-Takes-Shape.html; Andrew J. Hawkins, Las Vegas Is Expanding Its Self-Driving Shuttle Experiment, VERGE (Nov. 6, 2017), https://www.theverge.com/2017/11/6/16614388/las-vegasself-driving-shuttle-navya-keolis-aaa.

${ }^{314}$ Descant, supra note 313; Hawkins, supra note 313.

${ }^{315}$ Aspen Inst., supra note 25.

316 Template MOU for Autonomous Vehicle Testing in Boston, CITY Bos., https://www.boston.gov/sites/default/files/document-file-01-2017/template-mou-for-av-testing.pdf (last updated Oct. 26, 2019).

${ }^{317} I d$. at 3 .

${ }^{318}$ MCITY TEST FACILITY, https://mcity.umich.edu/our-work/mcity-test-facility/ (last visited Aug. 29, 2018); NORTH SAN JOSE TRANSPORTATION INNOVATION ZONE, https://www.arcgis.com/ home/item.html?id=68b10f2c69ff42ba97cc2c0efe93edc6 (last updated Mar. 7, 2017).

319 ATCMTD REPORT, supra note 313; CITY OF AUSTIN SMART MOBILITY ROADMAP 33 (2017), http://austintexas.gov/sites/default/files/files/Smart_Mobility_Roadmap_-_Final.pdf.

${ }^{320}$ Chandler, Ariz., Ordinance $4811 \S 2$ (May 10, 2018).

321 Tom Alberg, DANiel Li \& Craig Mundie, MAdrona Venture GrP., CONVERT I-5 INTO AN AUtONOMOUS VeHICLE CORRIDOR 3, http://www.madrona.com/wp-content/uploads/2017/09/MVG-I5Proposal-Digital.pdf (last visited Feb. 7, 2020); Edg, Loop NYC, VIMEO (2017), https://vimeo.com/225302665; Benjamin Preston, Berkeley Duo's Plan to Solve Traffic Jams: HyperFast Lanes for Self-Driving Cars, GUARDIAN (June 3, 2017), https://www.theguardian.com/ technology/2017/jun/03/self-driving-cars-high-speed-lane-berkeley-california.

${ }^{322}$ Omri Barzilay, The Road to the Autonomous Age Will Be Paved by Smart Cities, ForBES (Jan. 24, 2018), https://www.forbes.com/sites/omribarzilay/2018/01/24/the-road-to-the-autonomous-agewill-be-paved-by-smart-cities/\#c1bee4668c3e; Saber Fallah, Driverless Cars Are Forcing Cities to Become Smart, CONVERSATION (Apr. 24, 2018), https:/theconversation.com/driverless-cars-areforcing-cities-to-become-smart-94707. 
In sum, in regulating automated vehicles, most cities have relied on their proprietary authority to form public-private partnerships with firms or their regulatory authority to shape the physical space in which the technologies operate. A notable exception is the ordinance proposed in Chicago, which would limit automated vehicles to permitted firms for test purposes. ${ }^{323}$ The law's sponsors cited cybersecurity concerns and potential job losses to automation as motivations. ${ }^{324}$ They had considered an outright ban but withdrew that proposal in light of Illinois' preemption of local AV regulations. ${ }^{325}$

As with cities, state lawmakers differ significantly in their approach to AVs. Although Professor Bryant Walker Smith has argued that AVs are generally legal on public roads, ${ }^{326}$ many states have passed legislation or issued executive orders regulating them in some way. According to the National Conference of State Legislatures, at the time of writing twenty-one states have enacted some form of autonomous vehicle legislation, and six more have relevant executive orders. ${ }^{327}$ A large majority of states (forty-one) have considered legislation since 2012. ${ }^{328}$

Five of these states, Illinois, Nevada, North Carolina, Tennessee, and Texas, have preempted municipal regulation of autonomous vehicles in their legislation. ${ }^{329}$ Illinois' law is the narrowest. It states that a city may not "enact an ordinance prohibiting the use of Automated Driving System equipped vehicles on its roadways. $" 330$ However, cities may still regulate AVs for "traffic control purposes." ${ }^{331}$ Nevada prohibits cities from singling out AVs for taxes, permits, or other requirements, but preserves the state's

${ }^{323}$ John Byrne, Aldermen Consider Tough Regulations for Self-Driving Cars, CHI. TRIB. (Aug. 22, 2017), http://www.chicagotribune.com/news/local/politics/ct-chicago-driverless-cars-regulations-met20170821-story.html. It appears that the proposal was tabled for further discussion without being officially introduced. Alderman Ed Burke argued in favor of a ban on driverless cars with a movie clip from Back to the Future. Brendan Bakala, Burke to the Future: Chicago Alderman Wants to Ban Self-Driving Cars, ILl. POL'Y (Aug. 23, 2017), https://www.illinoispolicy.org/burke-to-the-futurechicago-alderman-wants-to-ban-self-driving-cars/.

${ }^{324}$ Bakala, supra note 323.

${ }^{325} \mathrm{Id}$.

${ }^{326}$ See Bryant Walker Smith, Automated Vehicles Are Probably Legal in the United States, 1 TEX. A\&M L. REV. 411, 412 (2014) ("The short answer is that the computer direction of a motor vehicle's steering, braking, and accelerating without real-time human input is probably legal.").

327 Autonomous Vehicles: Self-Driving Vehicles Enacted Legislation, NAT'L CONF. ST. LEGISLATURES, http://www.ncsl.org/research/transportation/autonomous-vehicles-self-driving-vehicles -enacted-legislation.aspx (last updated Aug. 27, 2018).

${ }^{328} I d$.

${ }^{329}$ Michigan also prevents local governments from levying taxes on the networks used to summon AVs. Mich. VEH. CODE $§ 257.606 b(2)$ (1949).

330 ILL. VEH. CODE ch. 11, art. II, $\S$ 11-208(e), http://www.ilga.gov/legislation/ilcs/ilcs4 .asp?DocName $=062500050 \mathrm{HCh} \% 2 \mathrm{E}+11 \& \mathrm{ActID}=1815 \& \mathrm{Cha}$ pterID=49\&SeqStart=113800000\&SeqEnd=139300000 (through Pub. Act 101-123).

${ }^{331} \mathrm{Id}$. 
ability to collect a generally applicable business license fee. ${ }^{332}$ Presumably other generally applicable laws are permitted as well. North Carolina, Tennessee, and Texas have much broader preemption, prohibiting any "regulation" of AVs by cities altogether. ${ }^{333}$ In addition, cities in Dillon's Rule states would not have the authority to regulate AVs unless state legislatures expressly grant it. However, even Dillon's Rule cities would likely have authority over certain local concerns that impact AVs, such as zoning, lane placement, and other infrastructure management issues (such as whether to deploy smart infrastructure that can communicate with AVs).

Other state laws such as California's have not expressly preempted cities but vested regulatory authority in an administrative agency such as the Department of Motor Vehicles (DMV). ${ }^{334}$ This regulatory scheme could have the effect of creating implied preemption, with the DMV taking regulatory power out of the hands of cities. Mayors in San Francisco and Pittsburgh have expressed that this is likely the case, at least as far as being able to ban AVs completely. ${ }^{335}$ However, the scope of city authority in this regard has not been tested in court.

Massachusetts represents a more collaborative model by creating partnerships with the Massachusetts Department of Transportation (MassDOT), companies, and local governments. Executive Order 572 requires companies to enter into a Memorandum of Understanding (MOU) with the Agency and the cities where they will operate. ${ }^{336}$ MassDOT and participating cities in Massachusetts signed a separate MOU to establish a common application for AV companies, approve testing locations in the cities, and periodically review technical and policy advances in the AV space. ${ }^{337}$ Now, in order to put AVs on the road in one of the urban testbeds in Massachusetts (like Boston), a company must sign an MOU with the city and then complete a permit application with MassDOT. ${ }^{338}$ This process involves numerous commitments from companies, including standards for

\footnotetext{
${ }^{332}$ NEV. VEH. CODE ch. $482 \mathrm{~A}, \S 110$ (2017).

${ }^{333}$ N.C. GEN. Stat. § 20-401(i) (2017); TenN. Code AnN. § 55-30-105 (2017); TeX. TRANSP. CODE $§ 545.452$ (b) (2017).

${ }^{334}$ CAL. VEH. CODE $§ 38750$ (2012).

${ }^{335}$ Joe Fitzgerald Rodriguez, Mayor Calls on Self-Driving Car Companies to Agree to Voluntary SF Safety Test, S.F. EXAMINER (Mar. 8, 2018), http://www.sfexaminer.com/mayor-calls-self-drivingcar-companies-agree-voluntary-sf-safety-tests/; Timothy B. Lee, Uber Wants to Test Driverless Cars in Pittsburgh Again-The Mayor Is Pissed, ARS TECHNICA (May 24, 2018), https://arstechnica.com/ cars/2018/05/uber-wants-to-test-driverless-cars-in-pittsburgh-again-the-mayor-is-pissed/.

${ }^{336}$ Exec. Order No. 572, To Promote the Testing and Deployment of Highly Automated Driving Technologies (2016), https://www.mass.gov/files/documents/2016/11/pg/eo572.pdf.

${ }^{337}$ Memorandum of Understanding to Facilitate Testing of Autonomous Vehicles, MAssDOT (June 21, 2018), http://www.mapc.org/wp-content/uploads/2018/06/Final_AV-MOU.for_.Signing_6-2118_.pdf.

${ }^{338}$ Autonomous Vehicles: Boston's Approach, CITY Bos., https://www.boston.gov/departments/ new-urban-mechanics/autonomous-vehicles-bostons-approach (last updated Oct. 28, 2019).
} 
safety drivers, compliance with vehicle safety standards, data sharing, and more. ${ }^{339}$ Although Massachusetts' approach is standardized across different cities, it appears to be the result of collaboration between the state and local levels rather than dictated from the top. Further, at this stage, cities with no wish to allow AV testing on their roads have no obligation to enter into the MOU.

Existing federal guidance and proposed laws envision a dominant and preemptive role for federal regulation of AVs. The National Highway Traffic Safety Administration's (NHTSA) guidance contemplates a dominant role for federal regulators as compared to states. ${ }^{340}$ The U.S. Department of Transportation has convened a series of meetings aimed at reducing regulatory barriers and promoting autonomous vehicle technology. ${ }^{341}$ NHTSA solicited comments from the public "to identify any regulatory barriers in the existing [Federal Motor Vehicle Safety Standards] to the testing, compliance certification, and compliance verification" of autonomous vehicles. ${ }^{342}$ Fatal and non-fatal accidents involving AVs have spurred investigations by the National Transportation Safety Board (NTSB). ${ }^{343}$

In Autonomous Driving Systems 2.0: A Vision for Safety, NHTSA "strongly encourages States to allow [the U.S. Department of Transportation] alone to regulate the safety design and performance aspects of $[\mathrm{AV}]$ technology. If a State does pursue [AV] performance-related regulations, that State should consult with NHTSA." ${ }^{444}$ The Agency lists state responsibilities as: (1) "[1]icensing human drivers and registering motor vehicles in their jurisdictions"; (2) "[e]nacting and enforcing traffic laws and regulations"; (3) "[c]onducting safety inspections, where States choose to do so"; and (4) "[r] egulating motor vehicle insurance and liability." 345

Federal legislation that has passed in the House contains broad preemption language that would prevent states and cities from regulating

\footnotetext{
${ }^{339}$ Template MOU for Autonomous Vehicle Testing in Boston, supra note 316.

${ }^{340}$ It was a federal agency that kickstarted the development of AVs. The Defense Advanced Research Projects Agency (DARPA) Grand Challenge is considered to have set off the current boom in AV research and development. Alex Davies, Inside the Races that Jump-Started the Self-Driving Car, WIRED (Nov. 10, 2017), https://www.wired.com/story/darpa-grand-urban-challenge-self-driving-car/.

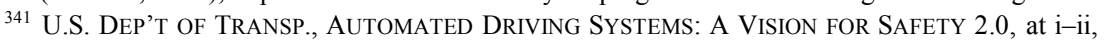
https://www.transportation.gov/AV (last updated Feb. 27, 2019).

${ }^{342}$ Removing Regulatory Barriers for Vehicles With Automated Driving Systems, 83 Fed. Reg. 2607 (Jan. 18, 2018) (to be codified at 49 C.F.R. § 571).

${ }^{343}$ Ryan Beene \& Alan Levin, U.S. NTSB Opens Probe of Second Tesla Autopilot Crash, BLOOMBERG (Jan. 23 2018, 4:49 PM), https://www.bloomberg.com/news/articles/2018-01-23/u-ssafety-board-opens-probe-of-second-tesla-autopilot-crash; Megan Rose Dickey, Uber's Fatal SelfDriving Car Crash Prompts NTSB Investigation, TECHCRUNCH (Mar. 19, 2018), https://techcrunch.com/2018/03/19/ubers-fatal-self-driving-car-crash-prompts-ntsb-investigation/.

${ }^{344}$ U.S. DEP'T OF TRANSP., supra note 341, at 20.

${ }^{345} \mathrm{Id}$. (The relevant section in the 2016 guidance under Obama was functionally the same).
} 
autonomous vehicles. The SELF DRIVE Act contains the following preemption language:

No State or political subdivision of a State may maintain, enforce, prescribe, or continue in effect any law or regulation regarding the design, construction, or performance of highly automated vehicles, automated driving systems, or components of automated driving systems unless such law or regulation is identical to a standard prescribed under this chapter. ${ }^{346}$

A "political subdivision of a State" refers to cities and local governments, as cities typically derive their police power from the state. ${ }^{347}$ The bill allows cities and states to maintain laws related to "registration, licensing, driving education and training, insurance, law enforcement, crash investigations, safety and emissions inspections, congestion management of vehicles on [state or city streets], or traffic unless the law or regulation is an unreasonable restriction on the design, construction, or performance" of autonomous vehicles. ${ }^{348}$ Companies say that this preemption language is necessary to avoid a patchwork of regulation that will hinder innovation, but it has drawn criticism from safety and consumer advocacy groups and state governments. ${ }^{349}$

The Senate AV START Act, which is still pending as of writing, originally had the same language as the House version. However, it has been amended to read: "No State or political subdivision of a State may adopt, maintain, or enforce any law, rule, or standard regulating the design, construction, or performance of a highly automated vehicle or automated driving system with respect to any of the safety evaluation report subject areas described in section 30107(b). ${ }^{, 350}$ This language is less broad than the House bill and preserves some powers specifically for state and local governments:

Nothing in this paragraph may be construed to prohibit a State or political subdivision of a State from maintaining, enforcing,

\footnotetext{
${ }^{346}$ SELF DRIVE Act, H.R. 3388, 115th Cong. § 3(b) (2017) (emphasis added).

${ }^{347} I d . \S 13$.

${ }^{348} I d . \S 3(\mathrm{~b})$.

${ }^{349}$ David Alpert, Have Senators? Ask Them to Let Cities and States Shape How Autonomous Vehicles Affect Us All, GREATER GREATER WASH. (Oct. 3, 2017), https://ggwash.org/view/65027/havesenators-let-cities-and-states-shape-autonomous-vehicles-avs-affect-us-preemption-congress; Tina Bellon, U.S. Push for Self-Driving Law Exposes Regulatory Divide, REUTERS (Sept. 15, 2017), https://www.reuters.com/article/us-autos-selfdriving-analysis/u-s-push-for-self-driving-law-exposesregulatory-divide-idUSKCN1BQ24J; Andrew J. Hawkins, Congress Is About to Hand Over the Keys to the Big Self-Driving Car Companies-And That's a Problem, VERGE (July 19, 2017), https://www.theverge.com/2017/7/19/15998356/self-driving-car-congress-legislation-lobbying-safety.

${ }^{350}$ S. 1885 , 115 th Cong. § 3(a)(3)(A) (2017).
} 
prescribing, or continuing in effect any law or regulation regarding the sale, distribution, repair, or service of highly automated vehicles, automated driving systems, or components of automated driving systems by a dealer, manufacturer, or distributor. ${ }^{351}$

However, one of the preempted subjected areas in section 30107(b) is the "expected operational design domain" of AVs. ${ }^{352}$ This means that the AV START Act preempts cities and states with respect to "any roadway and infrastructure assets required for the operation of the highly automated vehicle or automated driving system, such as roadside equipment, pavement markings, signage, and traffic signals, and how it will respond if that operational design domain unexpectedly changes." ${ }^{353}$ By extending the meaning of "design, construction, or performance" to the AV's operational domain, the ambit of the AV START Act's preemption is potentially very broad.

Both state and federal preemption of cities in the area of AV regulation are likely to be significant constraints of city authority. An exhaustive analysis of every state's constitutional scheme regarding home rule versus Dillon's Rule is beyond the scope of this Paper, but state laws that expressly preempt city AV laws will face few if any limitations. As noted above, several states expressly prohibit cities from regulating AVs in any form. Even without express language, cities may still be limited by implied preemption by state AV statutes. California's approach is an example of implied preemption effectively limiting cities. Because California DMV regulations allow AVs on the state's public roads, cities there are powerless to ban AV access on their streets. ${ }^{354}$ Such a ban would likely conflict with state law and, therefore, be preempted. However, there are many forms of regulation that fall short of an outright ban. Suppose cities wanted to create certain AV-free zones near public parks or impose lower AV speed limits. Or, perhaps the cities wanted to pass a rule requiring AVs to always yield to pedestrians. If courts apply broad field preemption or its functional state law equivalent, then cities will be foreclosed from doing so. If courts instead construe statutes narrowly and apply conflict preemption, then cities will have more control over their public rights-of-way. Imagine if a legislature mandated the creation of AV hyperlanes, as some in Washington State have advocated. Such a mandate could take important local decisions about street and sidewalk allocation and design out of the hands of the places that are most impacted.

\footnotetext{
${ }^{351} I d . \S 3(\mathrm{a})(3)(\mathrm{C})$.

${ }^{352} I d . \S 9$ (a).

${ }^{353} \mathrm{Id}$.

${ }^{354}$ California regulations do require firms to submit law enforcement interaction plans to cities, so there is some coordination built into the law. CAL. DEP'T OF MOTOR VEHICLES, ORDER TO ADOPT $\S 227.38(\mathrm{e})(2017)$
} 
State preemption could also deprive cities of important sources of revenue that may be lost as AVs transform the tax base of cities. If widespread AV fleets eliminate urban parking, as some have predicted, then cities will lose a significant source of revenue. Cities wishing to levy a tax on AVs to make up for this loss in Nevada, North Carolina, Tennessee, or Texas would be barred from doing so.

Proposed federal AV legislation would also create a great deal of uncertainty for cities. The SELF DRIVE Act's prohibition against "unreasonable" restrictions on AV "design, construction, or performance" could be read quite broadly, especially because it applies to congestion management and traffic laws. ${ }^{355}$ If constantly roaming AV fleets lead to an increase in miles traveled, traffic congestion, and urban sprawl as some predict, ${ }^{356}$ then cities would naturally want to enact policies to combat these problems. Is surge or congestion pricing aimed at AVs an "unreasonable restriction"? An AV company looking for a sword to wield against cities certainly might think so. As discussed above, the AV START Act is narrower than SELF DRIVE, ${ }^{357}$ but the meaning of the term "performance" presents a possible problem for cities. Some AVs can communicate with smart infrastructure and may even rely on these vehicle-to-infrastructure (V2I) capabilities to some extent. ${ }^{358}$ However, installing smart infrastructure can be expensive and time consuming. It is at least arguable that a city that refuses to install the "I" of V2I capabilities is hindering the performance of an AV. This interpretation is bolstered by the bill's definition of the "expected operational design domain," which includes infrastructure. Even "dumb" infrastructure impacts AV capabilities. For instance, many AVs have difficulty navigating traffic lanes that are faded or signs that are obscured. ${ }^{359}$ The locally built environment can be a significant factor in AV safety and performance, yet it is unclear whether and how AV START would constrain cities in this regard. Both laws may encroach on the traditional sphere of authority of cities if they are construed too broadly.

It is also unclear how state privacy rules might fare under federal preemption language in the AV START and SELF DRIVE Acts. The House bill currently requires companies to formulate a privacy policy for

${ }^{355}$ SELF DRIVE Act, H.R. 3388, 115th Cong. § 3(1) (2017).

${ }^{356}$ Sarah J. Fox, Planning for Density in a Driverless World, 9 NE. U. L. REV. 151, 166-68 (2017); Jacques Leslie, Will Self-Driving Cars Usher in a Transportation Utopia or Dystopia, YALE ENV'T 360 (Jan. 8, 2018), https://e360.yale.edu/features/will-self-driving-cars-usher-in-a-transportation-utopia-ordystopia.

${ }^{357}$ See supra note 350 and surrounding discussion (explaining that the AV START Act is narrower than SELF DRIVE).

${ }^{358}$ Conner Forrest, The X-Factor in Our Driverless Future: V2V and V2I, ZDNET (Feb. 1, 2018), https://www.zdnet.com/article/the-x-factor-in-our-driverless-future-v2v-and-v2i/.

${ }^{359}$ Alexandria Sage, Where's the Lane? Self-Driving Cars Confused by Shabby U.S. Roadways, REUTERS (Mar. 31, 2016), https://www.reuters.com/article/us-autos-autonomous-infrastructureinsig/wheres-the-lane-self-driving-cars-confused-by-shabby-u-s-roadways-idUSKCNOWX131. 
automated vehicles. ${ }^{360}$ Having a policy will open companies to enforcement action by the FTC if they break the promises contained therein. ${ }^{361}$ State attorneys general may bring similar actions under state law. However, some states have substantively stricter privacy rules that may create an "unreasonable restriction" on automated vehicles. For example, laws against collection of biometric data in Texas, Illinois, and Washington could interfere with facial recognition capabilities in automated vehicles. ${ }^{362}$

In December of 2018, The Verge reported that the Senate was working to pass an updated version of AV START. ${ }^{363}$ The outlet reported that the proposed amendments, which were not made public, would have addressed some privacy, safety, and consumer protection issues, but made no mention of the preemption issues discussed above. ${ }^{364}$ As of this writing, the bill has not passed in the Senate, but advocates continue to lobby Congress for national AV legislation. ${ }^{365}$

\section{Delivery Robots}

Cities have also been at the forefront of experimenting with delivery robots. Several cities, including Washington, D.C., Austin, Texas, and a few cities in the San Francisco Bay Area, have created pilot programs either through partnerships with firms or by passing ordinances to allow delivery

${ }^{360}$ See SELF DRIVE Act, H.R. 3388, 115th Cong. § 12 (2017) (requiring manufacturers of highly automated vehicles to, among other things, develop and notify vehicle occupants of privacy plans and commissioning a Federal Trade Commission study on privacy issues in the highly automated vehicle marketplace).

${ }^{361} I d$.

${ }^{362}$ Texas' and Illinois' laws have already prevented a Google facial recognition app from running in both states. Melissa Locker, Google's Art Selfie App Not Working in Texas or Illinois? Thank Tricky Biometric Laws, FAST COMPANY (Jan. 18, 2018), https://www.fastcompany.com/40518224/googles-artselfie-app-not-working-in-texas-or-illinois-thank-tricky-biometric-laws. However, Google prevailed in one lawsuit about whether using photos to train its facial recognition algorithm violated the Illinois law. Rivera v. Google Inc., 366 F. Supp. 3d 998, 1001 (N.D. Ill. 2018). The judge found that the plaintiffs suffered no injury and so he had to dismiss the case. Id. Other cases based on the Illinois law are pending. Shannon Liao, Google Wins Dismissal of Facial Recognition Lawsuit Over Biometric Privacy Act, VERGE (Dec. 29, 2018), https://www.theverge.com/2018/12/29/18160432/google-facial-recognitionlawsuit-dismissal-illinois-privacy-act-snapchat-facebook. Both a federal district court in San Francisco and the Illinois Supreme Court have recently ruled that plaintiffs do not need to show monetary damages to succeed in a lawsuit based on the Illinois statute: the violation of substantive privacy rights represented in the statute are enough to proceed with a lawsuit. In re Facebook Biometric Info. Privacy Litig., No. 3:15-cv-03747-JD, 2018 WL 2197546, at *2 (N.D. Cal. May 14, 2018); Rosenbach v. Six Flags Entm't Corp., 2019 IL 123186, at*10 (Ill. Jan. 25, 2019). Washington's law was recently enacted in 2017. H.B. 1493, 65th Leg., 2017 Reg. Sess. (Wash. 2017).

${ }^{363}$ Makena Kelly, America's First Self-Driving Car Bill Gets Last Minute Push from Congress, VERGE (Dec. 3, 2018), https://www.theverge.com/2018/12/3/18124750/av-start-act-congress-us-firstself-driving-car-bill-tesla-gm.

${ }^{364} \mathrm{Id}$.

${ }^{365}$ Maggie Miller, Advocates Rally on Capitol Hill for Self-Driving Car Legislation, HILL (Dec. 3, 2019, 5:48 PM), https://thehill.com/policy/cybersecurity/472889-advocates-rally-on-capitol-hill-forself-driving-car-legislation. 
robots. ${ }^{366}$ The Austin ordinance is public, and Redwood City has published its partnership agreement along with reports on the pilot. ${ }^{367}$ These laws and agreements tend to follow the same pattern. They define where the robots may operate (on sidewalks, not on highways) and create a permitting system for firms to gain permission to test the robots. ${ }^{368}$ They also define certain parameters for the robot, such as the maximum weight and speed, and impose certain safety requirements, such as not to interfere with pedestrians or bicycles. ${ }^{369}$ Not every city is so welcoming, however. San Francisco passed an ordinance that heavily regulates personal delivery devices (PDDs). ${ }^{370}$ The law requires a permit for each robot being tested and limits the total number of permits to nine at any given time. ${ }^{371}$ It also requires a human operator be present at all times and limits testing to industrially zoned areas away from high traffic. ${ }^{372}$ The law was said to be motivated by safety concerns, although media reports say the legislator who introduced the ordinance originally considered an outright ban. ${ }^{373}$

State and federal regulation of delivery vehicles is more nascent than laws for autonomous vehicles and more permissive for cities. As of writing, eight states have enacted laws to specifically allow and regulate delivery robots: Florida, Idaho, Ohio, Virginia, Wisconsin, Arizona, Utah, and

${ }^{366}$ Austin, Tex., Resolution 20170810-12 (Aug. 10, 2017); Redwood City, Cal., Conditions of Approval for Personal Delivery Device "PDD" Use Permit (Nov. 13, 2017); Lonsdorf, supra note 38.

${ }^{367}$ Austin, Tex., Resolution 20170810-12 (Aug. 10, 2017); Redwood City, Cal., Conditions of Approval for Personal Delivery Device “PDD” Use Permit (Nov. 13, 2017).

${ }^{368}$ Austin, Tex., Resolution 20170810-12, at*1-2 (Aug. 10, 2017) (limiting Personal Delivery Robotic Device operation to sidewalks); Redwood City, Cal., Conditions of Approval for Personal Delivery Device “PDD” Use Permit (Nov. 13, 2017) (establishing a permit system for Personal Delivery Devices and limiting their operation to sidewalks).

${ }^{369}$ Austin, Tex., Resolution 20170810-12, at*2-3 (Aug. 10, 2017); Redwood City, Cal., Conditions of Approval for Personal Delivery Device "PDD" Use Permit (Nov. 13, 2017).

370 S.F., CAL., PUB. WORKS CODE $\S 794$ (Jan. 21, 2018). For a general discussion of the San Francisco permit system, see Autonomous Delivery Devices, S.F. PUB. Works, https://sfpublicworks.org/services/permits/autonomous-delivery-devices.

${ }^{371}$ S.F., CAL., PUB. WORKS CODE § 794(b), (d)(3) (2018).

${ }^{372}$ Id. $\S 794(\mathrm{i})$.

${ }^{373}$ See Adam Brinklow, San Francisco Bans Robots From Most Sidewalks, CuRBED S.F. (Dec. 6, 2017), https://sf.curbed.com/2017/12/6/16743326/san-francisco-delivery-robot-ban (explaining that Board of Supervisors member Norman Yee previously wanted to ban delivery robots altogether "to protect public space from encroachment by private companies"); Brian Heater, San Francisco Made Things Much Tougher for Robotic Delivery Startups This Week, TECHCRUNCH (Dec. 7, 2017), https://techcrunch.com/2017/12/07/san-francisco-made-things-much-tougher-for-robotic-deliverystartups-this-week/ (explaining that Board of Supervisors member Norman Yee's initial language "was more akin to an outright ban" on delivery robots). 
Washington. ${ }^{374}$ Each state allows cities to pass their own PDD regulations or safety requirements, a marked difference from state AV laws. ${ }^{375}$

There is currently no federal law directly addressing PDDs. It is possible that the SELF DRIVE and AV START Acts could apply to PDDs, though that is far from clear. Both laws refer to section 30102 of chapter 49 of the U.S. Code, which defines a motor vehicle as "a vehicle driven or drawn by mechanical power and manufactured primarily for use on public streets, roads, and highways, but does not include a vehicle operated only on a rail line. ${ }^{\prime 376}$ While this definition arguably does not apply to PDDs that operate primarily on sidewalks, it could apply to larger delivery robots that operate on city streets.

At least for the moment, cities can regulate PDDs as they wish, free from preemption at the state or federal level. One interesting phenomenon is that we have not found any active PDD pilot programs in cities where the state has passed a PDD enabling law, even though the laws in each state explicitly allow cities to regulate PDDs for safety or, in some cases, ban them outright. It could be that pilot programs are simply not necessary where state law has already cleared the way for PDDs to operate on city streets. However, it is curious that no cities in states with PDD laws have created their own institutional arrangements for this technology on their streets. It is possible that state laws have inhibited cities' independent regulation of PDDs by signaling the priorities of state legislatures.

\section{Security and Entertainment}

Security robots have thus far escaped the attention of state and federal regulators. This is probably due to the fact that they are mostly operated on private property by private actors. Or perhaps they are simply less widespread or seen as disrupting a less vital industry than transportation or last-mile delivery. Should they evolve into government-controlled police robots, they will warrant greater regulation by state and federal actors. Professor Elizabeth Joh has predicted such a development and called for "uniform national policies" for police robots, such as the use of conditions

\footnotetext{
${ }^{374}$ C.S./H.B. 1027, 2017 Leg. § 2 (Fla. 2017); H.B. 204, 64th Leg., 1st Reg. Sess. § 3 (Idaho 2017); H.B. 49, 132d Gen. Assemb. § 4511.513(B) (Ohio 2017); S. 1207, 2017 Sess. § 46.2-908.1:1 (Va. 2017); S.B. 148, 2017 Wis. Act $13 \S 30$ (Wis. 2017); H.B. 2422, 53d Leg., 2d Reg. Sess. 33 (Ariz. 2018); H.B. 217, 2018 Gen. Sess. § 2(2) (Utah 2018); H.B. 1325, 66th Leg., Reg. Sess. § 2 (Wash. 2019).

${ }^{375}$ C.S./H.B. 1027, 2017 Leg. § 3 (Fla. 2017); H.B. 204, 64th Leg., 1st Reg. Sess. § 3 (Idaho 2017); H.B. 49, 132d Gen. Assemb. § 4511.513(B) (Ohio 2017); S. 1207, 2017 Gen. Assemb., 2017 Sess. § 46.2-908.1:1 (Va. 2017); S.B. 148, 2017 Wis. Act $13 \S 32$ (Wis. 2017); H.B. 2422, 53d Leg., 2d Reg. Sess. § 2 (Ariz. 2018); H.B. 217, 2018 Gen. Sess. § 2(2) (Utah 2018); H.B. 1325, 66th Leg., Reg. Sess. $\S 2$ (Wash. 2019).

37649 U.S.C. $\S 30102(a)(6)$ (2012).
} 
or strings attached to federal procurement grants to require that police departments enact policies governing the use of robotic force. ${ }^{377}$

As with the state and federal levels, security robots are largely unregulated at the city level as well. San Francisco is again a notable exception. In a widely publicized incident, residents complained about a Knightscope robot being used to chase off homeless people in the frontage space and parking area of a local Society for the Prevention of Cruelty to Animals (SPCA) animal shelter in the Mission district. ${ }^{378}$ The city's Department of Public Works demanded the SPCA cease using the robot because it was traversing public sidewalks. ${ }^{379}$ The source of the Department's authority is unclear and has not been publicly disclosed.

There has also been local action that would impact police use of robots. A member of the Board of Supervisors of San Mateo County drafted a resolution calling on Congress and the United Nations to ban killer robots, although he later withdrew it and the Board agreed to study the issue further. ${ }^{380}$ More substantively, Santa Clara County and the cities of Oakland, Berkeley, and Seattle have passed surveillance ordinances requiring citizen approval before police departments acquire new surveillance equipment. ${ }^{381}$ Cities could easily use their proprietary power over municipal police departments to regulate vendor agreements with the makers of any future police robots, even in the absence of a surveillance ordinance. ${ }^{382}$

As with security robots, entertainment robots are currently unregulated at all levels. This may be just as well, as most have not even been deployed in commerce yet. In some cases, the regulations for PDDs may apply, such as with Gita, the droid designed to "carry a case of wine." "383 Segway has

${ }^{377}$ Elizabeth E. Joh, Policing Police Robots, 64 UCLA L. REV. DISC. 516, 541 (2016).

${ }^{378}$ Sarah Buhr, Security Robots Are Being Used to Ward Off San Francisco's Homeless Population, TECHCRUNCH (Dec. 13, 2017), https://techcrunch.com/2017/12/13/security-robots-are-being-used-toward-off-san-franciscos-homeless-population/.

${ }^{379}$ Alisha Green, Security Robot That Deterred Homeless Encampments in the Mission Gets Rebuke from the City, S.F. BuS. TIMES (Dec. 8, 2017), https://www.bizjournals.com/sanfrancisco/news/ 2017/12/08/security-robot-homeless-spca-mission-san-francisco.html.

${ }^{380}$ David J. Canepa, Stop Killer Robots by San Mateo County Supervisor, David J. Canepa, COUNTY SAN MATEO BD. SUPERVISORS (Dec. 15, 2017), https://bos.smcgov.org/blog/2017-12-19/stopkiller-robots-san-mateo-county-supervisor-david-j-canepa (“So, my office drafted . . . a resolution calling on the United States Congress to adopt national laws and policies restricting the development and use of fully autonomous weapons and the United Nations to develop an international agreement restricting the development and use of such weapons.").

${ }^{381}$ Santa Clara County, Cal., Code OF ORdinance $§$ A40-2 (2019); OAKLand, Cal., Code of ORdinance $§ 9.64 .030$ (2019); Berkeley, Cal., Municipal Code $§ 2.99 .030$ (2019); SEATtLe, WASH., MUNICIPAL CODE $§ 14.18 .020$ (2019).

${ }^{382}$ Briffault et al., supra note 287, at 4. But see Elizabeth E. Joh, The Undue Influence of Surveillance Technology Companies on Policing, 92 N.Y.U. L. REv. 101, 102 (2017), available at http://www.nyulawreview.org/sites/default/files/Joh-FINAL_0.pdf (arguing that police and policing policy are actually subject to significant influence and control wielded by surveillance technology companies).

${ }^{383}$ Ian Bogost, The Cute Robot That Follows You Around the City, ATLANTIC (Feb. 28, 2018), 
also marketed package delivery as a possible use case for Loomo. ${ }^{384}$ Loomo's ability to carry people may qualify it to operate on city sidewalks as a type of personal mobility device under state law. Officials in the city of Austin speculated this would be true under Texas law. ${ }^{385}$ It is possible that as these types of urban robots proliferate, new laws may be proposed, but it is a little premature to speculate now.

\section{Drones}

Drones are a unique case for this Paper because they fly, and are therefore regulated by the Federal Aviation Administration, and because they have applications that cut across the categories of urban robots we have explored thus far. Autonomous drones that are large enough to fit a person could serve as a type of flying robotic taxi, while last-mile drone delivery has been a goal of companies (especially Amazon) for some time. ${ }^{386}$ Startup companies are working on security drones to monitor property, an aerial version of Knightscope, ${ }^{387}$ and the recreational drone was the "hot holiday gift" of 2016 and 2017. ${ }^{388}$ One research project even proposes to use drones to repair urban infrastructure. ${ }^{389}$ Drone use cases extend to several other fields such as construction and surveying, agriculture, and the military, but the four categories of urban robotics are what interest us here.

Of all of these technologies, drones have seen the most local legislative action. This may be because domestic drones hit the market earlier than other forms of robotics or because drones incited a more visceral reaction in the public (serving as a "privacy catalyst"). ${ }^{390}$ The National League of Cities cites Chicago's drone ordinance, passed in November 2015, as one of the

https://www.theatlantic.com/technology/archive/2018/02/piaggio-gita-jeffrey-schnapp/554222/.

384 See Loomo, SEGWAY RoBOTICS, https://web.archive.org/web/20180309082600/https://www.segwayrobotics.com/loomoGo (last visited Feb. 8, 2020) (describing the Loomo's delivery function). The marketing materials have changed several times since this original advertisement however.

385 Memorandum from Robert Spillar, Dir., Austin Transp. Dep't, Staff Response to Council Resolution No. 20170504-039 Robotic Delivery Model 3 (June 8, 2017), available at http://www.austintexas.gov/edims/pio/document.cfm?id=278182.

386 AMAZON PRIME AIR, REvising the Airspace Model for the SAFE INTEgRATION OF UNMANNED AIRCRAFT SYSTEMS 1 (2015)

${ }^{387}$ E.g., APTONOMY AERIAL SECURITY, http://www.aptonomy.com/ (last visited Aug. 30, 2018); NiGHTINGALE SECURITY, https://www.nightingalesecurity.com/ (last visited Aug. 30, 2018).

${ }^{388}$ John Cropley, Drones Expected to Be Popular Gift Again in 2017, DaILy GazeTTE (Nov. 24, 2017), https://dailygazette.com/article/2017/11/24/drones-expected-to-be-popular-gift-again-in-2017.

${ }^{389}$ Linda Poon, Drones Do the Dirty Work in a "Self-Repairing City", CiTYLAB (Oct. 20, 2015), https://www.citylab.com/life/2015/10/in-a-self-repairing-city-drones-do-the-dirty-work-ofinfrastructure-maintenance/411526/.

${ }^{390}$ M. Ryan Calo, The Drone as Privacy Catalyst, 64 StAn. L. REV. OnLine 29, 30-32 (2011) (arguing that the potential of drones to conduct surveillance in ways that grossly violate normative concepts of privacy will spur social and legal opposition). 
first comprehensive drone laws in a major city. ${ }^{391}$ The ordinance places a number of prohibitions on drone flights, such as: flying directly over a person or private property without consent; flying over a school, hospital, place of worship, prison, or police station; flying outside visual line of sight; flying between dusk and dawn; and flying for the purpose of surveillance. ${ }^{392}$ A 2017 study by the Center for the Study of the Drone found 133 local drone ordinances in 31 different states. ${ }^{393}$ The author found the most common rules to be restrictions against flying over public property or private property without the owner's consent. ${ }^{394}$

Cities may also enforce general regulations already on the books that can be applied to drones. Simple criminal matters involving a drone are within the scope of city power to regulate. An assault committed with a drone is still an assault. For instance, the city of Seattle successfully prosecuted a reckless endangerment case against a man who lost control of his drone and crashed it into a woman during the 2015 Pride Parade. ${ }^{395}$ Seattle has no law specific to drone endangerment; it simply prosecuted the man under Washington's reckless endangerment statute. ${ }^{396}$

Though there is a great deal of variety among state drone laws, many states have barred cities from regulating drones. According to the National Conference of State Legislatures, forty-one states have enacted laws relating to drones in some form and three more have adopted resolutions. ${ }^{397}$ State drone laws range from anti-peeping Tom or voyeurism laws (California), to designations of "critical" infrastructure that define the permissible airspace for drones (Nevada), to prohibitions on weaponizing drones (Oregon), to criminal sanctions on harming people or livestock (Utah). ${ }^{398}$ Several states

\footnotetext{
391 Nat'l League of Cities, Cities and Drones: What Cities Need to Know About UNMANNED AERIAL VEHICles (UAVs) 20 (2016), available at http://uavs.insct.org/wpcontent/uploads/2016/09/NLC-Drone-Report.pdf.

${ }^{392}$ CHI., ILL., MuNiCIPAL CODE $§ 10-36-400$ (b) (2019).

${ }^{393}$ Arthur Holland Michel, Drones at Home: Local and State Drone Laws, CTR. FOR STUDY DRONE BARD C., Mar. 2017, at 2.

${ }^{394} I d$.

${ }^{395}$ John-Michael Seibler \& Jason Snead, Seattle Case Shows Why Drone Regulation Should Be Local, Not Federal, DAILY Signal (Mar. 9, 2017), http://dailysignal.com/2017/03/09/seattle-caseshows-why-drone-regulation-should-be-local-not-federal/.

${ }^{396} \mathrm{Id}$. Seattle does have a proscription against flying motorized aircraft in public parks, but it was not at issue in that case. Seattle, Wash., Municipal CODE § 12.265 (2019).

${ }^{397}$ Current Unmanned Aircraft State Law Landscape, NAT'L CONF. ST. LEGISLATURES (Sept. 10, 2018), http://www.ncsl.org/research/transportation/current-unmanned-aircraft-state-lawlandscape.aspx.

${ }^{398}$ CAL. CIV. CODE $\S 1708.8$ (Westlaw through ch. 870 of the 2019 Reg. Sess.); Nev. Rev. STAT. $\S 493.020(2)$ (Westlaw through 80th Reg. Sess. 2019); OR. REV. STAT. § 837.365(1) (Westlaw through general effective legislation effective Jan. 1, 2020, enacted during the 2019 Reg. Sess. of the 80th Legis. Assemb.); Utah Code AnN. § 76-9-308(2)(c) (Westlaw through 2019 2d Special Sess.). See also Michel, supra note 393, at 2; Current Unmanned Aircraft State Law Landscape, supra note 397.
} 
have some kind of express preemption for local drone regulation. ${ }^{399}$ For instance, Florida prohibits a city from regulating the "design, manufacture, testing, maintenance, licensing, registration, certification, or operation" of a $\mathrm{UAV},{ }^{400}$ though cities may still enforce generally applicable laws that are not targeted at drones, such as nuisance, voyeurism, and reckless endangerment. ${ }^{401}$ Connecticut enumerates similar categories where cities are forbidden to regulate. ${ }^{402}$ By our count, ten other states preempt more broadly, prohibiting cities from enacting any regulation relating to drones except in very limited circumstances. ${ }^{403}$ Wyoming, however, takes a more collaborative approach, establishing a commission to promulgate rules in cooperation with the drone industry and local governments. ${ }^{404}$

Even with all the activity by cities and states, the federal government remains the principal regulator of drones, setting the rules that govern commercial drone operation. The Federal Aviation Administration (FAA) is the federal body charged by Congress to write rules to "safely accelerate the integration of civil unmanned aircraft systems into the national airspace system." " 05 The result is the "small unmanned aircraft systems [UAS] rule" codified in section 107 of chapter 14 of the Code of Federal Regulations. ${ }^{406}$ Section 107 applies to drones under fifty-five pounds and requires that recreational and commercial drone (also called UAS for Unmanned Aerial System) operators obtain a drone pilot certificate and register their drone with the FAA. ${ }^{407}$ The rules for safe operation also prohibit flying over 400 feet, flying over people, and flying outside visual line of sight of the operator. ${ }^{408}$ However, these safe operation rules can be waived with a "107

${ }^{399}$ Michel, supra note 393, at 2.

${ }^{400}$ FLA. STAT. ANN. $§ 330.41(3)$ (b) (Westlaw through 2019 1st Reg. Sess. of the 26th Legislature).

${ }^{401} I d . \S 330.41(3)(\mathrm{c})$.

402 ConN. Gen. StAT. AnN. $§ 7-149$ b (Westlaw through Public Acts enrolled and approved by the Governor on or before July 23, 2019 and effective on or before July 23, 2019).

${ }^{403}$ ARIZ. REV. STAT. ANN. § 13-3729(c) (Westlaw through 1st Reg. Sess. of the 54th Legis. 2019); Del. CodE ANN. tit. 11, $\S 1334$ (e) (Westlaw through ch. 37 of the 150th Gen. Assemb. 2019-2020); GA. CODE ANN. § 6-1-4(b) (Westlaw through 2019 Sess.); MD. CODE ANN., ECON. DEV. § 14-301(c) (Westlaw through legislation effective July 1, 2019 of the 2019 Reg. Sess.); MicH. COMP. LAWs ANN. $\S$ 259.305(5)(1) (Westlaw through P.A.2019, No. 47, of the 2019 Reg. Sess., 100th Legislature); N.J. STAT. ANN. § 2C:40-29 (Westlaw through L.2019, ch. 195 and J.R. No. 18); TEX. Gov'T CodE ANN. § 423.009(b) (2019 Reg. Sess. of the 86th Legislature); UTAH CODE ANN. § 72-14-103(1) (Westlaw through 2019 Gen. Sess.); VA. CODE. ANN. § 15.2-926.3 (Westlaw through 2019 Reg. Sess.); LA. STAT. ANN. § $2.2 \mathrm{~A}(2)$ (Westlaw through 2018 3d Extraordinary Sess.). Montana only prohibits cities from regulating drones in relation to wildfires. MONT. CODE ANN. § 7-1-111(20) (Westlaw through chapters effective July 1, 2019 of the 2019 Sess.).

${ }^{404}$ WyO. STAT. ANN. § 10-3-201(j) (Westlaw through 2019 Gen. Sess.).

${ }^{405}$ FAA Modernization and Reform Act, Pub. L. No. 112-095, § 332(a)(1), 126 Stat. 73 (2012).

${ }^{406}$ Small Unmanned Aircraft Systems, 14 C.F.R. pt. 107 (2019).

${ }^{407} 14$ C.F.R. $\S 107.3$ (2019). The registration requirement was struck down by a federal court in 2017 (Taylor v. Huerta, 856 F.3d 1089, 1090 (D.C. Cir. 2017)), but later reinstituted by Congress. National Defense Authorization Act of 2018, H.R. 2810, 115th Cong. § 1092(d) (2018).

${ }^{408} 14$ C.F.R. $\S 107.51$ (b) (2019). 
waiver" from the FAA. ${ }^{409}$ Legislation introduced in the Senate in 2017 directs the FAA to create an "air carrier certificate" for companies to conduct package delivery via drone. ${ }^{410}$ Congress' drone mandate made no mention of preemption, nor do the FAA regulations.

On January 14, 2019, the FAA announced new proposed rules that would allow some drone flights over people (especially important for flights over cities) and at night without the need for a waiver. ${ }^{411}$ Drones that could demonstrate certain safety features or that had certain design elements the FAA deemed safe, such as non-exposed rotors, may fly over people without prior authorization. ${ }^{412}$ The new rules do not seek to regulate privacy, which the FAA considers outside its mission. ${ }^{413}$

Proposed additional federal legislation seeks to clarify and preserve the authority of state and local governments to regulate drones. The Drone Federalism Act of 2017 directs the FAA to "ensure that the authority of a State, local, or tribal government to issue reasonable restrictions on the time, manner, and place of operation of a civil unmanned aircraft system that is operated below 200 feet above ground level or within 200 feet of a structure is not preempted." ${ }^{114}$ It also requires the FAA to receive permission from property owners before authorizing "the operation of a civil unmanned aircraft in the immediate reaches of the airspace above property." Congress has taken, or at least considered, a much more collaborative approach with states and cities for drones than for AVs.

Statements by the FAA and a recent federal district court case indicate that federal drone rules operate under conflict preemption, leaving room for states and cities to regulate so long as they do not conflict with federal law. In 2015, the FAA's Office of Chief Counsel issued a document that warned states and localities against creating a patchwork of rules that would hinder nationwide UAS safety, but listed examples of where states and localities would have authority to act. ${ }^{416}$ Examples include warrant requirements for

\footnotetext{
${ }^{409}$ Id. $\S 107.205$.

${ }^{410}$ Federal Aviation Administration Act of 2017, S. 1405, 115th Cong. § 2136 (2017).

411 DOT UAS Initiatives, FED. AVIATION ADMIN., https://www.faa.gov/uas/programs_partnerships/DOT initiatives/ (last visited Jan. 16, 2019).

412 Operation of Small Unmanned Aircraft Systems over People 2, Fed. Aviation Admin., https://www.faa.gov/uas/programs_partnerships/DOT_initiatives/media/2120-AK85_NPRM_ Operations_of_Small_UAS_Over_People.pdf (last visited Oct. 30, 2019).

${ }^{413}$ Id. at 149 . The Administration did conduct a privacy impact assessment as required by the Privacy Act, but it only addressed privacy issues with the rulemaking process, not the drones themselves. Office of the Chief Info. Officer, Privacy Impact Assessment: Small Unmanned Aircraft Systems Over People, U.S. DEP'T TRANSP. (Mar. 18, 2019), https://www.transportation.gov/sites/dot.gov/files/docs/ resources/individuals/privacy/334331/privacy-faa-suas-over-people-nprm-pia-approved-031819.pdf.

${ }^{414}$ Drone Federalism Act of 2017, S. 1272, 115th Cong. § 2(b)(1) (2017).

${ }^{415} I d . \S 3(\mathrm{a})$.

${ }^{416}$ OfFice of the Chief Counsel, Fed. Aviation Admin., State and Local Regulation of UNMANNED AIRCRAFT SYSTEMS (UAS) FACT SHEET 1-3 (2015), https://www.faa.gov/uas/resources/policy_library/media/UAS_Fact_Sheet_Final.pdf; see also Charles
} 
police use of drones and peeping Tom laws. ${ }^{417}$ The Agency also recently instituted a program for states, cities, and tribal authorities to partner with companies to bypass existing regulations more easily and experiment with advanced UAS applications at the local level. ${ }^{418}$

A recent court case also concluded that the FAA rules operated under conflict preemption, not field preemption. Singer $v$. Newton related to a city ordinance that sought to impose certain regulations on drone flight within the city. ${ }^{419}$ The city of Newton, Massachusetts passed a drone ordinance that applied to drone flights within the city limits. ${ }^{420}$ Michael Singer, an FAA-certified drone pilot who resides in Newton, challenged provisions that required drone operators to register with the city, banned flights over private property without the property owner's permission, banned flights over Newton city property without permission, and required visual line of sight flight. ${ }^{421}$ The ordinance also banned drone surveillance and interference with manned aircraft, but Singer only challenged the previous four provisions. ${ }^{422}$ $\mathrm{He}$ argued that air safety is normally solely regulated by the FAA, so field preemption should apply. ${ }^{423}$ However, Judge Young noted the FAA's statements about preserving some authority for state and local governments to regulate. ${ }^{424}$ At the same time, he concluded that the FAA had not created "an express carve-out for state and localities to regulate," but rather hinted that "whether parallel regulations are enforceable depends on the principles of conflict preemption." 425

The judge invalided each of the challenged provisions under conflict preemption. The FAA expressed its intent to be the "exclusive regulatory authority" for drones in the navigable airspace, and therefore the city's registration provision was invalid. ${ }^{426}$ The judge concluded that Newton's requirement that drone flights over private and public property first obtain permission was effectively a ban on drone flights over the city, which frustrated the FAA and Congress' intent to integrate drones into the

Raley, Local and State UAS Enforcement Authorities, FAA UAS SYMPOSIUM (2017), https://www.faa.gov/uas/resources/events_calendar/archive/2017_uas_symposium/media/Workshop_7

_Local_and_State_UAS_Enforcement_Authorities.pdf (providing examples of local enforcement).

${ }^{41 \overline{7}}$ OFFICE OF THE CHIEF COUNSEL, Fed. AviATION Admin., supra note 416, at 3.

${ }^{418}$ Alan Boyle, FAA Lays Out Process for Advanced Drone Operations, Giving a Lift to Amazon's Plans, GEEKWIRE (Nov. 2, 2017), https://www.geekwire.com/2017/faa-lays-process-advanced-droneoperations-giving-lift-amazons-plans/; UAS Integration Pilot Program, Program Overview, Fed. AVIATION ADMIN., https://www.faa.gov/uas/programs_partnerships/uas_integration_pilot_program/ (last updated Nov. 7, 2018).

${ }^{419}$ Singer v. City of Newton, 284 F. Supp. 3d 125, 126-27 (D. Mass. 2017).

${ }^{420} \mathrm{Id}$.

${ }^{421}$ Id. at $127-28$.

${ }^{422} I d$. at 128 .

${ }^{423} I d$. at 130 .

${ }^{424} \mathrm{Id}$.

${ }^{425} \mathrm{Id}$.

${ }^{426} I d$. at 131 . 
airspace ${ }^{427}$ Finally, the judge ruled that the line of sight rule impermissibly intervened "in the FAA's careful regulation of aircraft safety" because the FAA allows visual observers to augment line of sight flight or outright waivers of that requirement. ${ }^{428}$ The court's ruling makes sense given the FAA's policy statements about letting states and localities act in the drone space. However, it should stand as a warning against regulation that even seems like a ban on drones in the airspace. State or municipal attempts to regulate drone safety are especially suspect. ${ }^{429}$

Many city drone regulations would likely be preempted by either state or federal law, especially if they do not contain a savings provision. For instance, some of the Chicago provisions are similar to those overturned in Newton, namely the ban on flights over private property. ${ }^{430}$ However, the Chicago ordinance contains an exception for any flights authorized by federal or state law. ${ }^{431}$ It is important to note that this ordinance passed in 2015 , before the FAA promulgated its current regulations. The FAA currently allows waivers for flights outside visual line of sight, at night, or over populated areas, ${ }^{432}$ so without an exception allowing for such flights, the Chicago ordinance would almost certainly be preempted. A report by the Center for the Study of the Drone concluded that many of these city drone rules could conflict with federal or state laws. ${ }^{433}$ The Newton case may inspire others to challenge local drone ordinances, although the FAA was not involved in that case and has not yet challenged any such laws itself. The federal scheme relying on conflict preemption still leaves room for cities to regulate, however, as many local drone ordinances relate to privacy or trespass, which the FAA has deemed within the scope of local authority to act. $^{434}$

States with blanket prohibitions on city drone laws will naturally be much more constraining for cities. Cities will only be able to pass generally applicable laws that happen to include conduct by drones, such as reckless endangerment. The bounds of this authority are unclear and may need to be tested in court. For instance, a city might pass an ordinance that does not mention drones but defines trespass as causing an object to hover up to fifty feet over private property. Is this a generally applicable law or a back door into a drone ban?

${ }^{427} I d$. at $131-33$.

${ }^{428}$ Id. at $132-33$.

${ }^{429}$ Id. at 132 ("The Ordinance seeks to regulate the method of operating of drones, necessarily implicating the safe operation of aircraft. Courts have recognized that aviation safety is an area of exclusive federal regulation.").

${ }^{430}$ CHI., ILL., Mun. CODE $\S 10-36-400$ (b) (2019), http://ibrary.amlegal.com/nxt/gateway.dll/ Illinois/chicago $\mathrm{i} 1 /$ municipalcodeofchicago? $\mathrm{f}=$ templates $\$ \mathrm{fn}=$ default.htm $\$ 3.0 \$ \mathrm{vid}=$ amlegal $:$ chicago_il.

${ }^{431} I d . \S 10-36-400(\mathrm{c})$.

43214 C.F.R. $\S 107.205(\mathrm{c})(2019)$

${ }^{433}$ Michel, supra note 393, at 4, 6 .

${ }^{434} I d$. at 4 . There may be a tension between cities permissibly regulating trespass by drones and impermissibly banning flights over private property. 


\section{Preemption Can Interfere with Robotic and Environmental Design}

The preceding sections have shown how cities are playing an active role as testbeds of emerging robotics technologies and governance models. They have also shown that city authority in this area can be limited by both state and federal law and that the interplay of different levels of regulation can be complex and unclear. This Section argues that preemption at the state and federal levels will impact design decisions made about autonomous systems and the local built environment and may unintentionally foreclose some design choices, thereby stifling innovation.

The legal rules that govern urban robots will have consequences for autonomous systems and the urban built environment, and vice versa. For example, speed limits for automated vehicles or delivery robots will determine the machine's top speed. Or zoning laws will influence a neighborhood's use and character, including the design of public spaces and restrictions on the commingling of people with robotics. Laws that set a particular weight limit for machines enable some designs while foreclosing others. This very problem has occurred with some state delivery robot laws. Virginia's law defines a delivery robot as weighing under fifty pounds, but Marble, one of the main delivery robot startups, uses a machine that weighs over eighty pounds. ${ }^{435}$ Some accused Marble's competitor of writing the law to close off competition. ${ }^{436}$ A law that requires a robot to yield to pedestrians ${ }^{437}$ effectively requires the design of sensing and processing capabilities to achieve this end. On the other hand, laws that require people yield to robots could dramatically reshape environmental design. Such was the case with the advent of the automobile and jaywalking laws. ${ }^{438}$

Urban robotics, environmental design, and legal rules will likely interact in more indirect or diffuse ways that are nonetheless impactful on the local level. The placement of any future restricted automated vehicle "hyperlanes" could have significant opportunity costs by influencing the distribution of travel modes onto other transportation infrastructure. One major study has shown that ride-sharing apps increase traffic and reduce public transit ridership. ${ }^{439}$ This effect could get worse if the cost of automated vehicle

${ }^{435}$ VA. CoDE ANN. § 46.2-100 (Westlaw through 2019 Reg. Sess.); April Glaser, A Robot-Delivery Startup Helped Write State Laws That Are Locking Out Competition, ReCode (Apr. 22, 2017), https://www.recode.net/2017/4/22/15273698/robot-delivery-startup-starship-state-laws-lock-outcompetitors.

${ }^{436}$ Glaser, supra note 435.

${ }^{437}$ VA. CODE ANN. § 46.2-904 (Westlaw through 2019 Reg. Sess.).

${ }^{438}$ See Peter D. Norton, Street Rivals: Jaywalking and the Invention of the Motor Age Street, 48 TECH. \& CULTURE 331, 332 (2007) (describing the relationship between motorists and pedestrians).

${ }^{439}$ Regina R. Clewlow \& Gouri Shankar Mishra, U.C. Davis InSt. OF Transp. Studies, DisRuptive TRANSPORTATION: THE AdOPTION, UtilizATION, AND IMPACTS OF RIDE-HAILING IN THE UNITED STATES 27 (2017), https://itspubs.ucdavis.edu/wp-content/themes/ucdavis/pubs/ download_pdf.php?id=2752. 
ride-sharing plummets, and it further introduces the prospect, so evident today in cities with dockless car and bike share systems, of automated vehicles occupying streets and utilizing energy without passengers at all. In terms of long-term planning, it is important to consider that the provision of transportation infrastructure and services influences where people live in cities. $^{440}$ Transportation economists have long advocated for congestion pricing on roads to offset increases in miles traveled, and while this may be applied to automated vehicles, the need for increased density, specifically in public rights-of-way, highlights the need for other pricing structures, such as occupancy-based pricing for automated vehicles to promote shared vehicle and transit-scale systems. ${ }^{441}$ In all, there will likely be many unforeseen consequences to the proliferation of cheap, diffuse networks of last-mile logistics and public safety machines in the form of delivery and security robots, as well as automated vehicles for passengers and cargo.

Changes brought about by new technology often have consequences for environmental design and therefore need regulation that is sensitive to local context. Consider the impact of room sharing (Airbnb) on urban housing markets. While the anticipated death of the hotel business never came to pass, some research suggests that Airbnb contributes to housing shortages and drives up rents. ${ }^{42}$ This effect has been attributed to property owners permanently shifting their homes from the rental market to "private accommodations," and Airbnb has worked with local governments to combat this practice. ${ }^{443}$ This is just one example of technology's impact on local environmental design and legal rules, and more is in store as the industrial organization of the transportation sector shifts from the concentrated ownership of information technologies in today's sharing economy to more concentrated ownership of the mobile assets on the street.

State and federal laws that preempt cities on robotics may disrupt the natural interplay between the design of autonomous systems, urban environments, and local law, and so state and federal lawmakers should consider the local impacts of robotics laws and be wary of broad preemption. The controversy over the weight definition of PDDs locking out some models of PDDs is one example. ${ }^{444}$ Right now, the regulation in this space is still developing, but the chances of future conflict arise as more laws relating to automated vehicles are enacted. Proposals for exclusive automated vehicle highway lanes have already been floated to some state

${ }^{440} I d$. at 28.

${ }^{441}$ Fox, supra note 356 , at 194-95.

${ }^{442}$ Derek Thompson, Airbnb and the Unintended Consequences of 'Disruption', ATLANTIC (Feb. 17, 2018), https://www.theatlantic.com/business/archive/2018/02/airbnb-hotels-disruption/553556/.

${ }^{443} \mathrm{Id}$.

${ }^{444}$ Glaser, supra note 435. 
legislators. ${ }^{445}$ A proposed law in Illinois would require infrastructure updates for networked sensors that would collect vehicle and pedestrian traffic data and send it to automated vehicles. ${ }^{446}$ These laws are likely just the beginning. Further, there is a recent history of cities attempting to regulate these technologies, only to have states preempt them and reverse those rules. ${ }^{447}$ Advocates have also expressed concern over proposed federal automated vehicle laws that preempt "unreasonable restrictions" on these products. ${ }^{448}$ Not only could the law upset the regulatory balance between the federal government and states (and localities by extension), but the term "unreasonable restrictions" is seen as overly vague. ${ }^{449}$

In addition, legislating to specific verticals of robotics may prevent cities from planning holistically as technologies converge in robotics platforms. Consider the state laws enabling PDDs. Eight state laws allow PDDs and define them as "an electrically powered device that is operated on sidewalks, shared-use paths, and crosswalks and intended primarily to transport property" or something similar. ${ }^{450}$ This definition serves its purpose of providing explicit permission for delivery robots to operate within the state. It is written narrowly to cover delivery robots as they currently exist. ${ }^{451}$ However, new robots are already being marketed that can serve more than one function; they can be delivery robots, security robots, or personal mobility devices. ${ }^{452}$ What had previously been distinct categories of robot are beginning to converge into a multifunctional platform. If a

${ }^{445}$ Tom Banse, Dedicated Lanes on I-5 for Self-Driving Cars Get Ears of Washington State Officials, NW NEWS NETWORK (Oct. 17, 2017), http://nwnewsnetwork.org/post/dedicated-lanes-i-5self-driving-cars-get-ear-washington-state-officials; Rick Romell, Driverless Car Lanes on I-94 Being Studied for Foxconn, MilwaukeE J. Sentinel (Nov. 13, 2017), https://www.jsonline.com/story/ money/business/2017/11/13/driverless-vehicle-lanes-94-being-studied-foxconn/860515001/.

${ }^{446}$ Connected Multimodal Mobility Act, HB 2997, 100th Gen. Assemb. § 15 (Ill. 2017-2018), https://custom.statenet.com/public/resources.cgi?id=ID:bill:IL2017000H2997\&ciq=AsteigenHAV\&cli ent_md $=$ ff $84 \mathrm{cafdb} 9162 \mathrm{f} 7303 \mathrm{cc} 19 \mathrm{e} 4 \mathrm{a} 57 \mathrm{a} 9 \mathrm{a} 17 \&$ mode $=$ current_text. V2I communication will require a network protocol to communicate; so prematurely regulating V2I statewide could lock in certain network protocols over others.

${ }^{447}$ DUPUIS ET AL., supra note 303, at 3.

${ }^{448}$ Bellon, supra note 349.

${ }^{449} I d$.

${ }^{450}$ HB 2422, 53d Sess. (Ariz. 2018), https://legiscan.com/AZ/text/HB2422/id/1688912; CS/HB 1027, 2017 Leg. (Fla. 2017), https://www.flsenate.gov/Session/Bill/2017/1027/BillText/er/PDF; HB 204, 64th Leg., 1st Reg. Sess. (Idaho 2017), https://legislature.idaho.gov/wpcontent/uploads/sessioninfo/2017/legislation/H0204.pdf; HB 49, 132d Gen. Assemb. (Ohio 2017), https://www.legislature.ohio.gov/legislation/legislation-summary?id=GA132-HB-49; S. 1207, 2017 Sess. (Va. 2017), https://lis.virginia.gov/cgi-bin/legp604.exe?171+ful+CHAP0251; SB 148, 2017-2018 Wis. Leg. (Wis. 2017), http://docs.legis.wisconsin.gov/2017/related/acts/13. Washington and Utah's laws use a slightly different but similar definition. UTAH CODE ANN. § 41-6a-1119(1)(c) (Westlaw through 2019 2d Special Sess.); HB 1325, 66th Sess. (Wash. 2019).

${ }^{451}$ Except for Marble's robots, of course.

${ }^{452}$ Nick Lavars, Segway's Loomo Transporter Does Double Duty As a Robot, New ATLAS (Mar. 6, 2018), https://newatlas.com/segway-loomo-transporter-robot/53677/. 
machine can be both a delivery robot and a security device, which law applies? Does the applicable law change depending on how the robot is being used? Delivery robots are also defined as machines that operate on the sidewalk, but it is at least conceivable that engineers could build a robot that is equally capable of operating on both the sidewalk and the street. In fact, Bloomberg Philanthropies and the Aspen Institute categorize delivery robots as a type of automated vehicle. ${ }^{453}$ The convergence of delivery robots and automated vehicles could accelerate if cities redesign their streets for mixed robotic traffic, as some have suggested. ${ }^{454}$ So far, the states with PDD laws have left room for cities to act, although some are more permissive than others. For instance, Idaho allows cities to regulate PDDs for safe operation, ${ }^{455}$ but it is not clear how the Idaho law would handle the technological convergence described. This is another reason to allow cities the freedom to experiment and regulate accordingly.

There are of course some situations where regulatory certainty and uniform guidelines are warranted, and preemption may be the appropriate tool to achieve that policy end. We simply caution that when it comes to urban robots, preemption is a design issue in addition to a legal question.

\section{Federalism for Urban Autonomy}

This Section lays out specific recommendations for federal, state, and local authorities to craft their rules governing robots to avoid preemption interfering with local design.

Perhaps most pressingly, the preemption provisions of the SELF DRIVE and AV START Acts should be amended and clarified to preserve local authority over the built environment even when decisions about the environmental design have impacts on design or performance. The definition of "performance" specifications that are subject to preemption should not include the operational domain, i.e., the built urban environment. The AV START Act should include a specific exemption so that local governments are not preempted when regulating their own built environments that constitute the operational domain of AVs. A sunset provision for this exemption may be appropriate to reflect the fact that AVs are still in an experimental stage, but that stage will not last forever. The SELF DRIVE Act has already passed in the House, but it will likely need to be amended to resolve the differences with the AV START Act. SELF DRIVE's preemption language should be narrowed, and the authority of cities to act as sites of experimentation expressly recognized.

\footnotetext{
${ }^{453}$ Bloomberg Philanthropies \& ASPEn Inst., TAMing THE AUtonomous Vehicle: A Primer FOR CITIES 14-15 (2017), https://avsincities.bloomberg.org/downloads/Taming the Autonomous Vehicle.pdf; NACTO, supra note 5, at 49.

${ }^{454} \mathrm{NACTO}$, supra note 5 , at 8.

${ }^{455}$ IDAHO CODE ANN. § 49-605 (Westlaw through 2019 1st Reg. Sess. of the 65th Idaho Legislature).
} 
These changes are the minimum needed to preserve cities as sites of experimentation. An even better model to follow is the Drone Federalism Act and the FAA's own policy statements on preserving state and local authority in certain spheres. This approach could be combined with the Massachusetts model, which allows cities to coordinate and cooperate with state regulators and industry. This would allow cities to experiment to find the design and operational domain for AVs and the governance structures that best promote autonomous technology and the public good.

For other forms of urban robots, legislatures should expressly recognize and carve out authority for cities where the law impacts environmental design, including the deployment of related sensors and other information communication systems. States should recognize city home rule authority over environmental design and over system design to the extent it impacts environmental design. The state PDD laws that do this, especially Illinois', are a good model to follow. Again, FAA policy on state and local authority and the Massachusetts model for AVs are good approaches. Legislatures should consider the relative costs for firms and cities that preemption can create by forcing certain design parameters or precluding market competition. Robotics laws should work in the public interest and not force cities to bear socialized costs of system design.

Courts should recognize that local government design choices over their public rights-of-way are legitimate exercises of police power, not obstacles to federal rules that are meant to encourage the adoption of robots. They should define conflict in preemption cases related to robots narrowly. Choices about whether to offer robot fast lanes, whether to create designated robot zones, how to structure parking for shared robo-taxi fleets, and even how to price congestion to reduce traffic, all have a local character. Courts should only find preemption if it is clear that federal or state legislatures intended to preempt those design choices. This also means courts should avoid field preemption because broad readings of legislative intent will displace city prerogatives in local design.

Cities should not tempt fate by regulating so heavily that they draw a preemption challenge in court or inspire legislatures to act. ${ }^{456}$ Robotics ordinances should work with state and federal laws, not against them. Chicago was wise to create exceptions to its ordinance to avoid a preemption conflict.

Altogether, we advocate for true federalism in the system of robotics law. Cities should serve as the sites of experimentation for robotic system, environmental, and legal design. States can provide backstop rules that ensure cities act in the public interest, for example, by setting rules against

\footnotetext{
${ }^{456}$ The ACS notes that instances of punitive preemption, where state legislatures target cities to overturn specific laws, are on the rise. Briffault et al., supra note 287 , at 5.
} 
privacy harms or discrimination that could be exacerbated by robotics. ${ }^{457}$ They can also handle intrastate regional issues as they arise. The federal government can provide technical and regulatory guidance, issue grants, and, after the technology has had a chance to evolve through experimentation in cities, create rules for robots in interstate commerce. States and the federal government should adopt policies that limit or ban the practices that place cities in a race to the bottom. There are a growing number of proposals to balance deals between firms and cities in favor of the public interest, such as curtailing the use of non-disclosure agreements between cities and firms. ${ }^{458}$ Other policy tools will likely be relevant as well. For instance, there is a growing recognition that more vigorous antitrust enforcement may be necessary for large tech companies. ${ }^{459}$ As robotics firms seek to become indispensable service platforms providing everything from urban mobility to home delivery, state and federal antitrust regulators should watch carefully for similar antitrust concerns in physical urban spaces as in online spaces. Through careful, evidence-based policy, each level of government plays to its relative institutional strengths, ${ }^{460}$ while preserving local autonomy. Lawmakers at every level of government should remember that development of both robotics systems and the built environment can evolve over time, sometimes in unexpected ways. They should be platform agnostic to avoid early "lock-in" of design or the built environment. Robotics technologies are also likely to converge, which may render some rules out of date.

${ }^{457}$ Judith Donath, Driverless Cars Could Make Transportation Free for Everyone-With a Catch, ATLANTIC (Dec. 22, 2017), https://www.theatlantic.com/technology/archive/2017/12/self-driving-carsfree-future/548945/.

${ }^{458}$ For examples of the harms caused by such NDAs, see Caroline O'Donovan, When Cities Sign Secret Contracts With Big Tech Companies, Citizens Suffer, BuzzFeEd News (Nov. 20, 2018), https://www.buzzfeednews.com/article/carolineodonovan/amazon-hq2-google-foxconn-secret-nda-realestate-deals. On the specific issue of tax breaks, others have proposed a ban on states and cities giving tax breaks in exchange for jobs or a $100 \%$ tax on such incentives. Emily Badger, Should We Ban States and Cities From Offering Big Tax Breaks For Jobs?, WASH. Post (Sept. 15, 2014), https://www.washingtonpost.com/news/wonk/wp/2014/09/15/should-we-ban-states-and-cities-fromoffering-big-tax-breaks-for-jobs/; Jack Markell, Let's Stop Government Giveaways to Corporations, N.Y. TiMES (Sept. 21, 2017), https://www.nytimes.com/2017/09/21/opinion/incentives-businessescorporations-giveaways.html.

${ }^{459}$ See April Glaser, Antitrust in the House, SLATE (Jan. 16, 2019), https://slate.com/technology/ 2019/01/antitrust-david-cicilline-congress-facebook-google-monopoly.html. For additional discussion, see Lina M. Kahn, Amazon's Antitrust Paradox, 126 YALE L.J. 710, 717 (2016).

${ }^{460}$ For a discussion of this dynamic specifically applied to drones and privacy, see Margot E. Kaminski, Drone Federalism: Civilian Drones and the Things They Carry, 4 CALIF. L. REv. 57 (2013). 


\section{COUNTERARGUMENTS IN FAVOR OF BROAD PREEMPTION OF LOCAL GOVERNMENTS}

This Part concerns counterarguments, such as the need for regulatory clarity and consistency, the idea that state and national regulators are in a better position to negotiate with firms than cities, and the notion that cities do not necessarily act in the best interest of the region.

\section{A. Firms Require Regulatory Clarity/Consistent Rules}

Proponents of preemption might cite the need for regulatory clarity or consistent rules to ease the way for firms. Automated vehicle manufacturers have made such arguments in favor of the federal SELF DRIVE Act. ${ }^{461}$ Having to plan for and comply with fifty state-automated vehicle laws is more complicated, and therefore costlier, than just dealing with one federal law. In addition, being cars, automated vehicles are highly mobile and will eventually cross state lines. For the legal requirements to differ between states such that an automated vehicle from California cannot cross the border into Nevada without violating the law would be troublesome, to say the least. Overcoming such obstacles to interstate commerce is one of the reasons the federal government exists in the first place. Put another way, scale matters with technology.

We are sympathetic to these arguments and even grant that regulatory uncertainty can be a burden on firms, but the burden to firms is only part of the overall story. First, uncertainty creates a cost, and costs can either be internalized by firms or socialized to the public. Avoiding preemption allows for cities to be sites of experimentation and true partners in the system and environmental design for urban robots. Preemption may cut off that process too early. There will be a time when nationwide standards make sense, but it should be after cities have had a chance to experiment. In the meantime, the principle of permissionless innovation, which likely applies to automated vehicles and many other robots, ${ }^{462}$ should insulate firms from the worst regulatory excesses. Second, innovation proceeds unevenly, so regulatory standardization should as well. Certain safety standards may make sense to implement on a statewide or national level now. ${ }^{463}$ But there will be other areas where cities require room to experiment, especially as it impacts environmental design. There are situations with technology where scale can have undesirable consequences. For example, possible concern with creating a national health database is fear of a massive data breach that compromises the personal health data of every American, and as the integration of

${ }^{461}$ Bellon, supra note 349.

462 See Adam Thierer \& Ryan Hagemann, Removing Roadblocks to Intelligent Vehicles and Driverless Cars, 5 WAKE FOREST J. L. \& POL'Y 339, 346-50 (2015) (arguing the theory of permissionless innovation should apply to automated vehicles).

${ }^{463}$ Prohibitions on PDDs carrying hazardous material may be one. 
surveillance technology expands in service to the transportation industry, these issues will be compounded. Scaling a system of unsafe or inefficient $\mathrm{AVs}$ by acting too early is not a desirable outcome.

It is also possible to achieve some harmony and an environment that favors innovation without imposing a nationwide standard with broad preemption of local governments. The system of federalism for which we advocate recognizes roles for state and federal regulators. It merely preserves the design space for cities.

B. State/National Agencies Are in Better Bargaining Position vis a vis Firms

Another critique that is somewhat related to the first one is that scale matters in regulation. State legislatures and attorneys general may have more bargaining power as negotiators of the public interest. National regulators have even more bargaining power. Cities may become caught in a race to the bottom by attempting to lure firms, or they may get captured by special interests. ${ }^{464}$

Concerns that cities will race to the bottom by giving away public goods to robotics firms are warranted; we raised them ourselves above. For that reason, we think state rules that guard against socialized costs are a good idea. This is part of the reason that we hold up Massachusetts as a model; it allows cities to experiment while the state acts as a backstop to preserve the public interest. Still, any preemption provision for urban robots should weigh the potential regulatory economies of scale against the benefits of innovation with cities as distributed sites of experimentation. Further, cities have their own power as market makers when they are able to deal directly with firms. ${ }^{465}$ We also reiterate our support for backstop rules such as bans on non-disclosure agreements in public-private partnerships to help guard against such problems.

\section{Cities Do Not Act in the Best Interest of the Region (NIMBY)}

One might argue that cities will not plan in the best interest of the region or state as a whole, but instead regulate for narrow interests defined by NIMBY-ism (Not In My Back Yard). NIMBY-ism has been a problem in other intractable urban and regional planning issues like housing ${ }^{466}$ and transportation. ${ }^{467}$ The Competitive Enterprise Institute, a libertarian think

\footnotetext{
${ }^{464}$ The competition for "Amazon HQ2" is a prominent contemporary example of this problem.

${ }^{465}$ Whittington et al., supra note 11 , at 1964.

${ }^{466}$ Caroline O'Donovan, The Rent Is Too Damn High: In Search of the Truth About Airbnb's Impact on Housing, BuZZFEED (June 9, 2015), https://www.buzzfeed.com/carolineodonovan/ the-rent-is-toodamn-high-the-truth-about-airbnbs-impact-on \#.ypxOApdnd.

467 Doug Monroe, Where It All Went Wrong, ATLANTA MAg. (Aug. 1, 2012), https://www.atlantamagazine.com/great-reads/marta-tsplost-transportation/.
} 
tank, worries that ride-sharing companies will pressure cities to outlaw private ownership of automated vehicles by touting the environmental benefits of shared fleets. ${ }^{468}$ The group praised states that preempt cities in their laws to avoid just this outcome. ${ }^{469}$

We are sensitive to this concern as well. Cities are not and should not be the only stakeholders in regional planning. For cities to succeed in our model, they must operate within a patchwork of federal and state regulation and cooperate with private companies and regional stakeholders. We agree with Sarah Fox that regional tools like environmental impact reports or statements can support density or other positive regional planning goals. ${ }^{470}$ We also envision a possible role for Metropolitan Planning Organizations that can coordinate the needs of multiple cities in a given region; this is a common tool in regional transportation planning. ${ }^{471}$ Still, giving cities the tools to regulate robots means that some cities may abuse those tools. Further, the notion of experimentation implies that some failure will occur. But if cities are the site of experimentation, at least those failures won't proliferate across the entire state or country by fiat. Cities are not the only actors who can err in urban planning. For instance, some scholars believe that federal policy has contributed to suburban sprawl and low-density housing. ${ }^{472}$

To the specific concern that cities will ban individual car ownership, it is also possible that states could use preemption and enact policies that favor individual ownership to benefit entrenched interests, such as car manufacturers. ${ }^{473}$ Without taking a specific position on individual ownership of automated vehicles, we note that almost any policy choice will favor some interests over others. The question is which level of policymakers will make those choices. We argue in favor of local political bodies, as they must deal most directly with the consequences of those choices and are the most politically accountable for those choices.

\section{CONCLUSION}

Widespread deployment of robots in cities has the potential to drastically alter the way cities organize their public spaces and built environments. As the testbeds for this emerging technology, cities must have room to regulate

\footnotetext{
${ }^{468}$ Scribner, supra note 309.

${ }^{469} I d$.

${ }^{470}$ Fox, supra note 356 , at $174-82$.

${ }^{471}$ What Is a COG or MPO?, NAT'L ASS'N REG'L COUNCILS, http://narc.org/about/what-is-a-cogor-mpo/ (last visited Aug. 25, 2019).

472 Gerrit Knapp et al., Dep't Urb. \& Regional Plan., U. Ill., Government Policy and URBAN SPRAWL 1-5 (2014), http://citeseerx.ist.psu.edu/viewdoc/download?doi=10.1.1.505.9245\&rep $=$ rep $1 \&$ type $=$ pdf.

${ }^{473}$ Marina Lao et al., Direct-to-Consumer Auto Sales: It's Not Just About Tesla, Fed. TRADE COMM'N (May 11, 2015), https://www.ftc.gov/news-events/blogs/competition-matters/2015/05/directconsumer-auto-sales-its-not-just-about-tesla.
} 
these technologies in ways that fit the realities of the local built environment and local constituencies. While this technology is in the experimental stage, state and federal lawmakers should avoid broad field preemption to preserve a regulatory space for cities to design public spaces in a way that best serves the public interest. Rather than rushing prematurely to a state or nationwide standard, state and federal lawmakers should implement regulatory floors and backstops against a race to the bottom. Issues that do not implicate the design of the local built environment, such as vehicle safety or cybersecurity, may be ripe for such intervention. State and federal governments can also serve as conveners and disseminate experimental results and best practices in order to build consensus toward nationwide standards. The potential of robotics technology to deliver convenience, efficiency, and other benefits is exciting, and the urge to standardize in the name of promoting innovation is understandable. But that urge is misguided when the impacts of the technology are likely to be consequential yet unknown.

For their part, cities must ensure that robots promote the public interest rather than socialize costs that ought to be borne by firms. They should recognize their power as market makers when dealing with companies seeking to test their technologies in urban spaces. Local policymakers have both a civic and moral duty to do so. More work is needed to explore the possibility of a fiduciary duty or standard of care for cities that implement pilot programs or procure new technologies. ${ }^{474}$ City policymakers should be able to demonstrate their careful consideration of the impacts to privacy, safety, public finances, and public spaces. The implementation of citizen review committees for surveillance technologies may be one step toward this goal.

Urban robots are likely to reorganize not just the built environment but the social fabric of cities as well. Challenges to traditional notions of privacy (or lack thereof) in public spaces are just one manifestation of the social impact of urban robotics. For instance, marginalized communities of color could experience urban robots differently than more affluent communities, especially as a tool of law enforcement. There are also concerns that AVs could be used as a tool of social control by governments or for companies to exert undue influence on their passengers. ${ }^{475}$

Preempting a city's ability to regulate "performance," as AV START and SELF DRIVE do, could have far reaching implications beyond the technical specifications of the autonomous system. Robotics technologies such as AVs are envisioned as key components in the creation of a cutting

\footnotetext{
${ }^{474}$ Thank you to Anthony Luppino for suggesting this concept to us in our discussions.

${ }^{475}$ Donath, supra note 457; Self-Driving Cars Offer Huge Benefits-But Have a Dark Side, ECONOMIST (Mar. 1, 2018), https://www.economist.com/leaders/2018/03/01/self-driving-cars-offerhuge-benefits-but-have-a-dark-side.
} 
edge "smart transportation" system. ${ }^{476}$ However, if preemption prevents cities from directing these new transportation services, then local governments may struggle to ensure equity and access. A city that wishes to direct AV services to poor or minority areas might be prevented from doing so if a court finds this to be an "unreasonable" restriction on the AV's performance or operational domain. Or, preemption could remove a city's leverage to push companies toward more equitable services because local governments are forced to allow AVs on their public rights-of-way. This problem is not merely academic: a ride-sharing company called Via was found to have discriminated against poor and minority communities for years by confining its services to affluent areas of Washington, D.C. in violation of local law. ${ }^{477}$

The importance of design in local preemption debates should have application beyond robotics. As cities flex their power as economic and cultural engines in American society, they have repeatedly come into conflict with state and federal lawmakers. Preemption has been central to issues ranging from ride-sharing to short term rentals. Considerations of design and the built environment may not be the principal factor in deciding how to allocate authority over policymaking in these spheres, but they may still prove a useful facet through which to understand these problems.

More broadly, this Paper urges regulators at all levels to think carefully about the nature of robotics and the role of cities as sites of experimentation. For the sake of simplicity and organization, we have treated AVs, PDDs, security robots, entertainment robots, and drones as distinct devices. This is in part because the law has applied different rules as well. However, these devices share some common technical features and may have similar impacts as emerging technologies. Right now, governments apply different regulatory regimes based on the device classification and the nature of the right-of-way in which they operate: sidewalks versus streets versus airways. But as the technology converges, this regulatory separation may not be appropriate. Rather, from a designer's perspective, the sensible approach could be to treat cities as a single operating domain for this family of technologies we call robots. Doing so will require a paradigm shift in regulatory approaches and an emphasis on the city as the site of experimentation for new governance models. Cities, for their part, must learn to navigate the minefield of preemption and environmental design

476 Yuming Ge ET AL., CTR. FOR TeCh. InNOVATION BROOKINGS, SMART TRANSPORTATION IN CHINA AND THE UNITED STATES 1-8 (2017), https://www.brookings.edu/wp-content/uploads/2017/12/ smart-transportation_final.pdf; see also BLOOMBERG PHILANTHROPIES \& ASPEN INST., supra note 453, at 14-15; see generally NATCO, supra note 5 (explaining some of the challenges and advantages to AVs).

477 Mark Joseph Stern, A D.C. Ride-Sharing Service Illegally Discriminated Against Minority Communities for Nearly Two Years, SLATE (Apr. 9, 2018), https://slate.com/technology/2018/04/viadiscriminated-against-minority-communities-in-washington-dc.html. 
issues to foster experimentation with new technologies and new governance models for the sake of the public good. Cities are on the forefront of other important policy debates, such as how to implement a universal basic income. ${ }^{478}$ This Paper has attempted to help cities understand all of the tools that are available to them and the limits and contours of their authority to accomplish this task. The robotic future will be made in cities and will be felt most directly by the people who live there, so cities must take an active role in shaping it.

${ }^{478}$ Matthew Keegan, Benefit or Burden? The Cities Trying Out Universal Basic Income, GUARDIAN (June 27, 2018), https://www.theguardian.com/cities/2018/jun/27/benefit-or-burden-the-cities-tryingout-universal-basic-income. 